\title{
TŪMANAKO: KAUPAPA MĀORI INFORMED ACTION RESEARCH WITH YOUNG MOTHERS.
}

\author{
BY \\ CATHERINE PIHEMA
}

\author{
A thesis \\ submitted to the Victoria University of Wellington \\ in fulfilment of the requirements of a \\ Masters Degree
}

Victoria University of Wellington 


\section{Whakatauki}

Nā tō rourou, nā taku rourou ka ora ai te iwi

With your basket and my basket the people will thrive 


\section{Karakia}

Whakataka te hau ki te uru,

Whakataka te hau ki te tonga.

Kia mākinakina ki uta,

Kia mātaratara ki tai.

E hī ake ana te atākura he tio,

he huka, he hauhunga.

Haumi e! Hui e! Tāiki e! 


\section{Dedication}

This thesis is dedicated to my late grandparents Heira (George) Tooti Pihema and Elizabeth Pihema. Thank you for teaching me kindness, to appreciate what I have, to recognise and use my privilege to help others who are not as fortunate, to work hard and to do a good job (having to get out and restart the lawnmower to get one inch of missed grass, although ridiculous at the time, did actually stand me in good stead!). Your teachings and memory guide me through my everyday life. Moe mai rā. 


\begin{abstract}
This research is kaupapa Māori informed action research that was carried out in collaboration with a rōpū of young mothers and a local Wellington based film company. Originally intended as an action research project in collaboration with a group of young people to produce a mental health-themed resource, during a series of hui around experiences of the rōpu it became apparent that this project would be devoted to the creation of a short film. Specifically, an inspirational resource for other young mothers. The film was intended to promote hope for other young mothers who are going through the challenges of young parenthood, and offer advice around supports they can access to help them get through such times. This thesis documents how kaupapa Māori principles influenced the development of this resource, and also highlights common experiences, challenges, coping mechanisms and support accessed by the rōpū. Among other themes, it became clear that teen parenthood was not the 'cause' of challenges experienced by this rōpū, but a source of motivation and hope for the future.
\end{abstract}




\section{Acknowledgements}

Ehara taku toa, he takitahi, he toa takitini

My success should not be bestowed onto me alone, as it was not individual success

\section{but success of a collective}

An entire community stood alongside me through the completion of Tūmanako the film and Tummanako the thesis. My gratitude and appreciation is encapsulated in the above whakatauki and I want to emphasise that Tümanako Is a collective success of all of the people and organisations that banded together and volunteered their time to help and support this project. This contribution and support means more to me than can be explained through words. In this section I hope to acknowledge some people who were main players in the success of this project, who I am indebted to and extremely thankful.

To the young mothers from the school who walked this journey from start to finish with me, thank you. I learnt so much from you in our time together and cherish this life changing experience. You all worked so hard to selflessly help other young mothers. You all gave so many hours to create this film from attending script writing hui after school to committing to 12 hour film days over your weekends. You juggled babysitting, school and homework demands, often sacrificing your own downtime to do so. I am incredibly thankful for your dedication and I know many other young mothers will benefit from your passion and commitment to help. You are all the strongest group of woman I've ever met, wahine toa. You have all faced many challenges in life even before being a mother, and you have taken them with stride and you just want to build better futures for yourself, your pēpi and give back to others. This has been such a humbling and inspiring experience for me and I thank you immensely for letting me in to your lives and working on our common goal. I have really enjoyed the laughs, sharing kai and getting to know you all. You are incredible mothers and I know you all have the word at your feet - I can't wait to see what you all you all achieve.

Thank you also to all staff at the school. I heard from the young mother's just how incredible, kind and supportive you all are and how you go the extra mile to help, and then I felt this myself through working with you. Thanks especially go to Liora and Helen. I appreciated all of the hugs, the organisational help with the girls and all of the support. This was at a project level but also at a personal level. The small things 
such as having lunch plated for me too when I came in, rushing away to get a bag of oranges to give to me when you heard I was sick and continual check ins about how my year and exams were going, these all meant so much. I am hugely appreciative. The school and staff do such amazing things and all go beyond the call of duty everyday. Thank you for your commitment, kindness and all you do to support our young mothers of Wellington to achieve all they want to from life.

On a personal note I would like to thank my whole whānau (Graeme, Louise, Ashleigh, Christopher and Kaitlin) but especially my mum and dad. You both are the hardest workers I know and you both worked so hard and made so many personal sacrifices to get me to and through university. I hope you know the success of Tūmanako is as much your success as mine. You always encouraged me to put my all in to achieving my goals and always supported me. This didn't stop as a child and you always had your finger on the pulse of how I was going this year and stepped in to support when needed with so much love. I thank you both for absolutely everything and for being my backbone in all I do.

Thank you to my friends that helped me get through. Thank you to all my classmates in the Clinical Programme, especially Katie and Saara. Thank you for the companionship in the many late nights spent at uni, the many coffee sanity breaks and venting sessions. I appreciate all the check ins and care packages, these really kept me going so thanks so much for everything. Thank you also to Lynley for all the support, the hot lemon drinks when sick and help with formatting.

Thank you to my best friends Georgia and Alice. While everyone else saw the put together, managing fine Catherine, you two wore the moods, the frustrations and the stress. Thanks for the immense amount of support from helping brainstorm the hui, to prepping kai, to transport help with the girls to even fronting up and acting. Thanks also for the personal support, the 'real talk' and kicking me out of the house and making me go to uni when I couldn't bring myself to. Thank you for the aforementioned support this year but also for everything you have both done over the last 6 years living together, which got me here in the first place. I can't imagine doing life without you two by my side and all you do means more than I can put in to words. Thanks.

Thank you to my Youth Wellbeing Research team, Marc, Jessica, Kealagh and Gloria. You all at different stages provided invaluable advice on how to move 
forward on this project and offered such incredible support and faith. Thanks especially to my supervisor Marc. Not many supervisors would accept to supervise a project like this with all of its encompassed ambiguity and uncertainty. Not only did you accept but you put entire faith in myself and the kaupapa Māori process. I appreciate the never waning support, faith and advice in challenging times. You have an absolute dedication to equity and I appreciate how much you put in to this to work for better outcomes for Māori. I must also offer a huge thanks to Paris without whom the project would not have been completed. Thank you for your guidance both culturally and clinically and your friendship in this process. You came out to the majority of hui and played a part in every step of the process. Thank you for being so incredibly selfless and going the extra mile. I can safely say this would not have come in to fruition without you and I really am indebted to you and so appreciative. Lastly, thank you to Kaumatua Doug. Your advice and direction around tikanga Māori and mātauranga Māori and what this looks like in context made this the special kaupapa Māori project it was. Thank you for making yourself available to any questions and all of your encouragement and support. Thank you for also opening and closing the premiere making it tika and special. Thank you also to Dr Tia Neha who provided initial cultural supervision in the beginning stage of this project.

A big thank you is also owed to the film crew. Thank you to all the incredible people that donated their time, effort and equipment to make Tūmanako go from being a dream in to a reality. Thank you especially to Andy and Michelle, the two directors of the film. Your vision, expertise and work ethic lead to the success of this project. Thank you both for your patience and your flexibility in your approach to meet the different needs of this different project. You both took an active role in coaching and teaching the girls about acting and the film world and encouraged them to push themselves out of their comfort zone and reach their potential, which is not often common practice working with paid actors. Thank you for working tirelessly through the nights on many occasions - your incredible dedication and input to this project has not gone unnoticed and is immensely appreciated. Thank you to everyone else that stepped in and lent a hand in the different sections of production. A big thanks to the long-timers who stuck it out for the majority of the project, Jen (arts), James (sound), Ed (camera) and Brendon (lighting). Your dedication and many hours given is really appreciated. Thank you to Jesse also, the school of music student who 
produced the Waiata sung by the girls. Also a big thank you to the many volunteers who gave their time to be extras in the film.

As I mentioned at the beginning of the acknowledgement section, an entire community stood alongside me through the completion of Tūmanako. This support was felt from much wider than the psychology and film teams. Thank you to the other academics that helped out along the way including administrators, lecturers and academics from the New Zealand School of Music, the New Zealand School of Film and Victoria University school of film and theatre. Thank you to Avalon Studios for donating and making available your set studio for us to use, a magnitude we never thought possible and experiences we all didn't think we would have. Thank you to all community organisations that donated resources, financial support or their time including Wellington City Council, Havana Coffee, The Warehouse, Portsmouth Lighting, NZ Bus, Pete's Emporium and the Penthouse Cinema for hosting and making our premiere so special. A huge thank you goes to the Health Research Council of New Zealand. Without your funding none of this would have been possible. 


\section{Preface}

\section{Personal Reflection}

Ko wai au?

Ko Tangitu te maunga.

Ko Pupeke te awa.

Ko Māmari te waka.

Ko Ngati Uru me Ngāti Pakahi me Whānau Pani ngā hapū.

Ko Ngāpuhi te iwi.

Ko Patunga te marae.

Ko Heira Tooti Pihema toku tupuna tāne.

Ko Elizabeth Pihema toku tupuna wahine.

Ko Graeme Pihema toku pāpā.

Ko Louise toku māmā.

Ko Ashleigh Pihema toku tuakana.

Ko Christopher Pihema toku tungāne. Kua mate ia.

Ko Kaitlin Pihema toku teina.

Ko Catherine Pihema toku ingoa.

The mihi above acknowledges that on my father's side I am of Ngāpuhi Descent, from his father's Heira Tooti Pihema, line. From my father's mother Elizabeth Pihema (nee Bailey) I am from Scottish Descent and whakapapa to the Bailey Clan in Scotland. On my mother's side I am of Irish descent from her father's Michael Diggins, line. This whakapapa goes back to the Diggins Clan from County Kerry, Killarney in Ireland. From my mother's mother, Denise Diggins (nee Watts), I am from French and English descent.

It is important to contextualise my whakapapa to understand the strands that influence my kaupapa Māori approach to research. This is because the experiences of my ancestors have shaped how I have come to experience and view the world. This notion is particularly exemplified with my koro, Heira Tooti Pihema, and our relationship. He grew up in a particularly racist New Zealand. The belief held by many was that Māori was an inferior culture and that Māori should assimilate in to the Pākeha culture (Hayward, 2012). As such, koro lived through experiences such as not being allowed to speak Māori at school, and was often beaten by his teachers for 
doing so. This 'Māori as inferior' view was also held by my Grandmother, Elizabeth's, Pākeha family. They would not support her relationship with my Māori grandfather and my grandparents had to run away to be together. To be Māori and to live according to Tikanga was not a safe or fulfilling life for my grandfather. This was the beginning of the disconnect of my whānau to Te Ao Māori. My grandparents did not raise my father or his siblings in a Māori way, and thus Mātauranga Māori started to become lost in my whānau.

Following the Māori renaissance of the 1970's and 1980's a societal mind-set shift started to occur around Māori knowledge and culture, where the importance of the loss of these aspects started to become apparent. At this point the government started to adopt the idea that Māori language and culture should be adopted and recognised by the state (Hayward, 2012). The fruits of this shift and further progressions of beliefs around Māori culture and its importance, coincided with the beginning of my generation. As such, my grandfather taught me about Māori culture, told his old stories and taught me some Te Reo. This instilled a passion for Te Ao Māori within me and a want to acquire mātauranga Māori and bring this knowledge back in to my whānau.

My nana Elizabeth passed away in 2009 after a slow deterioration of her health. My grandfather Heira passed away soon after in 2011 and, although the attribution was to Pneumonia in the end, we believe his original decline was due to a broken heart without his "best mate". As well as grief-stricken, the loss of my grandfather left our whānau at a loss around our Māori Identity. Our connection to Te Ao Māori had passed and we did not have many other close whānau who could fill this void. My passion for Te Ao Māori and Mātauranga Māori still resonated strongly within me and I yearned for a way to get connected.

Amongst many other rich experiences, choosing and being afforded the privilege to go University allowed me this chance. I became involved in Māori rōpū such as Te Rōpū Āwhina; an on-campus whānau support group for Māori students enrolled in science. This allowed me to both tutor and be tutored in a tuakana-teina relationship (buddy system to do with ako or learning needs: Te Kete Ipurangi, 2009), to meet other Māori students and attend Māori hui and events. I was learning constantly. My involvement was strengthened in my postgraduate clinical psychology training. I am a member of He Paiaka Tipu, a rōpū for Māori students who are on the 
pathway to be registered clinical psychologists. This allows for rich Māori cultural experiences through noho marae visits, learning around Māori perspectives of heath and continual exposure to tikanga mātauranga Māori and Te Ao Māori. I also became part of a rich network of colleagues strong in tikanga and mātauranga Māori with whom I am able to talk to, ask anything of and learn from.

This learning also exposed me to the severity of negative health and general outcomes of my own Māori people, as well as drawing my attention to the lack of Māori-based works or resources actually available to help. Whilst the want and instinct to help people has always been a central part of me, at that point my emphasis turned to want to help my own people within Māori communities.

This led me to want to do Kaupapa Māori research to really help my people. As well as being able to help, I wanted to take this opportunity to further understand my Māori identity and learn more about mātauranga Māori and Te Ao Māori. I hoped to use this this opportunity to learn from the Māori I would be working with, whilst simultaneously bringing them resources and some academic knowledge on how to translate some of their goals in to reality. This led to many personal challenges, including reflecting on whether I was the right person to be doing this research - as I am still on my own journey and by no means an expert. I am also fair skinned and blonde which made me whakamā to approach such groups, feeling like a fraud.

However, the supportive comments, faith and aroha consistently received from my Māori mentors, those in my Māori rōpū and community kaumātua encouraged me to undertake this research and keep going when times were tough. They became a supportive rangahau whānau that gave me strength to do this project. A kaumātua pointed out that we are all at different stages in regards to tikanga and mātauranga Māori and I am on this journey forward with whoever I am working with. Regardless of where we start we are moving forward together in the same, positive direction.

A whole community came together to move in this 'same positive direction' and achieve our kaupapa. This was not just limited to the rangatahi or those in immediate circles of the research and film community, but also extended to the wider community. Thanks to the likes of the Kilbirnie resident, whose door we knocked on to ask to use their power to recharge our cameras in the bus scene, and who ended up staying on for four hours to be an extra in that scene. Thanks to local community business such as The Warehouse who kindly donated refreshments for the film 
premiere. Thanks to the likes of my research team, classmates and family who were on 'child-wrangling' throughout hui, giving many hours to babysit. As highlighted in the acknowledgement section, 'Ehara taku toa, he takitahi, he toa takitini: My success should not be bestowed onto me alone, as it was not individual success but success of a collective'. Thank you all that moved in this 'same positive direction' towards the kaupapa of Tūmanako. 


\section{Table of contents}

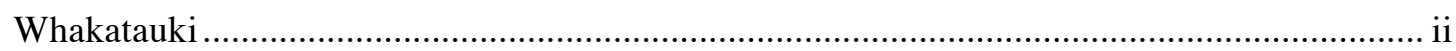

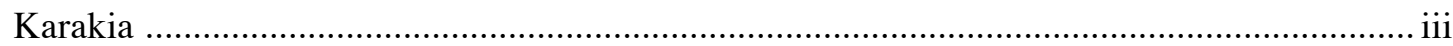

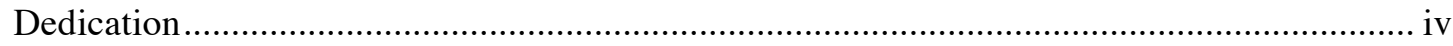

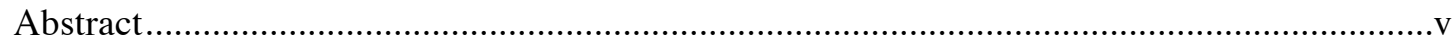

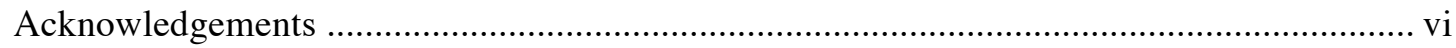

Preface

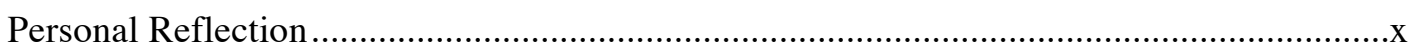

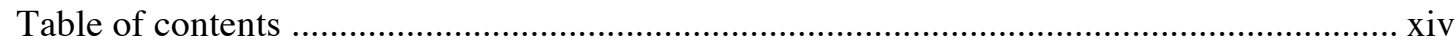

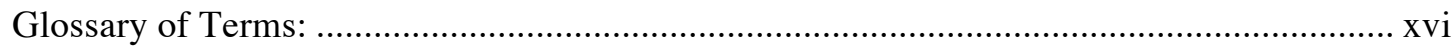

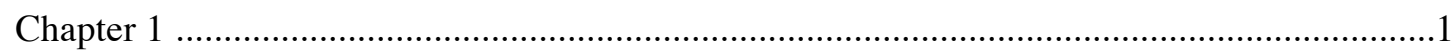

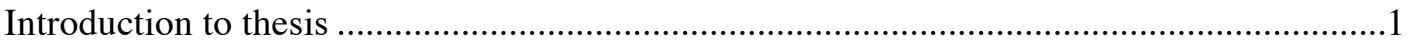

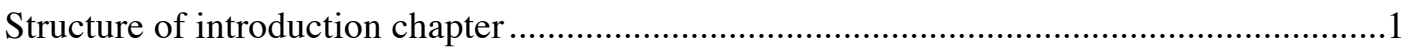

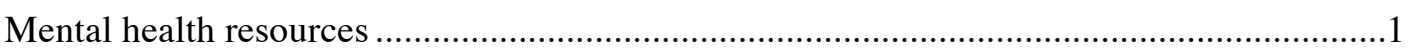

Chapter 2

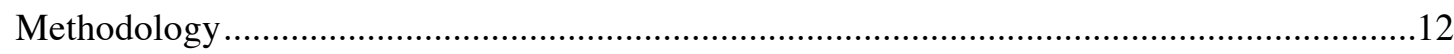

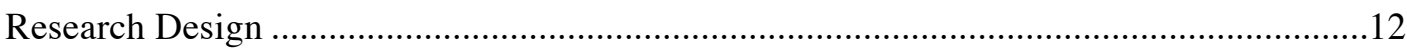

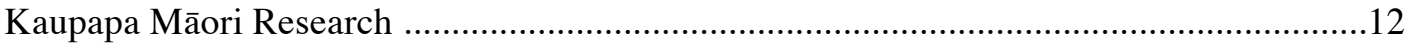

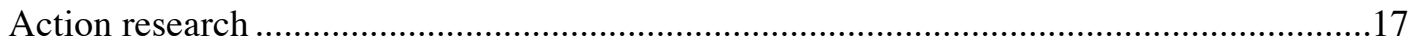

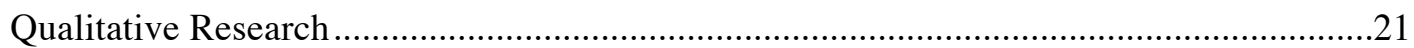

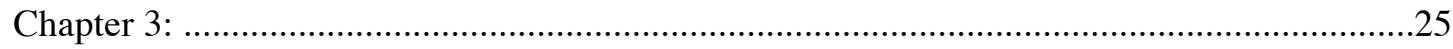

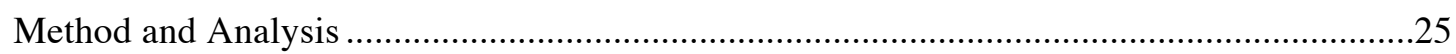

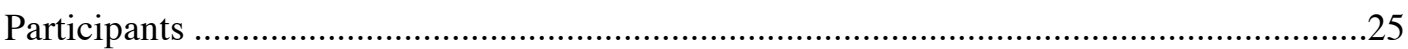

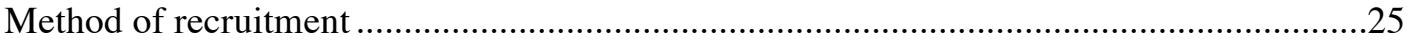

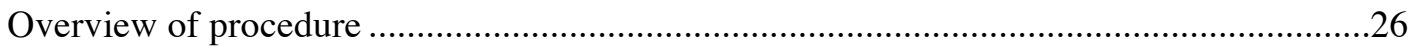

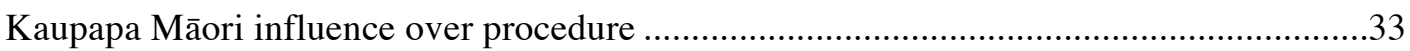

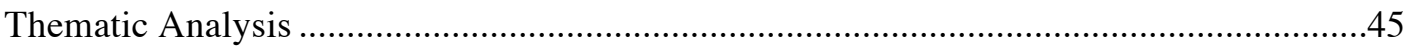

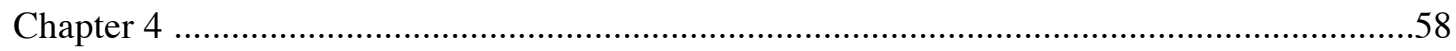

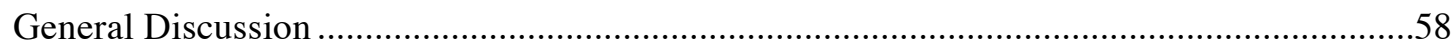




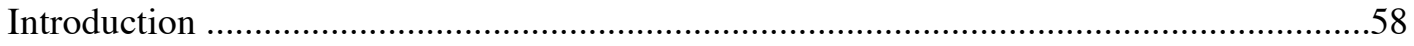

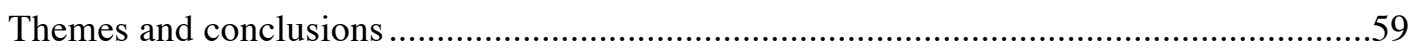

The process of making the mental health resource …....................................................65

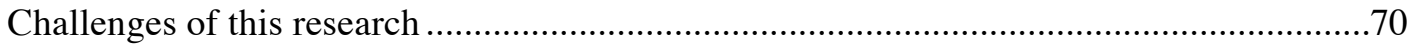

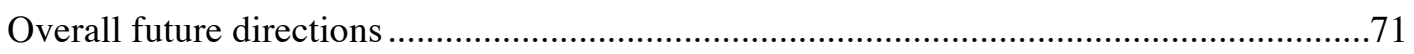

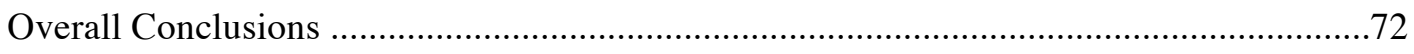

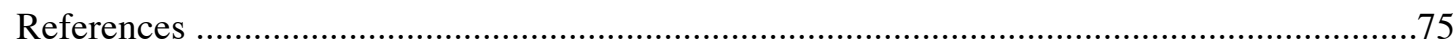

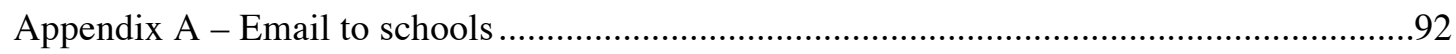

Appendix B - Consent and Information Pamphlet...............................................................93

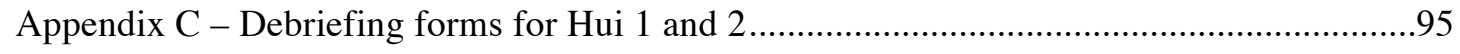

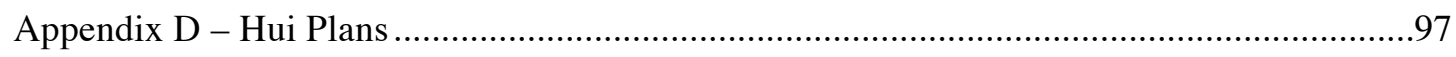

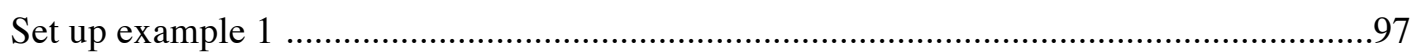

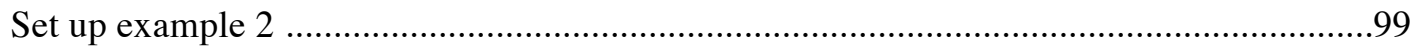

Hui plan for script development example ...................................................................... 101

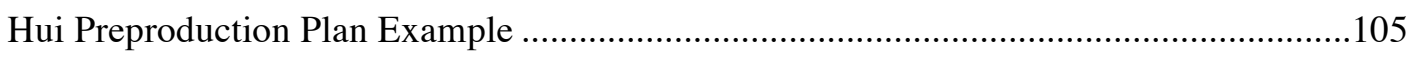

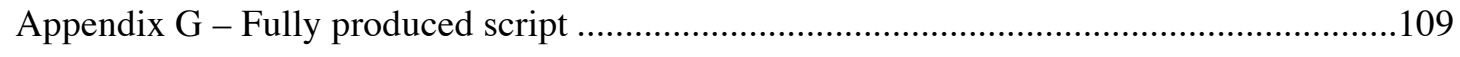

Appendix H - Shoot schedule (production example).........................................................121

Appendix I - Shoot Call Sheet (production example) ..........................................................122

Appendix J - Consent for film credit inclusion ...................................................................123

Appendix K - Dissemination examples (media) ……….....................................................124

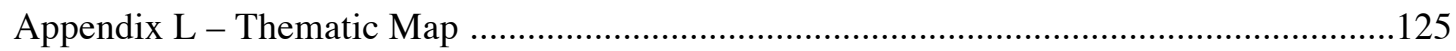




\section{Glossary of Terms:}

Note: In an effort to normalise Te Reo Māori (an official language of Aotearoa), Māori kupu are not translated throughout this text. I provide this glossary to assist those who are not familiar with Te Reo Māori.

Ahuatanga Māori: Natural feature

Ako Māori Principle: The principle of culturally preferred pedagogy

Ako: Learning needs, to learn

Aroha: To love, feel compassion for, empathise

Aroha ki te tangata guideline: Respect for the people

Hapū: Descent group, clan, sub tribe

Hauora: Wellbeing, health; to be fit well and healthy

Hui: Meeting, assembly, coming together

Iwi: Set of people bound together by descent from a common ancestor or ancestors

Kai: Food, to eat

Kaiāwhina: Helper, advocate

Kanohi kitea guideline: The seen face; present yourself to people face to face

Kapa haka: Māori cultural group, Māori performing group.

Karakia: Incantation, charm, spell, ancient rites, invocation; Christian prayers

Kaua e takahia te mana o te tangata guideline: Do not trample over the mana of people

Kaumatua: Elder, senior man or woman, community leaer

Kaupapa principle: The principle of collective philosophy

Kaupapa Māori: By Māori for Māori, Māori approach

Kawa: Rules

Kia mahaki guideline: Don't flaunt your knowledge

Kia piki ake i nga raruraru o te kainga: The principle of socio-economic mediation)

Kia tupato guideline: Be cautious

Kōhanga Reo: Māori language preschool

Kotahitanga: Unity, togetherness, solidarity, collective action.

Kōrero: to tell, say, speak, read, talk, address; speech

Korero āwhina: Affirming and validating whānau and staff approaches 
Koro: Grandather

Kuia: Female Elder

Kupu: Word

Kura kaupapa: Primary school operating under Māori custom and using Māori as the medium of instruction.

Mahi: Work

Mana: Prestige, authority, control, power, influence, status, spiritual power, charisma Mana motuhake: Mana through self-determination and control over one's own destiny

Manaaki ki te tangata guideline: Share and host people; be generous

Māori: normal, usual, natural, common, ordinary.

Matatipu: The beginning sprout

Mātauranga Māori: Māori knowledge - the body of knowledge originating from Māori ancestors, including the Māori world view and perspectives

Mauri: Life principle/force

Mihimihi/mihi: Greetings, to greet

Moe mai rā: Rest in peace

Pākehā: English, foreign

Pēpi: Infant

Pono: To be true, valid, honest, genuine, sincere.

Pūrākau: Myth, ancient legend

Rangatahi: Younger generation, youth.

Rangatiratanga: Chieftainship, right to exercise authority, sovereignty, principality, self-determination

Rōpū: Group, party of people

Tāngata whaiora: Mental health consumers

Taitamariki: Young people

Taonga tuku iho: The principle of cultural aspiration

Tautohetohe: Debate

Te Ao Māori: The Māori world

Te Kōkī: New Zealand School of Music

Te Reo Māori: The Māori language

Tika: To be correct, true, upright, right, just, fair 
Tikanga: Correct procedure, custom, protocol

Tino Rangatiratanga Principle: The principle of self-determination)

Titiro, whakarongo... kōrero guideline: Look, listen and then speak

Tuaka/teina relationship: Buddy system to do with $A k o$

Tūmanako: Hope

Wahine toa: Strong woman

Waiata: Chant, poetry; to chant, to sing

Whakahari: To rejoice, celebrate

Whakamā: Shy/embarrassed

Whakapapa: Genealogical table, to recite I proper order, to place in layers

Whakarerekē tuatahi, tuarua and tuatoru: Turning point/change 1,2 and 3

Whakatauki: Proverb or aphorism

Whakawhitiwhiti whakaaro: Facilitated discussion

Whanake: To grow, develop

Whānau: Extended family group, to be born, family

Whānau ora: Family health 


\section{Chapter 1}

This thesis describes the process of developing a short film, in collaboration with a group of rangatahi Māori and, therefore, it may be helpful to watch this film by visiting tinyurl.com/tumanakofilm before reading further.

\section{Introduction to thesis}

\section{Structure of introduction chapter}

The aim of this thesis is to develop a Kaupapa Māori (by Māori, for Māori: Smith, 1997) resource for rangatahi, designed to help with hauora. As such, the subsequent sections of this thesis will briefly introduce primary healthcare and describe the different forms of mental health resources that are currently available to support wellbeing. I shall then reflect upon the appropriateness of these resources for Māori, and the need to develop Māori specific resources, in the context of the typically poor mental health outcomes for Māori, compared with non-Māori groups in Aotearoa (see Ball, 2010; Baxter, Kani-Kingi, Tapsell, Durie \& Mcgee, 2006; Browne, Wells \& McGee, 2006; Gaines et al., 2003; Horwood \& Fergusson, 1998; Bushnell et al., 2003; Simpson, Wicken, Duncanson, Adams, \& Oben, 2016). As this research was conducted within a Kaupapa Māori framework, the following chapter will explain fundamental principles of the framework. Following this the thesis will describe the other methods and guiding paradigms used in this research, including action research and qualitative methods.

\section{Mental health resources}

Ki te kore ngā pūtake e mākūkūngia, e kore te rākau e tupu If the roots of the tree are not watered, the tree will never grow

\section{Primary mental health as a better focus}

Recent research has endorsed primary healthcare as a successful and promising strategy (Ministry of Health, 2009). The implementation of primary health initiatives have been perceived as being effective and responsive to mental health consumers' needs, and judged as successful by both service users and health professionals (Dowell et al., 2009). Primary health care for youth encapsulates the belief that wellbeing is greater than just the absence of mental health problems and illness, and that "becoming a competent and successful adult requires skills and 
competencies above and beyond being free of problems" (Bernat \& Resnick, 2006, p14). As such, rather than traditional treatment approaches that solely focus on the prevention of negative mental health outcomes, primary health approaches also strive for the achievement of positive outcomes for young people.

In support of primary approaches to healthcare, research has found protective factors (e.g. school connectedness, strong relationships with other adults, and having friends and interests) can buffer against the effects of risk factors (e.g. hardship and disadvantage factors (Bernat \& Resnick, 2006). Further, research has suggested that positive mental health and mental health difficulties are not opposites on a single spectrum. Whilst there are some factors that influence both (such as positive relationships and physical activity), there are some specific factors that influence wellbeing alone. This suggests that the traditional focus of reducing risk factors may not optimise positive mental well-being, and that strategies need to extend to the promotion of wellbeing (Aked et al, 2008).

Research in Aotearoa echoes the effectiveness of reorienting intervention foci to capacity building in youth, rather than the traditional focus on prevention and treatment of problem behaviours (Ministry of Health, 2009). The literature suggests such a problem-focussed approach to hauora can actually create barriers to both positive development and whānau ora. Specifically, focussing on an individual whānau member's problem (for example their mental disorder, truancy problems, etc.) in isolation loses the opportunity to resolve problems within a sustainable whānau-wide approach (Durie, 2009; Whānau ora taskforce, 2009). This whānauwide approach can be critical in promoting mental health of rangatahi, as whānau is extremely important to Māori. Many Māori are defined by their role within their whānau and what they contribute to their whānau determines who they are (Māuri Ora Associates, 2006). Thus, a problem-focussed approach that solely attends to the individual can result in missed opportunities to better hauora compared to a strengthsbased approach of increasing whānau support.

New Zealand's Ministry of Health have also acknowledged the importance of capacity building in their National approach 'Building on Strengths' (Ministry of Health, 2001), an approach and framework to promote Mental Health in Aotearoa. Within this strategy the definition of 'mental health' was a positive one. Specifically it asserted the importance of determinants of health and strength-based approaches. 
The three goals of the strategy were to "reduce inequalities; create environments supportive of positive mental health; and improve individual and community resiliency skills" (Ball, 2010, p13). The importance of promoting wellness was again recognised in the Ministry of Health's (2016) revision of their 2001 strategies and strategic plan for 2016-2026. The main emphasis of this new strategy is that "All New Zealander's [should have the opportunity to] live well, stay well and get well" (Ministry of Health, 2016).

This promotion, rather than prevention, strategy can include approaches such as, but are not limited to, providing young people with positive pro-social relationship experiences, support, opportunities, coping skills such as mindfulness, connectedness and engagement, confidence in their own self-worth, contribution to their community and giving, and opportunities and the provision of resources to become competent adults (Aked et al, 2008; Ball, 2010; Bernat \& Resnick, 2006; Browne et al, 2004; Guerra \& Bradshaw, 2008; Ministry of Youth Development, 2009). To focus on all aspects of the promotion strategy would be outside of the scope of this thesis. This thesis rather focusses on the provision of mental health resources.

\section{Diversity of Mental Health Resources}

Due to the increase in demand for mental health services (Mental Health Foundation of New Zealand, 2017) those within the mental health field have had to create and implement a variety of innovative strategies to meet mental health needs, of those who need it. These include but are not limited to self-help programs such as pamphlets, books, videos and internet resources about mental health issues (Kitzrow, 2003).

These resources are used for many different purposes, from the most commonly thought of health information leaflet (Coulter \& Ellins, 2007) to computer based learning environments that can teach coping techniques to war fighters and their families to enable them to cope with deployment stress (Procci, Bowers, Wong, $\&$ Andrews, 2013), as well as delivering traditional psychological therapies such as Cognitive Behavioural Therapy to depressed adolescents (SPARX; Merry et al., 2012). To illustrate the nature and diversity of mental health resources the graphic novel, leaflet, song/waiata, short film and website mediums will be explained in further detail. 
Leaflets and brochures. A popular mental health resource medium is a leaflet, which is often referred to interchangeably as a pamphlet, brochure or information sheet. Printed leaflets are often given with the aim to improve the health literacy of consumers to enable them to look after themselves and/or make good decisions relating to their health and wellbeing (Coulter \& Ellins, 2007). Research on leaflets and other written information sources generally suggests they are a "useful adjunct to professional consultation and advice and can improve health knowledge and recall, especially if personalised" (Coulter \& Ellins, 2007, p25). In regards to treatment, decision aid leaflets providing information on choices of treatment available, can also ensure a better match between a person's value and their chosen treatment (Coulter, Parsons \& Askham, 2008).

Graphic novels. A growing number of graphic novels (GN), more commonly known as comics, are being produced in social care and mental health areas (Williams 2012; Czerwiec et al., 2015). The use of GNs in the study and delivery of health care has been referred to as "graphic medicine" (Green \& Myers, 2010). The core part of the story or underlying theme in graphic medicine is generally the experience of living with a mental health condition. The stories can be autobiographical or fictional in nature (Farthing \& Priego, 2016). Graphic medicine enables "new insights into the personal experience of illness" (Green \& Myers 2010, p 574).

An example of such insight is offered through GNs produced by The Youth Wellbeing Study (YWS) team at Victoria University of Wellington (Youth Wellbeing Study, 2014; 2016). These GN's were designed in collaboration with young people, and depict young people navigating through mental health issues or experiences. As well as offering insight on these issues, these GN simultaneously provide advice to those that are experiencing these events and to people who may be supporting these issues. For example, the GN “A Change" tells the story of a young person, Ash, who is struggling with self-injury. The story highlights common themes of those that selfinjure including the experience of being judged, misunderstood, as well as stereotyped. It also depicts barriers around seeking help as Ash attempts to navigate through them. In relation to advice, the GN highlights the importance of 'just being there' for people who struggle with self-injury, not trying to 'fix' the problem, but rather offering support, distraction and friendship without judgement. Research has suggested GN's are an effective medium for young people, especially those of 
Generation 'Y' (those born between 1977 and 1994 (Morton, 2002)), who have grown up in environments where constant stimulation is the norm. The GN format meets the need for high stimulation that may be required for this "virtual" generation (Short \& Reeves, 2009).

Waiata and Song. Song has also been employed with the intention to better mental health. Research has revealed that music can have a positive effect on wellbeing (Clift \& Morrison, 2011) of people with mental health needs. For example, group singing has been found to increase well-being in a diverse range of people including homeless men, others from both disadvantaged and privileged communities (Bailey \& Davidson, 2002) and elderly populations (Houston et al., 1998; Cohen et al., 2006). Relatedly, Voice Movement Therapy (VMT), a therapy that amongst other processes includes sound making and singing, has been found to derive positive effects on mental health. Research has found that the addition of VMT to treatment as usual for self-harming youths, led to statistically significant improvements in selfesteem, emotion regulation, anxiety, alexithymia, somatic symptoms and social dysfunction as well as a non-significant trend for a reduction in depression and selfinjury (Martin et al., 2013).

In a New Zealand context, to Māori, music or song is known as waiata. Waiata are an integral contributing factor to Māori hauora and engaging in waiata has been shown to derive huge benefits in these areas (Abel, Marshall, Rikki \& Luscombe, 2012; Elder, Milne, Witehira, Mendes, Heslin, Cribb-Su'a \& Kalra, 2009; Hollands, Sutton, Clair \& Hall, 2015). In regards to mental health, many tāngata whaiora consider waiata as integral to their recovery (Te Pou o Te whakaaro Nui, 2009). Waiata is often used in group therapy sessions and as a 'resource' as it can help build cooperation and cohesion of the group, gauge the mauri or mood of that group and offer an outlet for creativity in session (Te Pou, 2010). Further, engaging in waiata has been shown to help promote connectedness, affirm one's own Māori cultural identity and can elicit a calm state as it involves controlled breathing, oral motor sensation and has soothing rhythm and tones (Hollands, Sutton, Clair \& Hall, 2015).

Whilst there is general evidence highlighting the therapeutic benefits of using music and waiata with individuals, there is little to no evidence on the effectiveness of songs created specifically as a mental health resource. Although there is little to no evidence on whether mental health can be improved by songs created specifically to 
address mental health, these songs have been created and do exist. For example, "You belong", is a music video from the 'Mental Health America of Texas' organisation, and written by the band Alpha Rev (2012), all of whom are volunteers in suicide prevention.

"The video opens in black and white with Casey on a bridge. He then walks through a recently burned landscape. Along the way are people holding signs of encouragement, "You Belong," "You Are Loved," "Help is Available, "... After he passes through some fog, he emerges in light and color at a 'tree of life' with his band surrounded by a circle of encouragement." (Word News, 2012).

The video then gives contact information for the National Suicide Prevention Lifeline and related suicide prevention websites and apps. One could infer this is a metaphor for dealing with suicidal ideation, highlighting the supports that are available and the potential of a light at the end of the tunnel. The combination of the information within the lyrics and music video clearly offer comfort and support options and would be valuable as a resource for individual's with suicidal ideation.

The next step for future research would be to evaluate songs created as mental health resources, as has been the case for other mental health resource mediums.

Short Film. Film, another innovative medium, has also been used within and around mental health contexts. The term 'film' in this context denotes films specifically created for the purpose of addressing mental health rather than fictional depictions of mental health difficulties such as 'Black Swan' and 'One Flew Over the Cuckoo's Nest". Laroi and Van der Linden (2009) showed a documentary film depicting the lives of schizophrenic patients to individuals. Exposure to the film led to a decrease in derogatory, negative and stereotypical beliefs amongst individuals who watched the film as well as a decrease in their desire for social distance from schizophrenic patients. Short films about mental disorders have also been shown to positively address stigmatisation of those that face mental health difficulties by nurses (Bilge \& Palabiyik, 2017). Specifically, nurses created short films around the experience of patients who faced mental health difficulties. This creation process, as well as watching the other films that were created, fostered empathy within nurses for these patients.

Taken together these studies highlight that film can offer insight and reduce stigma around those that experience mental health issues. These changes in perception 
could lead to better treatment of those experiencing mental health issues by the public. The importance of film and how it can be used in mental health has started to resonate within the academic community. For example, Kings College in London now offers 'Movie and documentary in mental health: from research to public engagement' as a course of study (Kings College London, 2017).

Within a mental health setting, film has a wider application than just addressing stigmatised attitudes and stereotypes. In a New Zealand context, Le Va and Te Pou organisations (Pacific Inc, 2017) have created a series of short films in response to New Zealand's extremely high suicide rates (Ministry of Health, 2014). These organisations have collaboratively produced short films from Pasifika communities. Young Pasifika individuals tell their suicide survival stories in the hope of emphasising to others that may be in the same situation and to professionals, that suicide is preventable and that lives can be saved. For example, Albert Fale (Le Va, 2014) told his story around his lowest point, when he felt that he was not supported and thought that overdosing on alcohol and ending his life would be the only way through. He provided messages of hope from his experience and thoughts now that he is on the other side of those struggles, "life is precious and there is no such thing as a worthless person, there's no such thing as a person who can amount to nothing" (at 4.13 minutes); spreading encouragement and hope to those that may be in that situation now.

Short film has also been used in New Zealand to encourage a different approach to the treatment of those that face mental health difficulties. 'Open Doors' (MHFNZ, 2012) was developed by 'Awareness: Canterbury Action on Mental Health and Addictions' as a training resource to encourage alternatives to mental health inpatient seclusion. This film depicted former seclusion patients talking about their traumatic experience. The film additionally presented views from their family and support worker before discussing effective recovery focussed alternatives.

Mobile Phone resources: mHealth. A further mental health resource option available is Mobile health (mHealth) apps or programs. mHealth has been defined as "medical and public health practice supported by mobile devices, such as mobile phones, patient monitoring devices, personal digital assistants, and other wireless devices" (World Health Organization, 2011, p.6). mHealth's greatest value lies in the fact that phones are personal and portable, meaning the consumer can be connected to 
support wherever they are (Adler, 2009). Research has provided support for the notion that mobile phones can aid health behaviour change through the use of text messaging (Cole-Lewis \& Kershaw, 2010; Fjeldsoe, Marshall, \& Miller, 2009) and the combination of text and voice intervention (Krishna, Boren, \& Balas, 2009).

Some New Zealand based mHealth initiatives have targeted smoking cessation (Whittaker, Merry, Dorey \& Maddison, 2012). This includes the STOMP (Bramley et al., 2005; Whittaker, Merry, Dorey \& Maddison, 2012) initiative that targets smoking behaviour with effective brief intervention techniques, and that has now been fully funded as a free national service for consumers (txt2quit; Milne, Bowler, Li, \& Salmon, 2009). STUB IT is a mobile video messaging intervention for smoking behaviour that aims to increase the self-efficacy of consumers for quitting (Whittaker et al., 2008), and is based on social learning theory (Bandura, 1986). Specifically, consumers are provided with video diary vignettes from role models to encourage observational learning enabling behaviour change, social support and potential altering of norms (Whittaker, Merry, Dorey \& Maddison, 2012). A final example includes the New Zealand based mHealth initiative, MEMO (Whittaker, Merry, Dorey \& Maddison, 2012). Currently being trialled for adolescents with depression, this initiative is based on Cognitive Behavioural Therapy principles as well as previous prevention work (Merry, McDowell, Wild, Bir, \& Cunliffe, 2004). This is in the form of multimedia messaging with colleagues and experts at the Werry Centre for Child and Adolescent Mental Health, under the Psychological Medicine Department at the University of Auckland (Whittaker, Merry, Dorey \& Maddison, 2012)

Websites. Finally, many mental health resources are provided through websites. Research has shown that websites can be an effective medium to improve health related behaviours (Webb, Joseph, Yardley \& Michie, 2010). They also derive a high level of user satisfaction (Coulter \& Ellins, 2007). There is an abundance of mental health website resources in New Zealand, the majority of which are hosted by The Mental Health Foundation of New Zealand (MHFNZ, 2017). There is a huge diversity in focus within these websites. They range from addressing stigma and discrimination surrounding mental health in New Zealand through to providing information, insight and perspective workshops (reTHINK; Mind and Body Consultants Ltd, 2012), to government orchestrated websites (Primary Mental Health, 
2017), to websites created by volunteer organisations offering mental health resources and information (Spinz, 2017). Some Mental Health resource websites have been established to target specific populations, such as farmers and their wellbeing (Farmstrong, 2017), Pacifica wellbeing (Pacific Inc, 2017) and more general website databases encompassing resources for all populations and needs (Mental Health Foundation of New Zealand, 2017). There is a gap in the literature on New Zealander's satisfaction with, and ability to access, mental health resources in New Zealand. This is an important area for future research.

\section{The lack of Māori resources and the current project}

The preceding section has highlighted that there is an abundance of Mental Health Resources available. These include, but are not limited to, graphic novels, leaflets, song/waiata, short films, mobile phone resources and websites. In spite of this abundance, there are few mental health resources that are equipped to meet the needs of rangatahi Māori. There is reason to be concerned at this relative lack of resources, given that Māori are a high-risk population:

Māori have disproportionately high rates of universal risk factors e.g. poor housing, low educational achievement, unemployment, and inadequate income (Durie, 2004), and may have poorer access to universal protective factors e.g. stable family life, school connectedness. There are also Māori specific risk and protective factors that affect mental wellbeing at the population level e.g. societal prejudice and discrimination, loss of sovereignty, dispossession, alienation from the land and from intellectual and cultural resources (Ball, 2010, p12).

Māori have very high contact with the mental health sector (Browne, Wells \& McGee, 2006; Gaines et al., 2003; Simpson, Wicken, Duncanson, Adams, \& Oben, 2016). Specifically contact rates of youths aged between 0 and 24 are higher for Māori than that of non-Māori and non-Pacific (Simpson, Wicken, Duncanson, Adams, \& Oben, 2016). Further, Māori evidence higher prevalence rates of mental disorders than non-Māori (Bushnell et al., 2003; Baxter, Kokaua, Wells, McGee \& Browne, 2006; Simpson, Wicken, Duncanson, Adams, \& Oben, 2016). Mental health issues are particularly prevalent and problematic for young Māori, rangatahi, aged 
between 15 and 29 years (Horwood \& Fergusson, 1998; Baxter, Kani-Kingi, Tapsell, Durie \& Mcgee, 2006; Baxter, Kokaua, Wells, McGee \& Browne, 2006; Simpson, Wicken, Duncanson, Adams, \& Oben, 2016).

While it might be assumed that resources targeting adolescents as a broad group will also benefit rangatahi Māori, there remains a need to develop Māori specific resources reflecting the values and aspirations that are not necessarily shared between Māori and non-Māori . To indigenous people such as Māori vital components of good health include strong relationships with one's whānau, hapū, iwi, sites of heritage, and land, as well as traditional knowledge of Māori culture. These aspects may not be commonly, or equally, shared with Pākeha (Durie, 2004). Durie (2004) asserts that health promotion initiatives such as resources for rangatahi must take in to account what is considered to be important to Māori, and be grounded in Māori values and aspirations. To assume all New Zealanders subscribe to the same views to health and health goals and thus developing 'one size fits all' mental health resources, may mean that resources may work for some but not others. Governmentlevel organisations (Ministry of Youth Development, 2009) support this culturally specific assertion and argue that, while some heath indicators may be universal, their community-level meanings are culturally specific. Additionally, how you achieve these universal indicators are also culturally specific. For example, promoting selfesteem in rangatahi may involve strengthening their Māori identity, an area specific to the Māori culture (Ball, 2010). Mental health resources must target such key determinants of health specific to the defined population (Ministry of Health, 2006a). This aligns with international literature that asserts more positive results are derived with indigenous children when they are based off traditional knowledge and modes (Browne, Gafni, Roberts, Byrne, Majumdar, 2004)

Taken together, research (Ball, 2010; Durie, 2004; Ministry of Health, 2006a; Ministry of Youth Development, 2009; Te Rau Matatini, 2009) suggests that, for a resource to be effective for Māori, it needs to have set goals and objectives that reflect Māori values and aspirations. The creation of such resources needs to be achieved through culturally appropriate methods that address Māori specific protective and risk factors (Ball, 2010). To create such a culturally appropriate resource using a culturally appropriate method, is the aspiration of the current project to be described. 
Specifically, I set out to develop a mental health resource, by rangatahi for rangatahi (Kaupapa Māori; Smith, 1997) with the intention to help with hauora. As my research was conducted within a Kaupapa Māori framework, the following section will talk to critical concepts of Kaupapa Māori. The following methodology chapter will also explain other research methodologies employed within this Kaupapa Māori framework, namely Action research and Qualitative research paradigms. 


\section{Chapter 2}

\section{Methodology}

Mā te rongo, ka mōhio;

Mà te mōhio, ka mārama;

Mā te mārama, ka mātau;

Mā te mātau, ka ora.

From listening comes knowledge;

From knowledge comes understanding;

From understanding comes wisdom;

From wisdom comes well-being.

\section{Research Design}

This whakatauki encapsulates the philosophies of the three interconnected methodological underpinnings of this project that I shall explain in detail below. The first of these is Kaupapa Māori research which served as the foundational framework. Although Kaupapa Māori can be seen as a distinctive approach underlined by Te Ao Māori and Māori world views (Smith, 1997), the "methods are likely to be subordinate to the issues and utility of the research" (Moewaka-Barnes, 2000, p. 13). Thus, a researcher can draw on a range of complimentary methodologies to use under a Kaupapa Māori approach (Moewaka-Barnes, 2000). In this specific project, these complimentary approaches included action research, with 'data' analysed using qualitative methods.

It is important to note that in taking a Kaupapa Māori approach the research was negotiated with kaumātua from the local Wellington community where the research took place. It is central in the practice of Kaupapa Māori to involve kaumātua as the kaumātua provides "guidance, protection, spiritual oversight and keep cultural practices in the forefront of research" (Glover, 2002, as cited in Walker, Eketone \& Gibbs, 2006, p.336). The following sections cover the research design that was negotiated and agreed upon by kaumātua.

\section{Kaupapa Māori Research}

Kaupapa Māori research is research conducted "by Māori, for Māori and with Māori” (Smith, 2015, p.47). Kaupapa Māori is both a theory and a research methodology. It is based on mātauranga Māori and, as a philosophy, asserts a theoretical framework that ensures the needs and aspirations of Māori remain central 
to the research process. It is initiated, defined and controlled by Māori. These characteristics ensure that cultural integrity can be upheld whilst analysing issues (and informing intervention) involving Māori and relevant to Māori (Pihama, 2015; Simmonds, Robson, Cram, \& Purdie, 2015). Kaupapa Māori advocates for a strengths-based approach to research, focussing on what's right with Māori. This contrasts with the deficit focussed and unfortunately rather common model that compares Māori against non-Māori standards (and in other jurisdictions, culturally dominant and subordinate groups), often representing Māori in an unfavourable light (Bishop, 1996).

Kaupapa Māori has been likened to critical theory (Freire, 1972; Jones, 1990; Smith, G., 1997; Smith, 1999). Within a research paradigm, critical theory has the primary intention of generating social change and seeks to achieve this through exposing unequal power relations. Researchers have aligned the two paradigms as both research approaches work towards addressing the continued oppression of Māori by exposing underlying assumptions that conceal power relations (Smith \& Reid, 2000). Kaupapa Māori arose as part of the resistance against Western hegemony (Bishop, 1996) and "rather than critiquing power relations, seeks to promote Māori advancement and Māori development using Māori concepts in a contemporary environment" (Eketone, 2008, p.7). As a theoretical framework, Kaupapa Māori does not have a set recipe to provide answers (Pihama, 2015) but is more fluid in nature, frequently referred to as a research approach that provides a methodology that guides Māori researchers.

\section{The six principles of Kaupapa Māori research}

Six primary principles guide Māori researchers in designing, planning, gathering data, analysing and disseminating research (Walker, Eketone, \& Gibbs, 2006). These six principles of contemporary Kaupapa Māori theory are based on those originally proposed by Graham Smith (1997). Subsequent researchers have expanded on Kaupapa Māori theory through its development (See Smith, 1997, Pihama, 2001). Although slight variations of Kaupapa Māori exist, the critical shared factor is that "Kaupapa Māori research validates Māori epistemology" (Eketone, 2008). The principles are as follows:

1. Tino Rangatiratanga (the principle of self-determination)

2. Taonga tuku iho (the principle of cultural aspiration) 
3. Ako Māori (the principle of culturally preferred pedagogy)

4. Kia piki ake i nga raruraru o te kainga (the principle of socio-economic mediation)

5. Whānau (the principle of extended family structure)

6. Kaupapa (the principle of collective philosophy)

I shall briefly elaborate on these principles, using Smith (1997), to highlight how these principles are crucial to the design and negotiation processes of the research.

Tino Rangatiratanga (the principle of self-determination). Derived from the Treaty Of Waitangi (1840), this principle represents the heart of Kaupapa Māori and can be understood in terms of autonomy, mana motuhake, sovereignty, selfdetermination and independence. This principle emphasises the goal of Māori seeking more meaningful control over their lives and cultural wellbeing. The creation of Te Kōhanga Reo and Kura Kaupapa Māori are the initial examples of kaupapa Māori initiatives guided by Tino Rangatiratanga; schools created with the explicit purpose of Māori controlling their own destiny (Pihama, Smith, Taki \& Lee, 2004). Tino Rangatiratanga has now been extended to a variety of services including Kaupapa Māori health, justice, housing and employment (Pihama, Smith, Taki \& Lee, 2004). In research, this principle emphasises that Māori should have greater autonomy in choice in key decisions and are able to exercise control over processes and outcomes (Smith, 1997).

Taonga tuku iho (the principle of cultural aspiration). This principle emphasises that to be Māori is valid, legitimate and taken for granted under a Kaupapa Māori framework. Te Reo Māori, mātauranga Māori, Tikanga Māori, ahuatanga Māori and all other aspects of Te Ao Māori are legitimate and valid. This principle also emphasises emotion and spirituality as prominent and strong components in Kaupapa Māori (Pihama, Smith, Taki \& Lee, 2004). This principle states that aspects of Te Ao Māori should guide and be implemented in the research process. It asserts these Māori ways of doing and understanding are valid in their own right. (Smith, 1997).

Ako Māori (the principle of culturally preferred pedagogy). This principle highlights the need for Māori ways of teaching and learning that are unique to tikanga Māori (Pihama, Smith, Taki \& Lee, 2004). It is important to incorporate culturally 
appropriate strategies for Māori that effectively connect with their life circumstances (socio-economic) and cultural background. To Māori, teaching and learning are not separate concepts as they may have historically been treated at other times for Pākeha (Smith, 1997). However, this principle states it is also important to not ignore "borrowed" pedagogies from other cultures - if they could benefit Māori and the Māori community rather than undermining Māori language, knowledge and cultural values (Smith, 1997). For example, differing methods such as qualitative and quantitative approaches can be adopted to serve the purpose of the Kaupapa Māori research (Moewaka-Barnes, 2000).

Kia piki ake i nga raruraru o te kainga (the principle of socio-economic mediation). This principle reflects the notion that we need to alleviate the negative pressures and socioeconomic disadvantage faced by Māori communities (Smith, 1997). In research, this principle highlights adhering to a Kaupapa Māori approach can address this disadvantage and protect whānau wellbeing. Māori community and whānau assume collective responsibility in this regard (Pihama, Smith, Taki \& Lee, 2004).

Whānau (the principle of extended family structure). This principle also sits at the heart of Kaupapa Māori. Whānau is a vital cultural structure within Te Ao Māori, reflecting and embedded in the collective nature of Māori communities. (Smith, 1997). Both whānau and engaging in whānaungatanga are integral to the makeup of Māori identity and culture (Pihama, Smith, Taki \& Lee, 2004). In a broad sense, whānaungatanga can be thought of as "the process of identifying, maintaining, or forming past, present, and future relationships which enable Māori to locate themselves with those present" (Walker, Eketone, \& Gibbs, 2006, p. 334). This principle asserts that collective responsibility, cultural values, customs and practises are to be emphasised within the research process (Pihama, Smith, Taki \& Lee, 2004).

Kaupapa (the principle of collective philosophy). This is the notion that Kaupapa Māori initiatives are bound together through a "collective vision and commitment" (Pihama, Smith, Taki \& Lee, 2004, p.50). This principle emphasises looking beyond individual motives, and adopting and encompassing a broad collective perspective that looks to achieve aspirations of the Māori community (Pihama, Smith, Taki \& Lee, 2004). 


\section{Kaupapa Māori Ethics}

Kaupapa Māori methodology has been enthusiastically adopted by researchers since it was coined in 1992 and has grown and developed within the educational setting (Pihama, Cram \& Walker, 2002). This includes the development of ethical guidelines for the Kaupapa Māori research process, proposed by Cram (2001) and Smith (2012). These guidelines derive from sayings of kuia that are often used when they evaluate the qualities of an individual (Smith, 2012). These describe foundational Māori ethics and values that must be honoured in research, over and above requirements determined by an ethics committee or research methodology (Brewer, Harwood, McCann, Crengle, \& Worrall, 2014). The guidelines are as follows:

Aroha ki te tangata. This guideline translates to "a respect for the people" (Smith, 2012, p. 124). The Kaupapa Māori researcher must ensure participants in the study are able to meet on terms the participants create and that the participants can define their own space (Cram, 2001).

Kanohi kitea. This guideline translates to "the seen face; that is, present yourself to people face to face" (Smith, 2012, p.124). In practice, the Kaupapa Māori researcher must be willing, and demonstrate they are comfortable, to cross the role divide between the researchers and the researched. This involves "fronting up" to participants (Cram, 2001).

Titiro, whakarongo ... kōrero. This translates to "look, listen . . speak" (Smith, 2012, p.124), and means the Kaupapa Māori researcher must learn through looking and listening to the participants prior to speaking themselves. This guideline is important to and should be applied in many different stages within the research process (Cram, 2001)

Manaaki ki te tangata. This guideline translates to "share and host people; be generous" (Smith, 2012, p.124). Respecting this guideline means understanding the research process as a joint collaboration with participants. The researcher learns from participants, in addition to conducting the research. The guideline encompasses the notion of sharing research findings with participants. The spirit that guides this sharing is one of reciprocity over 'just' knowledge exchange and transfer (Cram, 2001; Smith 2005). 
Kia tupato. This guideline translates to "be cautious and careful" (Smith, 2012, p.124), and specifically researchers' are cautioned to be "politically astute, culturally safe, and reflective about their insider/outsider status" (Smith, 2005, p. 98).

Kaua e takahia te mana o te tangata. Or "do not trample over the mana of people" (Smith, 2012, p.124). Although a complex concept to define, 'mana' can refer to prestige or dignity (Brewer, Harwood, McCann, Crengle, \& Worrall, 2014). Thus, adherence to this means being respectful of the entirety of the research process, uphold community engagement and similarly to "Kia tupato" - share the findings of the research when completed.

Kia mahaki. This guideline translates to "don't flaunt your knowledge" (Smith, 2012, p.124), and highlights that the researcher must be humble when sharing knowledge. This humility is naturally achieved by the researcher if they follow the guidelines above. For example, by not trampling on mana, listening, being cautious and ensuring respect to participants at all times (Cram 2001; Brewer, Harwood, McCann, Crengle, \& Worrall, 2014).

Over years of development, Kaupapa Māori has proven to be a valid and recognized approach (Bishop, 2005; Cram, 2001; Irwin, 1994; Pihama, 2011; Smith, 2005, 2011, 2012; Walker, Eketone, \& Gibbs, 2006). It has been employed effectively in a variety of disciplines including clinical psychology (Gavala \& Taitimu, 2007), education (Smith, 1997) and health (Elder, 2008; Harwood, 2012; Kerr, Penney, Moewaka Barnes, \& McCreanor, 2010; Pitama et al., 2011).

These Kaupapa Māori principles help embed Māori initiatives in to a theoretical framework (Mane, 2009). The Kaupapa Māori framework can be likened to a plant metaphor - Kaupapa Māori represents the soil into which future initiatives (seedlings) are planted. The provision of nutrients and stability of the soil allow the seedling to thrive and grow in to a strong and healthy plant. This is analogous to Kaupapa Māori providing guidelines that promote Māori initiatives in seeking positive outcomes (Pidduck, in press).

\section{Action research}

This research is Participatory Action research (PAR: Kidd \& Kral, 2005). Action research, as a research methodology, was created in the belief that social research did not align with practical issues; although concepts were being researched, 
people's lives did not change as a result (Lewin, 1946). The idea of Action research came about to bridge the gap between research and application (Sommer \& Sommer, 2002). An overarching definition is that PAR methodology "brings together action and reflection, theory and practice, in participation with others, in the pursuit of practical solutions to issues of pressing concern to people and more generally the flourishing of individual persons and their community" (Reason \& Bradbury, 2001, p. $1)$.

Specifically, PAR has two objectives; the research must derive knowledge and action that is of direct benefit and usefulness to a community and empowerment through raising consciousness (Reason, 1994). PAR is a process whereby the 'researcher' and 'participants' collectively develop the goals of the study, the methods that will be employed and also choose a way to disseminate the 'results' that will lead to an increase in critical consciousness and promote change in the direction of the research or wider community's goals (Reason, 1994). PAR involves dialectic movement between action and reflection stages. Over time this cycle of action and reflection forms the method and mode of action of the project thus illustrating the dynamic nature of the process (Kidd \& Kral, 2005).

A researcher engaged in PAR must accept that any preconceived means, methods, goals and action plans for their project must be amenable to change, as they strike the balance between bringing their knowledge to the project and incorporating knowledge and goals from the group they work with (Kidd \& Kral, 2005). They must recognise they are in the middle of people's lives and, as such, be prepared to feel a range of emotions from caring deeply, feeling confused or frustrated, and must be able to be quiet when necessary (Maguire, 1993). Such a position is somewhat antithetical to the stereotype of the researcher as a dispassionate observer.

As a process, PAR involves a continuous self-reflective cycle of reflecting, planning, acting and observing (McTaggart, 1997). It's important to note that this recursive, reflective and practice oriented nature is not just limited to PAR but is also encompassed in other research methodologies such as Grounded Theory (Glaser \& Strauss, 1967) and Discursive Psychology (Potter \& Wetherell, 1987). The initial stage of PAR often involves a meeting where dialogue is initiated and participants and researcher share experiences. After the sharing process the first question may be "what are the questions?" or "what do we want to do for your community?" (Kidd \& 
Kral, 2005, p189) As with other methodological lenses that have a social change agenda, the exploration of these aims and questions is common to PAR (Kidd \& Kral, 2005).

Previous research has shown that when utilised within a Māori context, Action research can enable positive change and improvement for Māori (Kerr, Penney, Moewaka Barnes, \& McCreanor, 2010). Additionally, PAR works well alongside a Kaupapa Māori framework as the principles of the two approaches align in the following ways:

Firstly, PAR's development from the unique needs, challenges and learning of a group (Kidd et al., 2005) aligns with a Kaupapa Māori emphasis on ensuring the needs and aspirations of Māori remain central to the research process (Pihama, 2015). PAR pursuit of practical solutions to help better peoples life situations and help their community to flourish (Reason \& Bradbury, 2001) clearly aligns with Kaupapa Māori 's strengths-based approach to research (Bishop, 1996)

Secondly, PAR's collective approach to developing goals, processes and outcomes of research (Reason, 1994) honours the Kaupapa Māori principle "Manaaki ki te tangata" (Smith, 2012). Additionally, the greater 'participant' control over processes and outcomes enables Māori autonomy in the research and thus enhances and honours the principle Tino Rangatiratanga (Smith, 1997)

Additionally, as PAR's initial stage often involves a meeting where dialogue is initiated, trust is established, and experiences are shared (Kidd \& Kral, 2005, p189), this component allows space for the cultural practice of whakawhānaungatanga, the establishment of connections crucial to Māori hui (Walker, Eketone, \& Gibbs, 2006, p. 334)

Further, in PAR, research and goals are achieved in participation with others (Reason \& Bradbury, 2001). The PAR researcher is very involved and present at all stages of the research process. This aligns with the vital Kaupapa Māori principle "kanohi kitea" where you must present yourself face-to-face in your research and not hide behind a research 'curtain' (Smith, 2012). Lastly, in PAR it is acknowledged that the researcher must be able to be quiet when necessary (Maguire, 1993), consistent with the Kaupapa Māori principle "Titiro, whakarongo . . . kōrero" which emphasises the researcher must learn by listening to the participants before speaking themselves (Smith, 2012) 
Eruera and Dobb (2009) exemplify engagement in participatory Action research with a Māori community, where research processes were guided by Kaupapa Māori principles. Specifically, they worked with a PAR group of taitamariki to collaboratively construct their taitamariki intimate partner relationship project. From this collaboration the researchers obtained the taitamariki perspective on how the researchers could best engage with other taitamariki when carrying out their research, so they would feel comfortable and safe. To gauge best engagement practices, researchers worked to ascertain a great deal of information from the taitamariki including how they defined intimate partner relationships, and what they thought the best words and questions were to be asked around how to prevent violence in these relationships.

Eruera and Dobb (2009) engaged in PAR to ensure taitamariki fully participated in matters that influenced their own lives - that their process ensured research was done "with" and not "on" taitamariki and that their voices were heard in the research field. This was because the researchers acknowledged the risk that any intervention/prevention programme created for taitamariki in intimate partner relationships (and violence) would fail without their voice influencing how they are shaped. Their PAR project also reflected a Kaupapa Māori focus as it encompassed principals including "emancipation, self-determining communities, effecting social change, acknowledging and transforming participant's expertise into solutions, meaningful participation, community development and capacity building, collaboration and ownership" (Eruera \& Dobb, 2010, p5)

The employment of an Action research programme under a kaupapa Māori framework has also been observed in partnership with the Aotearoa government initiative, 'Whānau Ora Collective', during 2012-2014 (Baker, Pipi \& Cassidy, 2015). The Whānau Ora Collective was created to improve health and social outcomes of whānau specifically by supporting a collaborative approach and delivery of effective services by Māori non-governmental' organisations. Throughout the development of the Whānau Ora Collective there was continual liaison with Action researchers (coordinated by Te Puni kōkiri) who supported their planning, evaluation and reflection phases. The main goal of using Action research within the Whānau Ora initiative was to support the use of successful whānau-based service delivery. Action research enabled systematic reflection, greater depth of inquiry in to service 
transformation, and enabled a high level of professional practice consistent with expectations of the Whānau Ora initiative (Baker, Pipi \& Cassidy, 2015).

The methods used in the Kaupapa Māori Action research included the "logic model and rubric development; documentation review; case studies; review and analysis of whānau PATH plans (Pipi, 2010); focus-groups; interviews; group reflective hui; participant observation; iterative discussions; and comparative coding (Pipi \& Baker, 2014). There were also in-depth wānanga reflecting on the development of the service model and framework. Appropriate evaluation methods then grew from methodological decisions and included methods such as wānanga, reflective hui and whānau interviews (Baker, Pipi \& Cassidy, 2015, p.118).

Throughout this process, the researchers were guided by kaupapa Māori principles to ensure centrality of Māori cultural epistemology within their work (Cram, Kennedy, Paipa, Pipi, \& Wehipeihana, 2015; Nepe, 1991). Consistent with kaupapa Māori principles, the Action researchers infused tikanga values of the Collective in to all methodological decisions and engagement activities. Tikanga of the Collective included using "karakia, mihimihi, whakawhitiwhiti whakaaro, kōrero āwhina and tautohetohe as necessary.” (Baker, Pipi \& Cassidy, 2015, p.118). Additionally, all research activities were conducted under the Collective's Māori values of tika, pono, aroha, kohitahitanga and rangatiratanga (Baker, Pipi \& Cassidy, 2015).

The authors concluded that by engaging in Action research it enabled personal reflection on the importance of relationships, whānau and the transformation of service providers. Action research also affirmed and validated their mātauranga Māori as significant to supporting positive whānau outcomes. Lastly Action research allowed the authors to develop tools and frameworks that would go on to support their future aspirations for whānau ora (Baker, Pipi \& Cassidy, 2015). Their overall conclusion was that the integration of Kaupapa Māori principles with Action research works well for Māori communities (Baker, Pipi \& Cassidy, 2015).

\section{Qualitative Research}

Qualitative methods were adopted for aspects of this research. Many versions of qualitative research aim to understand aspects of social life. Specifically it can aim to understand individuals lived experience, attitudes, beliefs, interactions and their behaviours (Pathak, Jena, \& Kalra, 2013). Data generated from qualitative research 
methods are generally in the form of words or text, rather than numbers, as observed in quantitative research (McCusker \& Gunaydin, 2015). Within healthcare, the most commonly utilised qualitative methods of 'data' collection are interviews and focus groups (Gill, Stewart, Treasure \& Chadwick, 2008).

Many Māori researchers believe qualitative methods are particularly well suited for use with the Māori community, and sit comfortably under a kaupapa Māori framework (Moewaka-Barnes, 2000). This reflects the allowance qualitative methods give for more equal conversations within research, as power between the researcher and 'researched' can be negotiated (Dyck \& Kearns, 1995; Bryman, 1988) and often the participant is the expert (Taylor \& Bogdan, 1984). In qualitative methods the researcher similarly co-learns with the participant, which enables the development of rapport, trust and understanding of the research aims (Pernice, 1996). Qualitative methods also align with the kaupapa Māori principle 'Kia mahaki' (Smith, 2012); the equality of power and space to co-learn within qualitative spaces leaves less room for a researcher to flaunt their knowledge.

Qualitative research also aligns with kaupapa Māori principles in its commitment to understand the experiences of the participants from their perspective of the world and its goal to develop shared meanings (Pernice, 1996). Developing understanding from Māori perspectives would ensure that the needs aspirations remain central to the research process (Pihama, 2015). Further, developing these shared meaning aligns with the 'kaupapa' principle (Smith, 1997); the research initiative is bound together through a collective vision and commitment (Smith, 2012) that, in a kaupapa Māori paradigm, is to achieve the aspirations of a Māori community (Pihama, Smith, Taki \& Lee, 2004).

Previous research has shown that the use of qualitative methods are appropriate, and can be empowering for Māori communities as they allow Māori to describe their experiences in a way that is meaningful to them and gives them the space to raise unprompted issues and concerns (Moewaka-Barnes, 2000). Although the majority of qualitative methods have been shown to suit Māori, certain kinds of qualitative research fit especially well within a Māori way of doing. These include oral histories and narratives, case studies, interviews and focus groups (Walker, Eketone \& Gibbs, 2006). 
Examples of previous research demonstrate that qualitative methods can be employed under a Kaupapa Māori framework. For example, Cram, Smith and Johnstone (2003) research used qualitative methods within a kaupapa Māori framework to look at: 1) How Māori kōrero about health, 2) Māori health more generally, and 3) Māori experiences with Māori and mainstream health care providers. Māori participants were recruited from marae-based health programmes as these programmes incorporated both Māori and Western health practices. The researchers conducted semi-structured interviews with the participants. The researchers asked open questions to introduce certain topics but actively encouraged the participants to talk rather than moving through set questions. In line with kaupapa Māori, the researchers realised that they carried the responsibility of disseminating the realities of their participants to wider audience in a representative way. They took this role seriously and ensured there was space for their Māori realities and voices to be heard and that these were considered valid. By listening to their participants they concluded that the provision of respectful and collaborative healthcare to Māori enables health professionals to positively benefit health of individuals and their whānau. This goes on to have a positive impact in turn on their communities, hapū and iwi (Cram, Smith \& Johnstone, 2003).

Jones, Tristram, Davies and Cram's (2010) work took this methodology one step further by developing and utilising the "Whānau Tuatahi Framework" in their research. The foundation of this framework is the explicit implementation of qualitative methods under a Kaupapa Māori framework. This framework particularly privileges the role, view and experiences of whānau. This framework in practice allows whānau to both control the research and interpret the results. This ensures the representative and accurate depiction of their stories and issues they face. This framework used the metaphor of a tool box and encapsulated the idea the framework provided 'tools' for whānau. The whānau are able to choose their 'preferred tool' and how to best express themselves with this tool. Within this this framework, the research employed semi-structured whānau interviews and drawings. These research methods were used to ensure whānau had their own voices and concerns heard in regards to their health and wellness goals, and participants responded positively to the adoption of a Kaupapa Māori and Qualitative framework (Jones, Tristram, Davies \& Cram, 2010). 
This chapter has explained the three interconnected methodological underpinnings of this research and how they can be used effectively alongside each other. These methodologies include the kaupapa Māori framework, Action research methods and qualitative methods. The following chapter will now detail the methodology steps in this research and will specifically talk to how kaupapa Māori principles informed the development of the mental health resource. The following chapter will also present information on the experiences and challenges of the rōpu that emerged as a step along the way of the resource development. 


\section{Chapter 3:}

\section{Method and Analysis}

To best reflect the multiple purposes of this project, and the fluid interplay between method and analysis, I've decided to intermix the method and analysis sections. The first purpose was to create a mental health resource for rangatahi with the rōpū and the second was to understand the experiences of the rōpū. As such, following participant and recruitment information, this method and analysis section will speak to how kaupapa Māori principles informed the development of the mental health resource. I shall then describe common challenges, supports and experiences of the rōpu that came out as a step along the way of the resource development. The nature of challenges and experiences of the rōpū will be illustrated with examples informed by thematic analysis (Braun and Clarke, 2006; 2012)

\section{Participants}

The rōpū included 11 females aged between 16 and 20, from a second chance teen pregnancy school in Wellington. All but one identified as Māori. The rangatahi that did not identify as Māori identified as Pasifika but understood this was kaupapa Māori mahi and supported the kaupapa.

\section{Method of recruitment}

The principle of recruitment was kanohi kitea, or face-to-face, whereby participants were approached directly and asked if they would like to participate. This followed an initial hui with the principal and social work support (staff member dedicated to providing support around personal, social or community issues for students) at the school to gauge the interest of the school to be involved with this project. They agreed to be involved. There was then a second hui with all rangatahi at the school where I explained the aspirations for the project and answered any questions. From there, a group of 11 rangatahi volunteered to be involved. Kanohi kitea enables the building of relationships beyond what is expected in typical psychological research. Rather, cultural relationships were established where the rangatahi could gain knowledge of my own whakapapa, including my whānau, hapū 
and iwi. This was essential to gain the trust and involvement of the rangatahi in the project.

\section{Overview of procedure}

Ethical approval was granted by the School of Psychology Ethics Committee under delegated authority of the VUW Human Ethics Committee (Ethics Application ID: 0000024658) prior to commencement. In the course of resource development, the rangatahi chose to create a short film. This section will provide a brief overview of the steps taken to create this short film and will be followed by the explication of how kaupapa Māori principles influenced this process. This overview of procedure section encompasses a great amount of detail, in list form. I attempted first to group these steps based on common 'functions' (e.g., those involving 'consultation' or 'hui'). However, presenting the information in such a format does not demonstrate the iterative nature of this process, omitting important information on how this project transformed after certain decisions were made or actions were taken. The result is a description that is information-dense but illustrates the process as it unfolded. For ease of reading the overview of procedure section has been divided by the turning points of the project. The turning points of the project splits the research steps in to the following stages: Matatipu (the beginning sprout/first shoot of this project), Whanake (the development of the project), Whakarerekē tuatahi, tuarua and tuatoru (turning point/change 1,2 and 3 of the project). Finally it ends with whakahari (celebration of the commencement of the project).

\section{Matatipu}

This phase of the project was characterised by establishing relationships, and initiating cultural consultation.

1. I originally expected to make a kaupapa Māori Graphic Novel focussing on a mental health experience of young Māori and how aspects of Te Ao Māori could help with hauora.

2. I discussed this idea with both cultural and academic supervisors, and we all agreed this idea was consistent with kaupapa Māori so long as the rangatahi determined the focus and content of the graphic novel. 
3. I consulted with a fellow student also engaged in kaupapa Māori research, after which I decided I would let the rangatahi determine the output of the research rather than constraining them to a Graphic Novel.

4. I emailed schools to see whether they would be interested in meeting about this project (See Appendix A).

5. I held an initial hui with Principal and Social Support of a school to gauge willingness to be involved. They agreed to being involved and requested a presentation to the students. The decision was made to work with this school alone.

6. I held an initial hui with rangatahi at the school. A group of 11 rangatahi consented to be involved in the study. Consent was validated through the signing of a consent pamphlet (See Appendix B for information and consent pamphlet). No parental consent was required as all rangatahi were over 16 .

7. I met with community Kaumatua Doug to explain and receive feedback on tikanga surrounding the project.

8. I initiated relationships at the New Zealand School of Film and Te Kōkī (New Zealand School of Music) to ensure I would be able to deliver on whatever output method the rangatahi chose.

9. I held an initial hui with a film director of a local film company to gauge interest (and appropriate kaupapa) in being involved in the project if the rangatahi were to choose to create a film.

\section{Whanake}

This phase of the project was characterised by whānaungatanga with the rangatahi, determining what they would like to create and consultation around the content of the resource and how the process was unfolding.

10. Hui 1 with rangatahi (see appendix D for Hui 1 plan and further examples of hui plans illustrating the different stages of the project): This hui included whānaungatanga, establishment of group kawa, and opportunity to share their life experiences in relation to their hauora. The rangatahi made the decision to make a film in this hui and preliminary ideas of content for the film were discussed. I explained to the rangatahi that their information would remain confidential unless there was concern around harm to self or others that their 
information would be stored securely, and any de-identified extracts used in the thesis would first have to be approved by them. This hui ended with the provision of a debriefing sheet encompassing what we had talked about in the hui and where they could access support if needed (See Appendix C). A debriefing was given after hui one and two in which rangatahi talked about challenging or distressing information or experiences. The remaining hui covered film making and did not require debriefing forms however there was verbal debriefing after every hui.

11. Hui 2 with the rangatahi, here I introduced the film director and film crewmember, who explained to the rangatahi what would be required to make a short film. This included preliminary discussion around the potential content for the film.

12. Hui with Clinical Psychologist and research lab member, in which I sought advice on how to make this resource meaningful as a mental health resource and how to combine their life experience with my psychological knowledge.

13. Hui 3 involved the rangatahi, the film director, and an actor who specialises in theatrical depictions of mental health challenges. This hui included discussion of content the rangatahi wanted in the film and how this could be shown within the film medium.

14. Hui with research team leader and Clinical Psychologist. This consultation sought advice on my concern of the direction of the project and the appropriateness of the involvement of the film team in the brainstorming process of this resource.

\section{Whakarerekē tuatahi}

This phase of the project was characterised by assuming responsibility of the script creation process, consultation with film experts and staff to upskill to facilitate this process and the creation of the script.

15. At this point I rearranged the research process. Following the hui around concerns of the research (including the film crew taking over the process; dictating ideas for the film and not providing enough validation and empathy to the girls when they were sharing their challenging life events), I changed the research process to ensure the rangatahi voices were heard, and that it was 
their project. I assumed responsibility for leading and facilitating the film creation process until we had a finalised script, rather than the film team leading this process. The film team would come in only once that had been achieved.

16. I met with a film graduate student to up skill on how to facilitate the creation of a film, including learning about basic film techniques such as the three act structure of film (Field, 1979) ${ }^{1}$, and how to lay out and write a script.

17. I sought cultural supervision to ensure my project was still appropriately aligned with kaupapa Māori theory and practice.

18. I held hui 4 with the rangatahi alone. This hui was a script-writing workshop, where I taught the three act structure to the rangatahi and we collaboratively worked through the themes and goals of the film, as well as the events, challenges, feelings, strategies and competencies they wanted to show.

19. I consulted with a University film and script writing lecturer to up-skill on how to facilitate the creation of a film. I learnt how to frame a storyline, and how to effectively brainstorm characters and dialogue.

20. Hui 5 was the final script-writing workshop and was held with the rangatahi alone. In this hui the rangatahi finalised characters, settings and dialogue they wanted included in the film.

21. Writing of the script followed. I took all the rangatahi ideas from events, feelings, dialogue and settings and put these together in to script format.

22. I met with the film director to go over the rangatahi final script. He offered feedback on the logistics of the story, what would need to be changed for it the film be created, provided feedback on what needed to be included that currently wasn't and how it would appear to the viewer.

23. I held hui 6 with the rangatahi alone. This hui was meant to be a space where the rangatahi could comment on the film director's feedback and make appropriate changes. However many of the rangatahi present had not been to previous hui, so this was spent updating them on film progress.

\footnotetext{
${ }^{1}$ This film structure proposes there are three acts within any film. Act 1 is the setup phase, act 2 is the confrontation phase and act 3 is the resolution phase. Under this structure act 2 is double the length of the other acts and encompasses a turning point in the middle section (Field, 1979).
} 
24. Hui 7 was held with rangatahi alone. Though intended to cover feedback on the script, only one rangatahi attended. As this hui really required the rōpū, it was spent rather discussing next steps of the project; splitting in to smaller film teams. The principal requested a read over of the script.

25. Hui 8 included rangatahi and the film director, and involved a read-over of the script at that point, so the story could be brought to life, and so any holes in the story could be made apparent to the rangatahi

26. I then met with the film director to create film teams required for the progression of the project. This included art, script development, acting, lighting, music and continuity teams (see Appendix D for student worksheet covering roles of different teams)

27. Hui 9 included the rangatahi and film director, in which we explained the process going forward, and the different film teams the girls would be part of according to their own interest. At this point, we asked them to get back to us with a schedule.

\section{Whakarerekē tuarua}

This phase of the project was characterised by the redistribution of workload and finalisation of pre-production decisions.

28. After the rangatahi didn't get back to us with their schedule, I held a hui with the director in which we decided to rearrange the approach. We redesigned the process so the rangatahi only had to put minimal effort in to the organisation of the film to ease the burden or workload required alongside their everyday responsibilities (such as caring for their child, study). The rangatahi still retained tino rangatiratanga and had final say in all decisions.

29. I held hui 10 with rangatahi alone. In this hui I ran both a script development and an arts workshop. I listed all film decisions required across all film teams and rangatahi went through and agreed, disagreed or made changes as they believed were needed. All final script, art and music decisions were made by the rangatahi here, and then a wider team (including me) were to implement the changes, and organise arts and props as indicated by the rangatahi. 
30. I presented to all staff of the school again around the project, progress we had made, and where we were headed. This was to give back and acknowledge their continual support, kia mahaki.

31. The next step involved organisation of waiata production. In the final workshop, a couple of rangatahi signalled they would like to sing waiata for the film. I organised with a contact from the New Zealand School of music, established at the beginning this process, and he agreed to record and produce the tracks.

32. Hui 11 involved the rangatahi, film director and film crewmember. In this hui the group did a read-over of the revised (finalised) script (see appendix G). Rangatahi were also allocated roles as extras of their choice, if they signalled they wanted to be.

\section{Whakarerekē tuatoru}

This phase of the project was characterised by a change in the planned production process and filming of all scenes of the film.

33. I met with the film director and a film crewmember, to address concerns around completing the film (including the growing extent of the project and its achievability as well as commitment of the rōpū as time requirements of the project increased). There was some debate on the appropriate way forward but we came to a final decision that we would change the process and shoot by location rather than in studio, which meant we could continue with the project in the timeframe remaining, and keep alive the kaupapa of the project.

34. Waiata production had been organised with a Te Kōkī student who had volunteered to record and produce the two young mothers covering the waiata. However, the rangatahi cancelled this session at the last minute. Options were reviewed and the school's whole performance arts group offered to sing the waiata together. This rōpū included the two original singers, singing as a rōpū alleviated the pressure they felt and they were happy to sing alongside their peers. This date was rearranged with the Te Kōkī student.

35. Shoot day 1 . The first day of shooting included shooting the 'tile sequence' scene at Avalon Studios. This included all rangatahi (11) and eight extras, and all required shots were achieved. 
36. Outside shoot day: This required five rangatahi and entire film crew and extras. All required shots were achieved.

37. Waiata production: The rangatahi sung a cover of the waiata they had selected, Tangaroa Whakamautai by Maisey Rika. Maisey Rika's stage manager was contacted who confirmed Maisey was happy for this to happen. This was recorded and produced by Te Kōkī student.

38. House shoot day 1: This required four rangatahi an entire film crew and film extras. All required shots were achieved.

39. House shoot day 2 (the subsequent day after House shoot day 1): This required four rangatahi an entire film crew and extras. All required shots were achieved.

40. School Shoot (see appendix I for the call sheet of this shoot, an example of what was required prior to every shoot): This required all rangatahi, the full film crew and extras. All required shots were achieved.

41. Bus shoot: This required two rangatahi, the entire film crew, thirty extras and a bus. All required shots were achieved.

\section{Whakahari}

This phase of the project was characterised the provision of koha and the dissemination of the completed film.

42. Koha was given to rangatahi: This served a number of functions, to foster any future relationships between participants and researcher, to recognise and reflect gratitude for rangatahi involvement and also to fulfil ethical requirements of Victoria University School of Psychology Ethics Committee.

43. The film premiere was held at a local Wellington Cinema. The rangatahi, film crew and wider research teams were given a chance to speak. Adhering to tikanga, kaumātua Doug opened and closed the premiere.

44. School screening of the film. This was to give the chance to those that could not make the event within the school community to view the film.

45. Media coverage was organised around the project (see appendix K for examples of coverage): The rangatahi wanted to spread their film widely so the messages of hope and support could reach many young mothers and so that insight in to their experiences could reach health professionals. The film 
and project was published in Stuff.co.nz, the Dominion post, the Victoria University of Wellington social media platforms and aired on Awa.fm radio, Māori TV and Te Reo channel. Large New Zealand organisations that believed in the kaupapa of the film also shared the film on their social media platforms, fulfilling the original intentions of the rangatahi.

\section{Kaupapa Māori influence over procedure}

The timeline above includes some references to kaupapa Māori principals and guidelines that informed the research process. I shall elaborate on each of these below, and illustrate how they were relevant to the project as it unfolded. I provide a general overview of each principle, followed by specific examples from the research steps listed above, to demonstrate how they influenced actions. See above (pp 11-16) for definition and explanation of kaupapa Māori principles and guidelines.

\section{Tino Rangatiratanga (the principle of self-determination)}

Adherence to tino rangatiratanga was in the front of my mind at every step of my project. I worked hard to ensure that I consulted with the rangatahi in every key decision or potential turning point of this project, in order to make sure they had a sense of meaningful control over much of the research processes and outcomes. Specific examples will be covered in methodology steps, but an illustrative example is letting the rangatahi determine the exact focus of my research. Although I had a particular interest in how cultural tools could benefit whatever experience they thought was important (e.g., kapa haka, pūrākau), these rangatahi wanted to focus on the experience of being a young mother. As this was their decision, this is where the project then went. I facilitated an environment in which they chose a short film - to create something visual that would have a strong reach online:

"You know we could all write a status on Facebook but we reckon a film will get across more. And yeah because everyone uses social media these days...you know once it's on Facebook, it's on Facebook. So it would get across to a lot of parents" [Extract 1: Rangatahi 4]

'It's about whether or not you know about available to young Mums. That's why we want to make the film. To inform them there are supports and 
options...Like there are young mums everywhere around the world but to them it feels like they are the only ones out there..." [Extract 2: Rangatahi 1] This presented an initial challenge in terms of my confidence in my own skills, so I sought out and brought in appropriate support, and upskilled myself to ensure we could honour their favoured choice. Throughout the entire script creation process I let them have full decision making rights in what content was included, events that would be covered, what emotions would be portrayed and how, and artistic decisions (e.g., props, lighting, etc.). Examples of research steps that aligned with tino rangatiratanga include the following:

Initial cultural supervision prior to beginning my research process: Prior to starting my research I sought cultural supervision with a Māori academic and kaiāwhina (helper or advocate) of the School of Psychology. These consultations were carried out with the idea that I would facilitate a group of rangatahi to create a graphic novel, following in the footsteps of my research team's previous experiences (see pp. 4 for a description of these). The purpose of seeking this guidance was to ensure that before I even approached any rangatahi, I could be confident my research was culturally appropriate, as well as meeting the expectations of a University programme of research, given.

Process change following consultation with a colleague with experience of kaupapa Mãori research: I consulted with a colleague who had conducted kaupapa Māori research to ensure I was honouring tino rangatiratanga and that my research was relevant. This consultation led to a change in my approach. She commented that it was not kaupapa Māori to go in with the preconceived idea to create a graphic novel. She commented that "who's to say this would be meaningful to them or even what they wanted to do". As such I broadened my research focus to let the rangatahi determine the output they would like to create.

Process change after initial meeting with principal and social support of the School: I initially presented my research idea to the principal and social support of the school to see whether the school and the students would be interested in my research project. They identified a concern with my research approach of working solely with Māori students. They explained that whilst they understood the importance of doing so, they had a strong whānau focus in their school and valued including everybody. They mentioned that a previous student project involving kaupapa Māori research at 
their school had started with just working with rangatahi Māori but then the rest of the school came in for reasons of inclusivity. I took this to two forms of cultural supervision and sought advice on the propriety of working with non-Māori under a kaupapa Māori methodology. My supervisors explained that kaupapa Māori methodology is good for all young people, not just Māori, and that this project could demonstrate a wider application of kaupapa Māori to health. They suggested throughout the process I should draw on other cultural information with which students might be familiar to make any other students feel comfortable. For example if my hui was focussing on Te Whare Tapa Wha (Durie, 1985), I could draw parallels to other cultures the students may be from, for example Fono Fale (Pulotu-Endemann, 2001), a Pacifika model which similarly endorses holistic health. I changed my research approach at this point to align with the school's whānau values, opening it up to students who may not have Māori whakapapa, so long as they believed in the kaupapa of the project.

Process rearrangement in meeting with film director and following hui: From the outset, the rōpū were very keen to make this film in principle, but there were also issues with organising this to happen, and for them to follow through with agreed tasks. This was due, in part, to their constraints as young mothers. Assigning tasks was originally done so they could have full autonomy in their project; however it became clear this was adding pressure in combination with their other priorities, children and school work. After a hui with the film crew (step 28) we assumed greater responsibility in the project to take the pressure off the rōpū. We decided we would gather together all considerations and decisions that needed to be made, and discuss this with the rōpū. After we had obtained their thoughts and opinions we would then complete the tasks required in a way that was consistent with their wishes, but didn't place heavy demands on the rōpū. This was done so in the recognition that their children and school work should be their top priority.

Organisation of the production of waiata: As we were working through script development (step 34 and 37 above), the rangatahi signalled they would like to sing in the film. This had not been part of the original plan, as I was worried about the scope of the project and being able to finish it in the timeframe. However, this was important to the rōpū, and so I returned to my initial contact with the New Zealand 
School of Film and organised the production of a waiata sung by the School's performing arts group.

\section{Taonga tuku iho (the principle of cultural aspiration)}

Throughout the research process I worked to ensure our hui was a space where the rangatahi were able to be comfortable with their Māori identity, Te Reo Māori, mātauranga Māori, Tikanga Māori and ahuatanga Māori. In line with the advice of the kaumātua, rather than assume any beliefs around tikanga practices - I simply asked the rōpū what they would like to do and what would make them comfortable. I started off the first hui with saying: "In regards to tikanga, I want to make sure I'm doing it right by you guys and what feels comfortable. Would you like to start with a karakia? If so do you have one for your school? If not I can say one." The rangatahi signalled they would like to begin and finish each hui with a karakia, but that there was no other tikanga practice expected. This process was repeated in each hui, and I checked regularly whether they wished any changes in this regard as the project progressed.

\section{Ako Māori (the principle of culturally preferred pedagogy)}

I incorporated culturally appropriate strategies into my research to create a space where the rangatahi could connect with their Māori cultural background. An activity in hui 1 is an example of Ako Māori. The activity invited the rōpū to put down their 'waka's journey to hauora' on a piece of paper: "Please put down 5 events or experiences that you think has led to you and your hauora/wellbeing right now". Though intended only to be a short exercise, and then lead to group themes, it lasted the whole hui. The rōpun needed the space to tell their journeys and this was prioritised over any of my other plans or time constraints. This was a highly emotive session in which we talked about the extreme hardships the rangatahi had faced

\section{Kia piki ake i nga raruraru o te kainga (the principle of socio-economic mediation)}

This project is a primary health approach intended to challenge some of the negative statistics associated with Māori (for reference see page 9), without adding to them. Developing a mental health resource that other young Māori mothers can look to for inspiration, and more adaptive ways to get through challenging times should 
work to strengthen this population and help to prevent some of these negative expectations from coming in to fruition. Examples of research steps that aligned with Kia piki ake i nga raruraru o te kainga include:

Consultation with Clinical Psychologist, Youth Wellbeing Colleague and related outcomes: While the point of the developing resources was to address disadvantage and protect whānau wellbeing in a meaningful way, it was not clear that the rōpu held the holistic understanding necessary. At this point of time I was worried that brainstorming and using the ideas of the rangatahi alone on coping alone may represent their experiences, but wouldn't be enough to develop a resource to address disadvantage and protect whānau wellbeing in a meaningful way. Specifically, I was becoming concerned around what the content of the film would be. If framed as a mental health resource, it would also need to cover important psychological concepts as well as the experiences of the rangatahi. I sought clinical supervision, and was encouraged to bring some ideas in on what research says helps in these challenging situations, to compliment what the rangatahi were saying, and work these ideas in collaboratively.

My advisors noted that the girls found it difficult to articulate answers in response to my questions about where they received support and strength: "it's like asking a depressed person why they are depressed and how to get through". They offered some research areas to explore and take to the rōpū. For example, clinical advice included the suggestion that the rangatahi may have great ideas on how to deal with stigma and stereotypes (such as blocking out, responding assertively etc.). Another suggestion concerned addressing cognitive distortions whereby once you have been judged, you're more likely to think you're being judged (even when you may not be). In the resulting film, this notion is challenged and we see one of the rangatahi reflecting upon this experience.

\section{Whānau (the principle of extended family structure)}

Throughout my project I ensured there was space for whānaungatanga in all hui, even when there were constraints. Whenever someone new was brought to the group there was time to introduce themselves, say where they are from, and for the rangatahi to form a connection with them. In adherence to this principle, Māori 
cultural practices customs and values were honoured - for example, hui always started and closed with karakia, kai was provided, etc.

\section{Kaupapa (the principle of collective philosophy)}

The exact nature of this project was determined from consultation with cultural supervision, kaumātua consultation, while the final decisions on process and output came from the rangatahi. In this regard I moved away from any individual motive I may have had in the research and focussed wholly on the needs of the rangatahi, their local Māori community, and the greater Māori community. This was to create a short film of their experiences of being a young mother, the challenges involved, and the ways that people in the same position can address these challenges with strength and independence. I continued to return to this collective kaupapa, to ensure that they thought we were working in what they thought was a meaningful way, to achieve our collective goal. This was especially important after film experts had been brought in. When I thought we were straying from our kaupapa I stepped in and made changes to the process to ensure we were working towards our collective vision. Examples of research steps that aligned with the kaupapa principal included:

Establishing relationships in other disciplines: To ensure it was possible to work towards our collective vision and goal, I established connections with a variety of practical disciplines to ensure I could deliver on what the rangatahi wanted. In the early hui, the rangatahi suggested they would be interested in creating a waiata or short film, artistic practices with which I was not familiar, and there wasn't anyone in my wider team who had created these form before. I contacted the directors of the New Zealand School of Music and the New Zealand School of Film. The School of Music referred me on to the department of Music Therapy who had individuals who were involved in waiata production creation, and were happy to be on standby to be involved in this project. The School of Film sent my email outlining my project, and what would be required, to the last three years of graduates. I was subsequently contacted by a range of people, from current film students to professional directors of their own film companies, all of whom had a side passion for creating community films, and wanted to be involved. After the rangatahi chose a short film I met with a film director of a local film company, to ensure he would be a good fit for the project, 
understood our kaupapa and kaupapa methodology more generally, and his role in facilitating the girl's' aspirations.

Rearrangement of the process after hui 3: I became concerned around how the process was advancing from Hui 3. I had anticipated that the film director would explain the film process and provide a template on how to brainstorm a film, and would then come back to him to produce the film. However, his expectation was that the film crew would take control of the project. Such an approach might necessitate the rōpū repeat the experience of sharing their life journeys (hui 1). I was concerned about doing this again and how it would affect the rangatahi as it was a highly emotive, raw experience.

I was also concerned about the direction the crew wanted the project to move in. By the end of hui 3 we had finally achieved momentum, the rōpu were aware of what was involved in the film creation process, and their thinking was aligning with the creation of the resource. The film team believed at this point in time we should revise the purpose of the project and have "creative sessions" where the rangatahi freely acted. Whilst this process might be useful if the girls were aspiring to be young actors, I felt that they would be confused about taking this direction. Following these sessions we would then have to come right back to the start and think about the themes we wanted in the film. Whilst the girls were passionate and wanting to help, they were also very busy

I consulted a Clinical Psychologist in my research team for advice on this issue and how I felt like the project was drifting from our kaupapa. She agreed with my concerns and recommended assuming greater control. I changed the process, and took control of the brainstorming and creation of the film script to ensure the film reflected the voices of the rōpu voices and validated their experiences. The film crew would be invited back in after the script was produced and produce the film. I found this particularly challenging, but also essential for the kaupapa of the project.

Up-skilling to ensure we could achieve our kaupapa: As a first effort I got in touch with a subject librarian of film for basic sources on 'how to write a film'. As well as studying these, I also met with professionals to ensure I knew enough to work collaboratively with the rōpū to create something. I met a film graduate who completed a Bachelor of Design and Innovation from Victoria University for advice around the film creation process, who taught me the basics of film such as the 'Three 
Act Structure' (Field, 1979) of script writing. We also discussed the different ways the girls might present their stories, and suggestions for the film creation process.

I also met a lecturer from the School of English, Film, Theatre and Media Studies at Victoria University of Wellington to consult around the film process. This lecturer supervises Māori and Pasifika Theatre and Drama and is currently researching in the area of Māori method and whakapapa of Māori performance. As such, she understood the kaupapa of our mahi. She offered advice on story development, how to frame the storyline to make sense to a viewer, and ways I could brainstorm characters and required dialogue for the film.

\section{Aroha ki te tangata (guideline around respect for people)}

In our first hui we established group kawa to ensure that we would be meeting in a way that all rangatahi wanted, and ensure there was consideration around what the girls thought important. For example we originally had the kawa "watch your language" but one rangatahi commented "Nah, sometimes I need to swear to show how I was feeling" - we dropped this rule. Throughout the research process I ensured the rōpū picked when we met. I used tools such as doodle polls, online calendars and physical calendars for the girls to mark when they were free and wanted to meet. I used this to organise the film teams and other external parties to ensure that the girls were meeting on terms that suited them first. For hui later in the night, the rangatahi mentioned it was easier with babies in the room, and that they liked to see them after school. Although I had volunteers prepped to help in the crèche with babies, this made keeping the rangatahi on track much harder, I ensured babies were welcome to sit on their mum's knees in sessions and kai for the little ones.

\section{Kanohi kitea (guideline around presenting yourself face to face)}

I initially met with the school (principal and social support worker) to discuss whether they would be interested in being involved, and what was important in their school community. I went and presented myself face-to-face, rather than discussing anything over email: kanohi kitea. This also enabled whānaungatanga before meeting, something that can't happen during email correspondence. I presented to the full school, kanohi kitea rather than leaving a stack of flyers. I introduced myself, why I'm interested in the form of research, and what the project would be about. I was also 
present at every stage of the research process, from brainstorming to script writing to every aspect of pre-production and production, even if it was a session led by the film team. Consistency with this principle also meant careful self-disclosure to reciprocate the girls' own willingness to share their lives and experiences.

\section{Titiro, whakarongo ... kōrero (guideline around looking and listening before speaking)}

Throughout the entire research process I listened to, and watched, the rangatahi so as to fully understand their experience, perspective or idea before I spoke on the topic myself - they are the experts of their own experiences. An example of this was in the initial hui when the girls stood one by one and told their stories to the group. In this time I did not ask the rangatahi any questions on their experiences before learning what was important to them. Although I facilitated the script-building sessions, I first listened to their suggestions fully before speaking myself

\section{Kia tupato (guideline around being cautious)}

Throughout this entire project I remained very aware of my inexperience of working within a kaupapa Māori framework, and the limits of my understanding of mātauranga Māori. Therefore, I ensured I had regular cultural supervision with my cultural supervisor and kaiāwhina. I also consulted with other students who had completed kaupapa Māori study, and consulted with community kaumātua. Examples of research steps that aligned with Kia Tupato include:

Consultation with kaumātua: I consulted with a kaumātua about my project before I started engaging with the rangatahi. The kaumātua offered me advice around my project, and the broader context for Māori, including how the concept of whānau has changed with urbanisation (necessitating consideration of wider support networks surrounding rōpū). He also reinforced taking a strengths-based and goal-oriented stance in the research "becoming pregnant and having baby is behind them now and should be looking to move forward, however there are key learning's from that time and event". The most influential piece of advice from the kaumātua was around tikanga. He pointed out that tikanga may not be immediately applicable to rangatahi who have not been brought up within a context of tikanga. He reminded me that tikanga is intended to facilitate process and to be mindful of what should be used with 
them. He provided me with a guide to tikanga considerations to keep in mind, developed from the late John Rangihau who created this from his work with whānau (D. Hauraki, personal communication, May 29, 2017).

In line with Kia Tupato, I followed this advice, mindful of tikanga in hui, and checked that practices such as karakia were appropriate for the rōpū. I kept in touch via email with the kaumātua to see how he thought the project was progressing and if he had any advice; once when the girls decided to make a film, and again when the girls finished the script and were moving in to production. He approved the project progression. To remain culturally safe and adhere to tikanga, the kaumātua also opened and closed the film premiere.

Mentorship by Kaiāwhina of Psychology: The kaiāwhina of Psychology is a position established to support Māori students in their studies at Victoria, and was occupied during my thesis research by a clinical psychologist who was involved in the majority of my research steps and decisions. I looked to her as a consultant, a supervisor and a mentor, and had many discussions around the research process with her. She structured my thinking in regards to what I needed to do, and how I could ensure that it aligned with kaupapa Māori, and offered advice that I used to inform the direction of my project. She came with me to many hui, thus adding another layer of cultural safety. As a registered Clinical Psychologist she also added a level of clinical support as, at times, we were discussing potent topics such as suicide, drugs alcohol etc. She ensured I was having the conversations in an appropriate way, and was there to guide decisions. She was also there for me to debrief with, which I found essential.

Awareness of my outsider status: I was aware of my 'outsider' status throughout this research. The position of the researcher as an insider or outsider to the community in which they research is a common point of tension in qualitative research (see Kerstetter, 2012). Although I am Māori, I am not a mother, and have no experience of the challenges the rōpu had faced. I acknowledged this outsider status in hui. The rangatahi said 'It's weird talking to people when they don't have kids. It's good but I feel like maybe it's different because you are older than us and you would have bit more of a feel if you are older than us". It was particularly important to acknowledge and validate this very understandable issue. This included acknowledging their status as experts in their lives, and the importance of their autonomy in decision-making. 


\section{Manaaki ki te tangata (guideline around sharing, hosting and being generous to people)}

I endeavoured to show the rangatahi manaakitanga throughout the entire research process, including providing healthy kai (in accordance with the healthy school policy) for the rangatahi and any other parties in all hui. Further, the entire project was built on collaboration. This project moved forward with the rangatahi as experts on their own experiences, my knowledge of psychology and resources from university, and the knowledge and skills the film team brought to production. We were able to have conversations where we all learnt from each other, and moved forward together. I reinforced this collaborative process at every opportunity, and gave the rōpū credit where it was due. This included ensuring the names of the rangatahi were included in all news, publications, TV airings or websites covering the research project, the film or the premiere. They were also all credited in the film credits. For example, I ensured that a local newspaper article explained that the rangatahi were the backbone of the project and, that the article included a named photo of the group to give them full credit.

Lastly, sharing of research information and findings come under this principle, and was important throughout the project. I sought confirmation from the rangatahi that I was able to use any quotes from hui before I included them in any presentation or write up (including this final thesis). All research findings in this project including common experiences, challenges and supports the rangatahi described were grouped together and fed back to the rangatahi and the school. While such measures are not uncommon in qualitative research, this was not only done at the end of the research process but throughout all research stages. For example, mid-way through the research process I presenting 'findings' and how the project was progressing back to the staff at the school. This was useful for communicating the time demands of this project, and what would be required from the rōpū as the project progressed. This illustrated manaakitinga by way of reporting back findings, but also reinforced their role a collaborators, such as through giving the rangatahi school time for activities. 


\section{Kaua e takahia te mana o te tangata (guideline around not trampling over a person's mana)}

I ensured the mana of the rangatahi was not trampled on throughout the research process. The sharing of life experiences in Hui 1 not only illustrates 'Kia piki ake i nga raruraru o te kainga' (pp 35-36), but is also consistent with Kaua e takahia te mana o te tangata. After completing the exercise all rangatahi wanted to be able to stand and tell their own story. This necessitated allowing space for the rangatahi to tell their life journeys in a way that was meaningful to them, though it meant not following the plan originally developed for that hui. For some it may have been the first time they had thought about how the combination of their life events led to how they feel now, and was incredibly moving and tearful. To rush them through their journeys or not allow the space would have trampled on their mana.

Meeting to defend the kaupapa: Towards the end of the project, after the script and arts had been finalized and shoot production finalised, I held a hui with the film crew. In this hui I had to engage in strong debate to reinforce the kaupapa of the film and project, in order to protect the mana of the rangatahi. Specifically, this was a meeting about the logistics around finishing the project, and the concern of the film crew around the growing extent of the project. The film crew asked would happen if the film couldn't be made. I emphasised that this would go against the principle kaua e takahia te mana o te tangata, and would strip the mana away from the girls who had invested so much time and energy in to this project. I was frustrated as I didn't think this was a conversation we should have at this point as we were essentially "finished". This was long after the scope and kaupapa of our collaboration was made clear at the beginning, but allowed to grow beyond these parameters because of decisions made by the crew. I had to think carefully about how I framed debate points as while I was protecting the mana of the rangatahi, I also had to balance this with also protecting the mana of the film crew. They were the experts on film and whilst the project had unintentionally grown beyond our original scope, this was only done so from good intentions from the film crew. As such, whilst discussing miscommunications and next steps, I also ensured I commended all of their great work and effort. The film crew suggested shortening the film by either reducing locations in the script, or taking out a story line, but either would have been inconsistent with the decisions the rangatahi were supported to make. To move forward, the film crew and I achieved a 
common ground that would mean we could still the entire shoot as written by the rangatahi, but shooting by location rather than doing a studio shoot. This would lessen time requirements, as there would be no setup

\section{Kia mahaki (guideline around not flaunting your knowledge)}

Given my position as the academic 'expert' in the context of this project, it was important to ensure the rangatahi knew that they were the experts on their lives, and how this project should be made. I made it clear that whatever knowledge or expertise I held was to facilitate what they thought was important, and what they wanted to achieve. I also worked to ensure any experts or external contributors brought in to the film would adhere to this principle too, and reinforced the collaborative nature of the project.

\section{Thematic Analysis}

I was solely responsible for transcription of the hui, as the rangatahi did not give consent for their transcripts to be read by anyone else. In line with kaupapa Māori practice (and in common with practice in qualitative research more generally), the rangatahi were given the option to remove any extracts they did not want to be included in the thesis, though none chose to do so. Identifying features and names of the rangatahi have been removed from the quotes provided in the analysis section.

My approach to analysis of the transcripts was informed by Braun and Clarke's $(2006,2012)$ constructionist framework of Thematic Analysis (TA). Thematic analysis is a research method used with qualitative data. It enables the identification, analysis and interpretation of themes, or patterns of meaning, within such data (Clarke \& Braun, 2017). My analysis was informed by, rather than fully faithful to, thematic analysis because the aim of this project was primarily about the journey of the creation of a resource - the identification of themes was secondary to the creation of the film.

Thematic analysis provides a set of steps for generating codes and themes from qualitative data. The highest level of interpretation in TA is that of themes; patterns of meaning that are all underpinned by a shared core idea as an organising concept. The level of analysis of this project will be limited to themes rather than further analysis of 'codes'; TA's smallest unit of interpretation and building blocks of themes. This 
decision was made as this project had a smaller emphasis on revealing 'something', as is standard in qualitative research, but was more focussed on the journey of creating mental health resource and the nature of experiences that arose from this process. TA was chosen for its utility to identify patterns, perspectives and lived experiences and for its alignment with critical psychology perspectives (Clarke \& Braun, 2017).

I shall now describe how thematic analysis was used to analyse the young mother's discussions from hui of their lived experiences. Sections of data relevant to the young mothers lived experience rather than film development were coded and recoded in to semantic level themes (interpreting the patterns of talk by outlining the issues that were discussed by participants). There were six stages to this analysis applied to transcripts of the first two hui where rangatahi discussed their experiences. I conducted this thematic analysis alone as the rangatahi explained they did not wish anyone else doing this work. In line with kaupapa Māori, permission was granted for the use of quotes chosen for use in this thesis.

Phase one of the analysis involved immersion in to the data. Firstly, all hui were transcribed, an initial step in familiarisation (Riessman, 1993) and identification of meaning from the data (Lapadat \& Lindsay, 1999). This phase also involved active reading (that is, simultaneously searching for meanings and patterns within the transcript), and rereading, of the transcript. During this process I started making notes on salient and interesting points as a first step to identification of aspects that may be important for potential themes.

Phase two involved generation of initial codes. Giving full and equal attention to each data item, I worked systematically through the transcripts to further identify salient and meaningful aspects of the data that could form potential patterns.

Phase three involved examining the identified data codes and sorting them in to potential themes. Additionally this phase involved identifying relevant data extracts that would fit under identified themes. A thematic map was constructed to help sort identified codes in to themes (see appendix L). Constructing this visual representation aided my conceptualisation of relationships between codes, between themes and between different levels of themes.

Phase four of the analysis involved reviewing themes. I reviewed extracts I had identified to support the potential themes, in order to decide which were to be removed and/or kept. Preliminary themes that had few supporting extracts were either 
removed (e.g. 'faith') or subsumed in to other themes (for example 'drugs' and 'alcohol' were subsumed in to the theme of 'substance use').

Phase five involved refining identified themes to reflect the overall findings of all hui data, and to ensure they linked back to the original research area of experiences of young Māori mothers.

The sixth, and final stage, of the thematic analysis was the production of a report. I selected extracts that reflected findings within each theme. This led to the formulation of five final themes

\section{The five themes within the young mother's experiences}

The five themes I identified to explain common experiences of the young mothers in hui are outlined in the following sections, along with supporting quotes. These experiential themes are framed as statements to capture the idea that these results represent certainty of the young mother's actual lived experiences: 1) The young mothers faced many challenges both before and after having their child. 2) The young mothers responded to these challenges with a variety of emotions, and originally manifested maladaptive coping mechanisms in relation to their challenges and emotional states. 3) The young mothers have had positive and negative experiences with mental health care professionals. 4) The young mothers then leant on adaptive external and internal supports to get through their challenges. 5) The young mother's exhibited a strong will to help.

\section{Theme 1: The young mothers faced many challenges both before and} after having their child. Challenges faced by the rōpū included being subject to unsafe or unstimulating home environments, partner conflict and in some severe cases a lack of access to basic human necessities including shelter (homelessness) and food. They further identified stigma and judgement as a challenge.

\section{Unsafe home.}

Some members of the rōpū reported feeling unsafe from certain family members in their home.

Rangatahi 1: "I was in a bit of a situation at home where I really didn't want to be there, that was not a safe space for me...After a while I just got kinda sick of the shit going on at home and I couldn't deal with it anymore...I 
took XXX to court and he got jail time [for what was happening at home]." [Extract 3]

\section{Partner conflict.}

Some rangatahi explained that conflict with their partner increased after getting pregnant or having their child.

Rangatahi 3: "Everything was alright but through my pregnancy when I was 6 months he left me for another woman ...cheated on me... and then that left me depressed... "[Extract 4]

Rangatahi 7: “It wasn't always easy, I had to go through court because his father wanted custody because he's fucking stupid so my mum got custody but my son makes me so happy and I may not see him all the time but I love him with my whole heart [Extract 5]

Rangatahi 4: “...it's hard cos you're fighting [ex-partner] for someone you gave birth to and it's like why should I have to fight for you when I just want to make sure he/she is safe". [Extract 6]

\section{Lack of basics.}

Many of the rōpū reported coming from backgrounds where basics such as food and money was scarce. After they became pregnant some of the rangatahi reported losing access to the little basics they had prior.

Rangatahi 1: "I got pregnant and I told my mum and I basically got homeless. I was homeless, had no money ....so I basically starved trying to find food and stuff for the first 14 weeks of my pregnancy...I had a prem baby... They don't know what caused it but I put it down to like stress and not really eating...” [Extract 7]

\section{Judgement.}

The rangatahi reported being subject to judgement once they became pregnant or had their child.

Rangatahi 2: "You know I hate it when people look at us...the views people give us it hurts so bad, it doesn't help at all" [Extract 8]

Rangatahi 4: "Yeah I've come across a few people that think my son is like my brother or something like that and I'm just like caregiving for him but 
I'm like ae just because I'm a teenager doesn't mean I rely on my parents" [Extract 9]

Rangatahi 2: "Yeah cos I don't know about you guys but I got kicked out of my [first] college cos I was pregnant. I wasn't allowed to be" [Extract 10]

Extracts 1 and 5 demonstrate that the rōpū experienced ongoing lack of access to resources that is often taken for granted by the general population. Extracts 2-4 and 6-8 showed that for this rōpū, having their babies brought about extra challenges including greater partner conflict and experience of being and feeling judged.

Theme 2: The young mothers responded to these challenges with varying emotional states and originally manifested maladaptive coping mechanisms in relation to their challenges/emotional states. The mothers explained they felt scared and depressed and reported engaging in suicidal behaviour, self-harm and further substance use.

Rangatahi 2: "Ah and I was depressed, confused ahh I overdosed on two occasions, cut, smoked weed, drunk alcohol...So yeah I overdosed, cut, smoked weed, drank alcohol every chance I got. I was still a good mum though. Went through court, went to jail, still had my son, still had my son, still came to school but yeah I was all of those. Um and so the I felt like I lost hope and everything. [Extract 11]

-Yeah I felt alone, like no one was there but I had all my mates but I still felt alone... ah the whole process of everything was hard and yeah Ifelt lost. [Extract 12]

Rangatahi 4: “Oh yeah it's just because I have tried too [commit suicide], I was so close it wasn't even funny ... you know how they say suicide and stuff is really selfish because of the people you leave behind...yeah but would you rather take your anger out on other people and get charged and go to jail for it or take it out on yourself?" [Extract 13]

Rangatahi 3: ... [partner cheating and leaving] And that left me depressed... when I was depressed I ended up nearly losing [points to friend] cos I always locked her out and she was the one who tried to be there for me 
the most...I locked my whole family out because of it and because of this I felt alone because they all weren't him" [Extract 14]

Rangatahi 8: “...then I started getting in to heaps of shit: stealing from houses, stealing from shops and smoking, smoking drugs, drinking, doing whatever I wasn't allowed...I wouldn't have gotten pregnant if I wasn't getting $n$ to so much trouble growing up and drinking" [Extract 15]

Rangatahi 6: "My life is pretty fucked right now ae...to be honest... and that's all I'm saying. It's gone...nah...Nah I reckon depression gets the best of everyone ae” [Extract 16]

Extract 11, 12 and 16 demonstrate the rōpū reported strong emotional responses to the challenges they faced. Extracts 13,14 and 15 demonstrate that the rōpū did not have the emotional regulation skills or coping repertoire to be able to cope with such challenges and emotions. That being said, in many instances the magnitude of emotional responses and extent of maladaptive coping mechanisms is perhaps unsurprising in light of the severity of challenges faced by the rōpū.

Theme 3: The young mothers have had positive and negative experiences with mental health care professionals. Negative experiences included the limited success mental health services can have in managing real hardships, as well as potential consequences for disclosing these hardships as a young, already stigmatised, mother. Further, being told what to do and not listened to and feeling judged contributed to negative experiences and feeling unworthy. As well as describing less positive experiences, the young mother's explained that being listened to, nice therapists, and kai in sessions contributed to more positive experiences.

\section{What didn't work?}

Rangatahi X: "Some of the one's I've seen didn't listen properly and they just assumed stuff when I tried and talk to them. Especially about alcohol and drugs. Like they always assume the worst. And then they will think oh you're not suitable to look after your kid. You just have to be so careful about what you say cos they could report it to CYFS and stuff and it will look bad on you." [Extract 17] 
(kind of bad advice they have got) "If you didn't get pregnant then you wouldn't be in this situation. Like what's done is done. Don't be so judgy. If we do things backwards it's okay." [Extract 18]

\section{What did work?}

Rangatahi X: "Just for them to listen. Like actually listen. Not just pretend to listen and then give us the feedback they think we want. Like don't give us not proper advice as if you weren't listening properly cos sometimes that's happened to me. Or looking at us differently because we are teen mums." [Extract 19]

Rangatahi 2: "I don't respond well to when people tell me to do things, like don't tell me what to do kinda thing. Um but when people challenge me I'm like yip I'm going to do that-you challenge me and I'm going to do it, but you tell me what to do and I won' 't' [Extract 20]

Rangatahi X: "When they actually listened to me. Oh and when they took out to eat. Eating made me feel more comfortable. It's good if they are easy going and nice but if they shut down and get straight to the point that doesn't work." [Extract 21]

Extract 17 highlights the barriers to access mental health support as a youth mothers, potential disclosures to get help can (or are expected to) result in negative consequences for the rōpū, such as CYFS (now Oranga Tamaraki) involvement and review of their parenting competencies if they admitted finding parenthood difficult. Although the young mothers need help more than adult parents, they also have much more to lose. Further, this extract (along with extract 18) highlight how stigma around young parenthood can be present within interactions with mental health professionals, reinforcing the feeling of being subject to judgement, Extracts 19-21 highlight that there were also approaches that mental health professionals took that did work for the rōpū. This included active listening, challenging rangatahi to change rather than telling them to do so, and taking the effort to make the rangatahi feel comfortable.

Theme 4: The young mothers then leant on adaptive external and internal (factors) to get through their challenges. The mother's reported having their child, going back to school and the support offered by whānau and friends helped them 
through their challenging times. A range of internal factors within the young mothers such as their mind-set and hardworking nature.

\section{External factor 1 - Having a baby.}

The rōpū explained that having their child and becoming a mother was a strong source of support. This appeared to be due to an increase in motivation and access to further support

Rangatahi 8: "The whole concept changed in my head cos yeah I didn't want my son growing up with me like that so I started trying to be a good parent before he was even born and sorted my shit out, I tried to...Yeah my baby changed me for the better. [Extract 22]

Rangatahi 2: "If our babies are happy we are happy... and if they are safe and everything like that and they have a house, we are too" [Extract 23]

Rangatahi 9: "It [having a baby] gives you something to care about, motivation, and responsibilities." [Extract 24]

Rangatahi 6: "No you don't need to have a baby, but you get so much more support if you do" [Extract 25]

Rangatahi 7: "I didn't really care if he was going to be with me or not [partner] because knowing I was going to have her turned my life around pretty much. I came to school every day instead of a truancy officer being on my left side, police officer on my right side and me in the middle...my baby girl changed my life for the better". [Extract 26]

Rangatahi 4: It just feels so good to be independent and I just think that baby changed my life cos now I have a goal and things to look forward to in the future instead of just doing nothing at all.

-but yeah having baby taught me new things like I already knew what I wanted but he made me feel stronger, like a reason to be here. Um yeah I just feel like he saved me [Extract 27]

\section{External factor 2 - Going back to school and school friends:}

Going back to school and meeting friends became a strong source of support for the rōpu. This appeared to be due to the increase in available support and resources as well as peers that can relate to their experiences. 
Rangatahi 1: ... and my life has been sweet since I have been here. I think I've only got you guys to thank for that [friends at school] cos you know, second family. No but honestly I love you all so much. Like I wouldn't be able to do anything without you. Like honestly I have not family. [Extract 28]

Rangatahi 4: I'm really happy to be here and the school can help and stuff. And meeting other mums who are in the same situation, it's pretty cool. [Extract 29]

Rangatahi 6: I reckon being at this school has been a mean experience ae...Nah but honest everyone has their own story, everyone. [Extract 30]

Rangatahi 3: “...yeah like everyone here has their own story, but in a way they all relate. Nah we all put it out there, what would we be doing if we weren't here...like if this school wasn't here" [Extract 31]

Rangatahi 4: I'm happy to be here at this school...It can be intimidating when you first start somewhere and they all know each other...once you get her you realise all the support you have within the school, even though they aren't family. Like you may not have family support but you have everything else you need here like getting picked up in the morning just to get here, getting fed every day at school... [Extract 32]

Rangatahi 2: And everyone can relate to at least something everyone else is going through in each and every one of our lives...like we all had sex, got pregnant...got cheated on or like NCEA L2 is hard...we all have something to relate to... [Extract 33]

\section{External factor 3 - Family:}

Some of the rōpū identified their family as strong sources of support.

Rangatahi 2: My family, they were all used to supporting me, making me happy and encouraging me through everything in my life [Extract 34]

Rangatahi 3: I work, study and be a mum at the same time and I got all the love of my family and friends to help, they have my back. [Extract 35]

\section{Internal Factor 1 - Mind-set:}

Many of the rangatahi explained their own mind-set and thought processes helped them get through challenging times. 
Rangatahi 2: Like people may have helped or contributed [support] but they didn't do it, like without your own mind-set you would have gotten nowhere... Cos we all could have chosen to commit suicide you know but when you're a mum, you're a mum ... [Extract 36]

Rangatahi 6: Nah to negative thinking, think positively. You always need to think positive in times like that. When you think negatively you feel even worse. And also have heaps of support as well. I reckon if I didn't have support, I wouldn't have been able to get through. [Extract 37]

Rangatahi 8: “... and you need to cut off or block out anyone that has a negative opinion of you-Say I don't give a fuck right now can you tell me later?" [Extract 38]

\section{Internal factor 2 - Hardworking nature:}

The hardworking nature of many of the rōpū meant they could achieve their goals.

Rangatahi 4: ... when I was coming here [school] I had to catch 4 buses a day. But that was every day for a year cos I never missed a day last year. It was hard but when you look at the big picture it's good... and yeah because of that it's just being independent, it's the best feeling ever cos you don't have to rely on anyone and it sucks cos you don't have anyone to fall back on but you gotta think about butting yourself in the situation that you don't need to. It's like I need help with this, but I do it myself. [Extract 39]

I don't have family and did it all myself, I have my own house, my own car it's like real hard to get there but when you do it's just like aww it's a big weight off your shoulders because you can' ever have anyone saying like I did this for you, I did that because no you didn't, I did... [Extract 40]

Extracts 22-27 highlight that, in opposition to societal beliefs, having a child could be a positive- and life changing experience for the rōpū. This enabled them to obtain meaning and motivation to achieve goals, as well as enabling access to support they did not have prior to having their child. Extracts 28-33 show the positive benefits of going back to school for the rōpū. It enabled access to educational, goal directed, practical and emotional support and the opportunity to be around and befriend others 
who can relate and understand their situations, increasing available support. Extracts 34 and 35 highlight that some of the rōpū also had another layer of family support on top of newfound support through the school. Extracts 36-40 demonstrate that it wasn't just support around the rōpu that helped them get through, but also factors within themselves (such as their mind-set and hard work) they were able to apply in challenging situations. While the rōpu rarely articulated the extent of their ability and commitment to working hard, it was overwhelmingly apparent from the transcripts in relation to the sheer amount of effort, tasks, and day-to-day challenges the young women described. While they didn't see these tasks as adding up to evidence of hard work, but just what needed to be done.

Theme 5: The young mother's exhibited a strong will to help others. This strong will to help others was the main reason they chose to be involved in the project:

Rangatahi 2: it's about keeping our young mums safe

-Yeah hard I want to change people's lives...my sister and cousin are pregnant and I don't want them to go through what I went through...

[Extract 41]

Rangatahi 7: It will be hope for them [Extract 42]

Rangatahi 6: It's about whether or not you know about available supports to young mums. That's why we want to make the film ... to inform them there are supports and options...Like there are young mums everywhere in the world but to then it feels like they are the only ones out there... [Extract 43]

Rangatahi 2: When you grow up on the struggle, on the benefit with no food in the cupboards, hukery as ka, walking to school and stuff like that, you know when you go through stuff like that you like automatically change your mind-set to not have your kid, or anyone else you know go through that. [Extract 44]

Extracts 41 and 44 demonstrate that the rōpū used adversity they had experienced as motivation to help and empower others to not have to go through the same hardships they did. Rather than being understandably resentful in light of their 
negative experiences, the rōpū see past their own situation to a bigger picture in which they can play a part in better futures, not only for themselves and their babies, but also other young mothers. Extracts 42 and 43 explain how their participation in this mahi serves to fulfil their desire to help others, and their intentions for this resource.

\section{Summary of overall themes}

These themes paint a redemption story, a life story common across many of the rangatahi in the rōpū. The rōpū all initially faced challenges including but not limited to becoming a mother, and had difficulty coping with these challenges. Many of the rōpū went on to access mental health services and had varying positive and negative experiences within such services. The rōpū all began to work through their challenges adaptively by leaning on external supports and internal supports. The rōpū are all now at the stage that they want to give back to others to ensure they do not go through challenges as they did. Working to complete the short film Tūmanako is an example of their aspirations to give back.

It is important to note there is a bigger picture that underlies these themes. The first of which appears that pre-baby life for many of the rōpū was already difficult, and perceived as lacking meaning and access to basic support; often taken for granted among the general population. The rangatahi described their difficulties, and ways they tried to cope, with these challenges. Having their children and other 'saving factors', such as going back to school, provided meaning in their lives, motivation to achieve goals and access to support they had not previously had. Support included access to truly basic needs such as food, financial assistance, educational and career assistance and emotional support. Although having baby opened doors to more support, at the same time it also meant at times the rōpū could were paradoxically less likely to access it as accessing that support and disclosing information could have serious consequences. As children themselves, desperate to do their best for their own children, they are in a vulnerable position and have more to lose.

The second take-home message regards societal and systemic factors that underlie the experience of the rōpū. Not having yet learnt adaptive emotional regulation (see Koole, 2009) or coping skills to deal with challenges and the associated benefits, they tried to cope in other, less beneficial, ways that are perhaps 
understandable. This reflects the extreme nature of challenges faced by the rōpū including homelessness, poverty and abuse. Such challenges need to be addressed at a deeper level, and socio-economic pressures alleviated, before we make judgement calls on how maladaptive the rōpū strategies to deal with these experiences were. In light of the adversities they had faced, the rōpū want to help to ensure their children, and other young mother, don't go through the challenges they did.

The third overall theme related to resilience. The resilient traits of the rōpu were not explicitly mentioned or even recognised by the rōpū but rather evident in the thematic analysis, in light of hearing about their reactions to adversity and the desire to keep progressing towards positive futures, rather than being resentful or giving up. It could be hypothesised that this was not recognised by the rōpū, due to overwhelmingly negative stereotype that by becoming pregnant as a teenager, you are a failure. The transcripts made it apparent that the rangatahi had internalised this stereotype even while trying to resist against it. Further, due to the nature of the histories of the rōpū, it could be hypothesised that they may not have had successes recognised or celebrated in the past, even prior to becoming parents.

An important theme reflects the nature of experience with the mental health system. The fact that those that need mental health assistance the most feel deterred by sheer fear of potential consequences from describing their struggles, suggests that the system needs reworking. It is our job to work in a way that gets the best outcomes from our rangatahi. As this rōpū explained, this means listening and reserving judgement, and working to make them feel comfortable. Knowing what works stems from listening to rangatahi and their suggestions, the intention if this research project. 


\section{Chapter 4}

\section{General Discussion}

Whäia te iti kahurangi, ki te tuohu koe me maunga teitei

Pursue that which is precious, and do not be deterred by anything less than a lofty mountain

\section{Introduction}

This research was kaupapa Māori-informed action research intended to lead to the development of a mental health-related resource. As this project advanced through iterations the nature of the project became clearer. I collaborated on this project with a rōpū of young Māori mothers. Currently, the rate of teenage pregnancy in New Zealand is around 16 births per 1000 woman. New Zealand reflects the global trend of declining rates of teenage pregnancies, currently sitting at half of the rate in 2008 (33 births per 1000 woman: Statistics New Zealand, 2017). As the project progressed, they reflected on the nature of their challenges and supports and they themselves suggested we should create a short film as a mental health resource for other young mothers and people who support them. The rest of the project was spent developing this idea, and later producing this resource which was based on the experiences of the rōpū, how they got through hardships (both adaptively and maladaptively), and my psychoeducation relating to relevant psychological concepts. The rōpū wrote the film script, determined all artistic considerations, sung and acted in their film.

This general discussion will begin by reflecting on the themes that came out of the experiences of the rōpu, and how these align with previous literature. It is acknowledged that in a conventional thesis the literature review typically resides in the introductory chapters. However, due to the iterative nature of this process, the themes and ideas explored in relation to literature did not become apparent until the mid-point of the project. As such, additional links to relevant literature will take place in this section. The underlying ideas to be covered relate to challenges faced by the rōpū, the positive experience of having a child, the importance of returning to school, resilience and the state of our mental health system in New Zealand. The second part of this general discussion will explicate the process of developing a mental health resource within a kaupapa Māori framework. It will speak to the decision to make a 
short film, the benefits (and challenges) of working within this methodology and kaupapa, and personal reactions towards working collaboratively with the community and the young mothers in this project. This section will conclude with recommendations for future directions and overall conclusions.

\section{Themes and conclusions}

\section{Underlying message 1- Challenges faced by rōpū}

The themes identified using thematic analysis highlight that the rōpu faced significant challenges both before, and after, having their child. This typically included experiencing an unsafe home life, and a lack of access to basic necessities such as food and safe shelter. This is consistent with previous literature - that Māori children are more likely to be assessed as abused or neglected, experience poorer living standards and greater material hardship than European children and families. Further, young Māori have been shown to be more likely to live in poor households, households of which are less likely to report that they can always afford to eat, in comparison to European households (Te Manatū Whakahiato Ora, 2004). Challenges

of this nature have been echoed within research on young mothers; young mothers are more likely to experience disadvantage in relation to wellbeing and economic circumstances (Keys, 2007). Analyses also highlighted that the rōpū struggled with mental health. This aligns with research indicating that young mothers experience high rates of anxiety and depression symptomatology (Kendall \& Peterson, 1996; Quinlivan et al., 1999), and poorer levels of mental health compared to older mothers and teenagers who are not mothers (Liao, 2003). Research has found that diagnoses, such as depression, among young mothers are strongly associated with life circumstances and a lack of partner support (Keys, 2007).

In spite of the obvious focus on the challenges of motherhood for these young Māori women, analysis also identified themes encapsulating positive messages. Indeed, this project was intended to be strengths-based, rather than focusing again on what's wrong with Māori and specifically young mothers.

\section{Underlying message 2 - Having baby was a positive experience}

Analysis indicated that, in opposition to common societal belief, having a child at a young age was a positive experience for the rōpū. Popular press, fiction, and 
literature often explain teenage pregnancy as a tipping point of a downward spiral of negative consequences including a life of poverty dependant on benefits, dropping out of school, remaining single (SmithBattle, 2007) and negligent or incompetent parenting that continues the cycle with their children (SmithBattle, 2003). This public scorn for teen mothers persists in spite of growing evidence that negative outcomes have been exaggerated, that negative outcomes reflect a legacy of childhood disadvantage (SmithBattle, 2007) and that, in some cases, teens would not have fared any better had they waited for children.

Specifically, contrary to popular beliefs but consistent with recent literature, becoming a mother had a positive effect and drove positive changes in the lives of the rōpū. Consistent with current research it promoted positive behavioural change; providing incentives to reduce their substance use and risky behaviour (Bessant 2004; Hope, Wilder, \& Watt, 2003; Shanok \& Miller, 2005; Quinlivan and Evans 2002), and providing meaning in their lives which they identified prevented their own suicide, incarceration and continuation of chaos in their lives (Key, 2007).

It is important to reflect on what came with having a baby for the rōpu that helped drive such positive change in their lives, as a rangatahi should not have to have a child to attain opportunity for wellness. As introduced in the summary of themes section (pp 54-56), it appears by having their children the rōpū were provided meaning in their lives, motivation to achieve goals and access to support they had not previously had.

Meaning and motivation provided by having a child. The notion that motherhood can provide meaning and motivation has been supported in previous research. Key's (2007; see also Salusky, 2013) work found motherhood led to the development of a new purpose, where having a child provided a reason to keep on living and ameliorated suicidal thoughts. Mothers commented they found meaning through increasing responsibilities arising from the birth of their child. Although often viewed as a 'burden' and as a loss of freedom by society, mothers credited increased responsibility with maturity and active changes in their behaviour and priorities. This helped them move from a chaotic to a more stable lifestyle. Also, as identified in the current rōpū, Key (2007) found becoming a mother increased their emphasis on future orientation and planning and motivation. The mothers reported having a child meant they were more focussed and goal driven around what they wanted out of life. 
Thus, taken together, contemporary research reflects themes also identified in the current project; having a child provided meaning to lives, motivation and access to support. As observed in this rōpū, this led to self-reported improvement in well-being and prevention or avoidance of serious adverse consequences for the rangatahi.

Support obtained from having a child. As well as subjective psychological and motivational benefits, in the experience of the rōpu, having a baby increased the amount of support available to them as young mothers (Key, 2007); Rangatahi 3: “No...You don't have to have a baby, but you get so much more support!" Negative outcomes associated with young motherhood are generally reflective of childhood disadvantage rather than becoming a mother (SmithBattle, 2007), and it appears having a child can provide a gateway to support that was always needed to address some of the disadvantage faced by rōpu before having their child. This includes financial and housing support, provision of basic needs such as food, as well as support around emotional and personal development. For example, a single young parent (aged between 16 and 20 years) is entitled to a gross payment of $\$ 329.57$ per week (WINZ, 2017a), a significant financial support not available to other young people that may be struggling without a child. Further, under this young parent payment plan, a youth service provider is sourced to help the young person manage money and they are provided with courses such as budgeting and parent training to develop skills. The youth service provider will also ensure the young person's training or educational needs are being met (WINZ, 2017b). This intensive support over many domains may not be as accessible to other young people who are not mothers. As will be explained in the subsequent section, returning to the second chance teen parenting school was presented at the main mechanism for opening the gate to support for the rōpū.

Future research. An important future direction for researchers and clinicians is to devise a way to identify at-risk rangatahi and help them discover meaning and motivation in their lives, and ensure they have adequate supports. Clearly, rangatahi should not have to have a child to be afforded equal chances at wellness. This is no easy feat due to socio-economic disadvantage felt so strongly by many Māori in New Zealand. This is particularly difficult in the health sector as Māori experience systematic disparities in health; disparities in health outcomes, health system responsiveness, representation in the health sector workforce and health outcomes in 
general (Pōmare et al., 1995, Ministry of Health 2004; 2006b; Ministry of Health \& University of Otago, 2006). However, a step towards this end goal is required.

Strengths-based collaborative community approaches to research and clinical practice are one way to get meaningful information on specific needs, and what we need to work towards (see Gibson \& Kindon, 2013; Collie, Liu \& Kindon, 2010). The advantages of such an approach will be explained in the subsequent section.

\section{Underlying message 3 - The importance of returning to School}

Another important message that arose from the analytic themes is the positive benefits of returning to school for the rōpū. Returning to school in general negates the negative 'conventional wisdom' alluded to previously, that pregnancy derails girl's education. Inconsistent with previous literature, many of the rōpū dropped out of school before they became pregnant and cited becoming a mother as the reason they re-enrolled (see Pillow, 2004). Motherhood appeared to be a highly isolating experience for the rōpū, a characteristic echoed in previous research (Barclay, Everitt, Rogan, Schmied \& Wyllie, 1997; Marks \& Houston, 2002). It seemed the school provided the rōpū access to a community of others with whom they could relate, having all experienced similar challenges, and sharing their status as young mothers. The school this rōpū returned to is unique as a second-chance learning school for young parents, providing the kind of additional support specific to the needs of young parents. They focus on holistic development and provide additional support in addition to education, such as in-house medical consultations, and workshops on a vast amount of topics such as emotional regulation, legal rights and career progression. These opportunities, in addition to the emotional support and belief provided by the staff, is what the rōpū explain helped them to 'turn their lives around' and thrive the most. This again emphasises the point made earlier concerning how, as researchers and clinicians, can we ensure these resources and supports are available to all at-risk teenagers, and not just teen parents.

\section{Underlying message 4 - Resilience}

The third overall theme that came through from the analysis of conversations with the rōpū concerned resilience. Resilience has been conceptualised as an adaptive capacity or ability that can protect an individual from negative effects of adversity and risk (Everall, Altrows \& Paulson, 2006). The rōpū have experienced abuse, isolation, 
poverty and a lack of access to basic needs such as food, shelter or emotional support. Many have experienced partner conflict, and some have been through court and even been incarcerated. Further, many of these rangatahi have had a childhood characterised by moving from Oranga Tamariki placement to Oranga Tamariki placement. The majority of the rōpu have also struggled with suicidal thoughts, have attempted suicide in their pasts, struggled with substances including alcohol and drugs and have engaged in self-harm to help regulate their emotions. Despite experiencing ongoing adversities throughout their lives the rōpū have survived and have overcome these challenges. They are grateful for what they have and are determined to better their lives and support a positive life for their children.

It is important to note that resilience of the rōpū was not explicitly articulated or even recognised by the rōpū. Instead, the resilience of this rōpū was obvious to me in light of hearing about their reactions to adversity; their desire to keep progressing towards positive futures, rather than being resentful about past experiences or giving up. It could be hypothesised that any success from overcoming adversity was not recognised by the rōpū because of the dominant societal message that, by becoming pregnant as a teenager, you are a failure. They constantly perceive the message that teen pregnancy is a poor life choice that reduces your potential to thrive (Holgate, Evans, Yuen, 2006). Further, due to the nature of the histories of the rōpū including unstable home lives or placements, it could be hypothesised that they may not have had successes recognised or celebrated in the past. It could also be hypothesised that resilience may only be a concept an individual can reflect on should they have the luxury to do so. The focus of the rōpū as young parents appeared to be on the here and now and their energy was devoted to looking at how to fulfil their present and immediate needs. Perhaps they have never had time to reflect and process their strengths, as people living under imminent threat of death by war may not have time to stop and consider their strengths in relation to how they are making it through.

\section{Underlying message 5 - Mental health systems}

The last important point arising from the thematic analysis concerns the nature of the New Zealand mental health system, from the positions of these young mothers. The rōpū explained that they might be paradoxically less likely to access mental health services as a mother, out of concern about potentially losing their child. They 
expressed concern that seeking help for problems such as suicidal ideation or substance use may bring their capability to parent in to question by mental health services. There are several issues with this system and associated beliefs. The first of which is the objective risk of losing their babies; the problems that may bring a young mother to see a health professional can lead to the very real consequence of having their child taken from them. The second of which is the subjective fear that young woman may lose their babies; those that need mental health assistance the most might be deterred out of sheer fear of potential consequences from describing and seeking help for their struggles. The fact that a young mother can be punished for seeking mental health support and the fact that they can be deterred from even making contact with a mental health professional for the sheer fear of this consequence, means the system needs reworking.

This research also highlighted the need for more of an emphasis on primary health care within the mental health sector, rather than an ambulance at the bottom of the cliff approach. The need for an emphasis change is highlighted by the fact that negative consequences generally associated with teen pregnancy, have been found to rather be explained by childhood adversity (SmithBattle, 2017). The rōpū explained that becoming a mother opened up the gates to supports, support they actually desperately needed to help with challenges prior to having their children. The mental health system needs to move to identifying at-risk young people and ensure they have access to practical and emotional support, to stop negative developmental cascades (Moffitt et al., 2011) before they develop momentum, As well as structural changes, we also need to address how the mental health system is perceived, so as to encourage young people to seek help without fear of putting themselves in a weaker position. As well as a refocus of the mental health system, the rōpu explained that on the individual level, a health professional that listened, reserved judgement and one that worked to make them feel comfortable was very helpful. It is our job to work in a way that achieve the best outcomes for our rangatahi and we need to incorporate these helping aspects into our own practice. This research project was founded on the notion of identifying the needs of, and what works for, rangatahi, by listening to them. 


\section{The process of making the mental health resource}

\section{Why the rōpū chose a film}

This thesis was originally expected to be a more traditional account of the themes arising from analysis of discourse occurring during development of a mental health resource. Ultimately, this research has become more than 'just' a thematic analysis, but more about the process of creating a mental health resource within a kaupapa Māori framework. It's significant to focus on why the research ended up how it did. The rōpū requested we created a short film, because of the greater reach the rangatahi believed a short film could achieve, embracing the technological age these rangatahi grew up in. They stated it would be much more accessible to other young mothers if it was able to be uploaded to on to internet platforms including social media sites and video-platforms. They believed this reach would not be attainable by traditional mental health resource formats (such as leaflets) as not every young person would go to a health agency to get a leaflet, and their experience that leaflets delivered to mail boxes are often discarded by young people. They also believed a short film would be easier to access in comparison to other interactive formats, such as a mobile app, which would require searching specifically for the app and downloading it to a smart device: "You know we could all write a status on Facebook but we reckon a film will get across more. And yeah because everyone uses social media these days... you know once it's on Facebook, it's on Facebook. So it would get across to a lot of parents" (Rangatahi 3).

\section{The benefits of listening to participants}

Because of my commitment to the principles of kaupapa Māori research (Smith, 1997), I placed a great deal of emphasis on the importance of Tino Rangatiratanga. This inevitably required me to listen to, and collaborate with, my 'participants' in a way that is more typical of action research than other traditional approaches to research on, rather than with, participants. I reflect below on the benefits of this approach.

Benefit 1 - The research is meaningful. It is also appropriate to focus on the benefits that listening to participants in research, evidenced in this kaupapa Māori approach embracing Tino Rangatiratanga, enables. A primary benefit is that the research is more meaningful. Listening to the rōpu in this research meant the research 
was more meaningful to the rangatahi due to its focus on a topic they thought was important. The rōpū felt empowered by creating a resource for other young mothers and can be proud of their meaningful work as they see the 'view count tick over' on their short film, knowing they are helping and making a difference in others' lives, or raising awareness. One rangatahi commented, "Far I'm just so stoked we are helping our young mums eh...would have been so good when I was going through the struggles ae". Irrespective of whether the results of the study or the mental health resource is widely disseminated however, participating in this research alone appeared to be a meaningful experience for the rangatahi. For example, on top of helping others, this research also allowed the rōpū a context to discover and develop aspects of themselves. One rangatahi commented "I never step out of the box and this is so far out of the box for me like I don't even really talk in front of groups... This is like the proudest I've ever been of myself..." [In response to challenging herself to act]. When asked whether this would mean she would be more willing to try other new things, she said yes. The fact that that this research can empower 'participants', create opportunities for them to be proud of their achievements and enable them to discover and develop aspects of themselves, speaks to the research being more meaningful, and resulted from listening to the participants in the first place.

Benefit 2 - Engagement of the participants. The fact that the research was more meaningful to the rōpū meant it was intrinsically more motivating for them to participate in this project than it might otherwise have been in a more traditional study. This led to greater engagement in the project from the rōpū. This is beneficial as the rangatahi were more likely to think harder about their experiences to give back to the research and give greater effort to the construction of the mental health resource. This could be hypothesised to have led to more authentic responses from the rōpū and, therefore, more meaningful 'results'. This could differ from traditional approaches such as a potentially lengthy one-off survey on experiences of being a young Māori mother. An unmotivated, or extrinsically motivated, participant may give less thought to answers. In spite of the considerable demands this project placed on me, others involved in the production, and most importantly the rōpū, it is notable that there was no 'participant' attrition during the process. It seems reasonable to conclude that this is a product of the process adopted, and the resulting investment by 
already busy young people. This highlights a further benefit of listening to 'participants' in a kaupapa Māori framework.

Benefit 3 - Expanded Possibilities. A further benefit of listening to participants is that the scope and perspective of the research is widened, as are the nature and possibilities for success. As a sole researcher devising a research topic you may be limited by your own experiences and knowledge. Working and listening to diverse participants provides perspective to research ideas and directions that might not otherwise have crossed your mind. As a young female (albeit one older than my 'participant' group) who is not a mother, I would not have self-generated the same idea to create a mental health resource targeted at young mothers. Further, as a Psychology student, I am familiar with particular research processes and 'results', and would not have self-generated the idea to create a film. This led to an opportunity for me to learn, and the prospect of the research to grow and develop in a meaningful way that serves the needs of community as they themselves see them.

Benefit 4 - Rapport/Relationship with participants. Listening to participants in research also lead to greater rapport with the rōpū. This lead to an increase in trust which meant they shared aspects of their lives, providing insights that may not have otherwise occurred without being made to feel valued and heard. However, working within this framework and developing close knit relationships did not proceed in the absence of challenges. As time went by my relationship with the rōpū strengthened, especially with my adherence to kanohi kitea (being present at every phase of research). Although helping with rapport it did bring the nature of the relationships in to relief in a way that is unusual in traditional research. At times, I questioned my role within the rōpū, as the boundaries between being a researcher, a friend or a support person became blurry. This became especially apparent as the rōpū said they came to see me more as a positive role model, and would ask for personal support from me. There were also many 'car conversations' where the girls would disclose further information around their experiences, challenges and motivations as their trust in me grew, ideas that would have aligned with my research aims. I spent much time deliberating my role with the rōpū, deciding that I must wear many 'hats'(roles); there were times where I would need to fulfil many different roles with the rangatahi, but also times where a particular 'hat' would not be appropriate. When the rōpū asked for personal support or shared experiences about their lives outside the 
initial hui dedicated to gathering information on their experiences, I removed my researcher 'hat' and wore more of a support role 'hat'. I treated these as privileged communications - choosing not to use this information towards research findings as research was not their intended purpose for telling me.

At all times I adhered to manaaki ki te tangata and aroha ki te tangata, trying to respect the needs and wants of the rangatahi, and respond in a way that was kind. Although at times I removed the researcher hat, I always considered ethical practice and what this looked like in the forefront of my mind. As a clinical psychologist-intraining, I ensured my work always aligned with ethical principles (New Zealand Psychologists Board, 2002). As well as demonstrating manaaki and aroha and thus demonstrating cultural sensitivity (Ethical principle 1.4.1) in these situations, working in this way also ensured I "took all steps to protect research participants from physical and mental discomfort or danger" (Ethics principal 2.6.4). I recognised the vulnerability of these young people (Ethics principal 2.4.1.) and maintained appropriate boundaries (Ethics principal 3.3.2.) (New Zealand Psychologists Board, 2002). As such, there were times where I did not respond or act, such as when the film crew would push me to text or call the girls at midnight to organise a shoot for the morning. I did not do so.

Benefit 5 - Immersion in to the community. Lastly, engaging with participants under a kaupapa Māori framework necessitates immersion in to the community - participatory action research. Not only does this result in a collaboration with the community to create the project but has also had the consequence of access to community physical and social resources to help achieve our kaupapa, as the research is meaningful to the community too. The whakatauki "Naku te rourou nau te rourou ka ora ai te iwi (With your basket and my basket the people will live") (Woodward Ltd, 2017) encapsulates the benefits of community immersion. The cooperation and combination of resources and expertise of the rōpū, university, school, and broader community resources including the film team and wider support not only made the project possible but also significantly increased the scope and success of this project. This was one of the most eye-opening experiences of completing this research. Different disciplines and people with a range of different skills contributed in meaningful ways to help for the kaupapa of this project, in ways I would never had thought of. This ranged from film professionals giving their time to 
produce a film, to arts specialists creating resources, to academics at university giving their time to help me upskill to attain this project. This opened my eyes to the giving nature of people within the community and the sheer magnitude of success that can be achieved when we work together.

Further benefits of a Kaupapa Māori framework. Beyond the benefits accruing from enacting Tino Rangatiratanga, the use of a kaupapa Māori framework also derived further benefits, instilling a culture within the project that is difficult to describe. Relationships were strengthened between all parties involved with continual whānaungatanga in this research. We emphasised the idea that everyone was valued in the process and we would all take time out to greet and establish connections with anyone who came in to the project, no matter how short their time was. Kaupapa Māori also enabled the wellbeing and intentions of the rōpū to be at the forefront of every research step. The framework provided safety for making decisions that may not have suited other external parties in the research. For example, if the film crew were expecting too much of the rangatahi at different stages or trying to change their ideas, they needed only reminding of the kaupapa Māori framework underlying the project and they would change the ways they would proceed. The protective nature and final say gifted with the use of a kaupapa Māori framework may not be as strong in other research methodologies.

Working with many different disciplines (e.g., psychology, film production, acting, and music) under this framework also provided a learning opportunity for everyone to understand kaupapa Māori and its benefits, as they lived the experience. I found that living this learning opportunity differs strongly from reading principles listed in a text book, and had fruitful consequences. For example, agencies that heard of this research requested follow-up teaching in this area. Following a presentation of this approach at a guidance counsellor workshop - an agency approached the researcher and expressed their openness to learning and implementing kaupapa Māori within their workplace. I subsequently presented at their workplace annual general meeting. The dissemination of this approach is a great step forward for tikanga within research and workplaces and embodied the nature of kaupapa Māori, collaboration allowing a lived experiences of the principles. 


\section{Challenges of this research}

Working under different approaches and agencies presented challenges in regards to clashing of methodologies, processes and agendas. The first of which was the tension between working under a kaupapa Māori framework and trying to fulfil expectations arising from Western research paradigms dominant in a University. For example, the ethics board generally requires explicit detail of the research project including the resulting outputs, explication of exact steps that are to be taken, and risks to be aware of, prior to commencing research. This level of detail is not able to be provided at the outset of a kaupapa Māori research project, as intentions and steps of the project evolve from ongoing conversations with the community of which you are working with.

The second challenge was the competing agendas of kaupapa Māori framework and agendas of an established and experienced film crew. The commitment to kaupapa Māori principles upon which my research was founded did create some areas of difficulty. At times the film crew attempted to dictate the process to be taken consistent with their experience and expertise, making decisions on what would be best that might require and expect too much, often placing pressure on the rōpū under time constraints. At this point, a kaupapa Māori approach dictates that the rōpū should have final say and should be treated with manaakitanga and aroha ki te tangata, which runs counter to such pressures. There were ongoing considerations, conversations and decisions that needed to be navigated in regards to clashing methodologies and agencies, and this was particularly challenging as I was extremely grateful for all parties engagements. It became apparent there were many grey areas around how much autonomy I should grant to the rangatahi especially in decisions relating to film over those that are expert in the field. Throughout this research I had to give serious consideration to how I could achieve a balance between my needs as a researcher, the wider involved teams and the autonomy of the community, without privileging one over the other. I addressed this by being very open about the clashing of agendas when they came up with both the rangatahi, the film crew and my supervisors. From this point we would all collectively problem solve appropriate ways forwards, what could be sacrificed and what could not be negotiated for each group and come to common ground. 
A further challenge engaging in this project with the rōpū was managing my own emotions. Although I was aware of challenges faced by some rangatahi in our society, this was the first time I had heard first-hand a group of rangatahi talking and reacting to injustices and challenges they had faced. I often found myself saddened and frustrated by the privilege bestowed upon me and how unequal society is. The rangatahi in the rōpu faced many unfair challenges that $\mathrm{I}$, as a middle class individual of privilege, had never had to be concerned about. This included privileges often taken for granted - access to safe shelter, food, having a bed at night and being able to afford necessities such as sanitary items. Being immersed in to a rōpu that did not have access to all I had through no fault of their own and no link to how hard they worked, was a big challenge for me. I often felt frustrated for them and wanted to do more to be able to help. I was able to manage my experience by adhering to the kaupapa Māori framework, I reflected on the fact that this project empowered the rōpu, gave them a voice and did not speak for them. Further, having open conversations with the rōpū about this helped. One rangatahi explained, “We don't want a hand up ae like a lotta CYFS [now Oranga Tamariki] think. We wanna make our own way there and work hard to get our goals. Yeah it might be harder but it's worth it to get it all and see our baby happy".

\section{Overall future directions}

There are many future directions from this research across academic, community and governmental levels. The first of which is to follow up with the roppu what it meant to be involved in kaupapa Māori action research specifically. Was this an empowering process for them, would they change any part of the process? This is important to look in to, to ensure the success of future community based research. Future research could also look in to the effectiveness of the film as a mental health resource. For example how many views the film received and the geographical reach of the film. This research could also invite rangatahi/health professionals/parents who have watched this film to offer their thoughts to determine how it may have helped, and if there was any gaps of required knowledge in the resource. This could lead to a sequel with more information or the creation of other mental health resources.

Future research could also follow up with the rōpū or other young mothers and focus on what supports were needed for the rangatahi before they became pregnant 
and what could have helped. This knowledge gathering could facilitate a primary health intervention providing specific support to the rangatahi so rangatahi do not need to become pregnant for required supports to open up. This could serve as a starting point from a research and academic perspective to support the shift in emphasis of the mental health system away from an 'ambulance at the bottom of the cliff' approach.

A future community direction is the possibility of taking the film around schools or hospitals to spark conversations around support that is available to young people and young mothers. This direction was put forward by the rōpū from this project, the explained that they would have been more receptive to information coming from young relatable people in the same situation rather than social workers, teachers or health professions. This could be a new avenue to continue this project.

\section{Overall Conclusions}

This research was kaupapa Māori-informed (Smith, 1997) action research aimed at developing a mental health resource by rangatahi for rangatahi, and intended to help hauora. Guided by kaupapa Māori principles and guidelines, this project advanced through many iterations and resulted in the creation of a short film by a rōpū of young mothers at Wellington based Teen Parent Unit in collaboration with a local Wellington Film Company. This film covers just some of the challenges that were faced by the rōpū, and how they coped with these challenges both maladaptively and adaptively. Challenges included becoming a mother at a young age, being subjected to judgement, as well as withdrawing from peers and feeling isolated. The nature of challenges also included how the rōpū attempted to cope including the use of substances and self -harm. This film is intended to send the message of Tūmanako to others that are in similar situations, that life can be better, and that they are not alone in experiencing such challenges. This film also covers how the rōpū adaptively coped with their experience, the supports they leant on, and the supports are available to other mothers. These included positive thinking style and goal- and future-oriented thinking, realising that not everyone is judging you and to ignore anyone who may be doing so, going back to school (and the particular benefits of a teen parent unit and what extra supports come with such a school) and reaching out to friend and family support. 
The specific nature of the experiences, supports, and challenges of the rōpū became evident at each step along the way of the process to create the short film. This was an important side step as the themes identified revealed important messages for other young mothers, health care professionals, society and the government.

The first message was that pre-baby life for many of the rōpū reflected preexisting difficulty, a lack of meaning, and lack of access to basic support. We need to work towards all rangatahi having the opportunity to find meaning and motivation for their lives and ensure they have access to support, including access to basic needs such as food, financial assistance, educational and career assistance and emotional support. The second message was that societal and systemic factors underlay many of the challenges of the rōpu - their experience of homelessness, poverty and abuse. This needs to be addressed at a deeper level, and socio-economic pressures alleviated before judgement calls can be made on 'maladaptive coping responses' of the rōpū to such adverse events. Despite adversities the rōpū had experienced, they wanted to help others, to ensure that their children and other young mothers do not experience the challenges they did. The third message was that the rōpū were incredibly resilient, taking extreme adversity in stride and wanting to better their own futures and those of their children. Finally, the last message that arose from the experience of the rōpū was that the mental health system needs to change from an ambulance at the bottom of the cliff approach, to more of a primary health approach. It should go without needing to be said that rangatahi should not have to have a child to be eligible for support, and the mental health system should not be set up in such a way that a young mother would be deterred from accessing the support they need for fear that their child will be taken.

Although this research presented challenges, such as navigating different and sometimes opposing approaches, methodologies and agendas, this was outweighed by the benefits of this project being kaupapa Māori-informed action research. These include that this research was much more meaningful to the rōpū and, thus, they were more motivated and engaged in comparison to a traditional research approach. Approaching research in this way led to greater rapport and relationships with 'participants' through immersion in to the community that, together, led to the achievement of much greater feats than if the research had been crafted in isolation. I hope that this signals to future researchers, even if research isn't conducted under a 
kaupapa Māori framework, the benefits of listening to and involving the community in the research.

In conclusion, this research project was an incredibly humbling and inspiring experience. I learnt so much from working alongside the rōpū including appreciating my privilege and using it for good, just how far one's mind-set can take you, and was able to witness and hear of such incredible strength from the rōpū. I feel very honoured that the rōpu trusted me and opened up their lives and experiences to me in order to go on to help other young mothers. I enjoyed working hard alongside the rōpū and community, watching some rangatahi grow and challenge themselves in this process. I will not forget the many laughs and the 'real' and emotional moments. These young woman have the absolute world at their feet and I was, and am, honoured to walk alongside these rangatahi, the film crew, and community on the journey towards our kaupapa, tūmanako. Ehara taku toa, he takitahi, he toa takitini. My success should not be bestowed onto me alone, as it was not individual success but success of a collective. 


\section{References}

Abel, S., Marshall, B., Riki, D., \& Luscombe, T. (2012). Evaluation of Tu Meke PHO's Wairua Tangata Programme: A primary mental health initiative for underserved communities. Journal of Primary Health Care, 4(3), 242-248. doi: 10.1071/HC12242

Adler, R. (2009). The landscape of texting 4 health. In B. J. Fogg \& R. Adler (Eds.), Texting 4 health: A simple, powerful way to improve lives (pp. 9 19 ). Stanford, CA: Stanford University

Aked, J., Marks, N., Cordon, C., \& Thompson, S. (2008). Five ways to well-being: The evidence. London: New Economics Foundation.

Alpha Rev. (2012). You Belong: Music Video from Mental Health America of Texas. Retrieved from https://www.youtube.com/watch?v=UeJL9F-4rNA

Māuri Ora Associates. (2006). Best health outcomes for Māori: Practice implications. Wellington, New Zealand: Medical Council of New Zealand.

Baileyand, B., \& Davidson, J. (2002). Adaptive characteristics of group singing: perceptions from members of a choir for homeless men. The Journal of the European Society for the Cognitive Sciences of Music, 6(2), 221-256. doi: $10.1177 / 102986490200600206$

Baker, M., Pipi, K., Cassidy, T., \& Hau Āwhiowhio ō Otangarei Whānau Ora Collective, T. (2015). Kaupapa Māori action research in a Whānau Ora collective: An exemplar of Māori evaluative practice and the findings. Evaluation Matters-He Take Tō te Aromatawai, 1, 113-136. doi: 10.18296/em.0006

Ball, J. (2010). Review of evidence about the effectiveness of mental health promotion programmes targeting youth/rangatahi. Auckland: Mental Health Foundation of New Zealand. Retrieved from www.mentalhealth.org.nz/assets/ResourceFinder/Review-ofevidence-abouteffectiveness-ofmental-health-promotion-programmes-targetingyouth.pdf 
Bandura, A. (1986). The explanatory and predictive scope of self-efficacy theory. Journal of social and clinical psychology, 4(3), 359-373. doi: 10.1521/jscp.1986.4.3.359

Barclay, L., Everitt, L., Rogan, F., Schmied, V., \& Wyllie, A. (1997). Becoming a mother - an analysis of women's experience of early motherhood. Journal of advanced nursing, 25(4), 719-728. doi: 10.1046/j.1365-2648.1997.t01-11997025719.x

Baxter, J., Kingi, T., Tapsell, R., Durie, M., \& McGee, M. (2006). Prevalence of mental disorders among Māori in Te Rau Hinengaro: The New Zealand Mental Health Survey. Australian and New Zealand Journal of Psychiatry, 40(10), 914-923. doi: 10.1111/j.1440-1614.2006.01911.x

Baxter, J., Kokaua, J., Wells, J., McGee, M., \& Browne, M. (2006). Ethnic comparisons of the 12 month prevalence of mental disorders and treatment contact in Te Rau Hinengaro: The New Zealand Mental Health Survey. Australian and New Zealand Journal of Psychiatry, 40, 905-913. doi: 10.1111/j.1440-1614.2006.01910.x

Bernat, D., \& Resnick, M. (2006). Healthy Youth Development: Science and Strategies. Journal of Public Health Management and Practice, 12(6), S10S16.

Bessant, J. (2004). Habit and habitat: Housing, government policy, drugs, and pregnant women. Australian Journal of Primary Health, 10(2), 9-20.doi: 10.1071/PY04021

Bilge, A., \& Palabiyik, O. (2017). The Effect of Short Films About Mental Health and Disorders on Preventing Stigmatization in Nursing Education. Archives of Psychiatric Nursing, 31, 88-92. doi: 10.1016/j.apnu.2016.09.006

Bishop, R. (1996). Addressing Issues of Self-Determination and Legitimation in Kaupapa Māori Research. In He Paepae Kō rero: Research Perspectives in Māori Education (pp. 142-160). Wellington: New Zealand Council for Educational Research. 
Bishop, R. (1998). Freeing ourselves from neo-colonial domination in research: A Maori approach to creating knowledge. International Journal of Qualitative Studies in Education, 11(2), 199-219. doi: 10.1080/095183998236674

Braun, V., \& Clarke, V. (2006). Using thematic analysis in psychology. Qualitative Research in Psychology. doi:10.1191/1478088706qp063oa

Braun, V., \& Clarke, V. (2012). Thematic analysis. In V. Braun, \& V. Clarke, APA handbook of research methods in psychology, Vol 2: Research designs: Quantitative, qualitative, neuropsychological, and biological. (2 ed., pp. 5771). Washington, DC: American Psychological Association. doi: $10.1037 / 13620-004$

Braun, V., \& Clarke, V. (2017). Thematic Analysis. The Journal of Positive Psychology, 12(3), 297-298. doi: 10.1080/17439760.2016.1262613

Brewer, K., Harwood, M., McCann, C., Crengle, S., \& Worrall, L. (2014). The Use of Interpretive Description Within Kaupapa Māori Research. Qualitative Health Research, 24(9), 1287-1297. doi: 10.1177/1049732314546002

Browne, G., Gafni, A., Roberts, J., Byrne, C., \& Majumdar, B. (2004). Effective/efficient mental health programs for school children: a synthesis of reviews. Social Science and Medicine, 58(7), 1367-1384. doi: 10.1016/S02779536(03)00332-0

Browne, M., Wells, J., \& Mcgee, M. (2006). Twelve-month and lifetime health service use in Te Rau Hinengaro: The New Zealand Mental Health Survey. Journal Australian and New Zealand Journal of Psychiatry, 40(10), 855-864. doi: 10.1111/j.1440-1614.2006.01904.x

Bryman, A. (1988). Quantity and quality in social research. Unwin Hyman: London Clift, S., \& Morrison, I. (2011). Group singing fosters mental health and wellbeing: findings from the East Kent "singing for health" network project. Mental Health and Social Inclusion, 15(2), 88-97. doi: 10.1108/20428301111140930

Cohen, G., Perlstein, S., Chapline, J., Kelly, J., Firth, K., \& Simmens, S. (2006). The Impact of Professionally Conducted Cultural Programs on the Physical Health, 
Mental Health, and Social Functioning of Older Adults. The gerontologist, 46(6), 726-734. doi: 10.1093/geront/46.6.726

Cole-Lewis, H., \& Kershaw, T. (2010). Text messaging as a tool for behavior change in disease prevention and management. Epidemiologic reviews, 32(1), 56-69. doi: 10.1093/epirev/mxq004

Collie, P., Liu, J., Podsiadlowski, A., \& Kindon, S. (2010). You can't clap with one hand: Learnings to promote culturally grounded participatory action research with migrant and former refugee communities. International Journal of Intercultural Relations, 32(2), 141-149. doi 10.1016/j.ijintrel.2009.11.008

Coulter, A., \& Ellins, J. (2007). Effectiveness of strategies for informing, educating, and involving patients. $B M J, 335(7609), 24-27$. doi: 10.1136/bmj.39246.581169.80

Coulter, A., Parsons, S., Askham, J., \& World Health Organization. (2008). Where are the patients in decision-making about their own care? Denmark: World Health Organization

Cram, F. (2001). Rangahau Māori: Tona tika, tona pono - The validity and integrity of Māori research. In Research Ethics in Aotearoa New Zealand (pp. 35-52). Auckland: Pearson Education.

Cram, F., Kennedy, V., Paipa, K., Pipi, K., \& Wehipeihana, N. (2015). Being Culturally Responsive Through Kaupapa Māori Evaluation. In Continuing the Journey to Reposition Culture and Cultural Context in Evaluation Theory and Practice (pp. 289-311). North Carolina: Information Age Publishing.

Cram, F., Smith, L., \& Johnstone, W. (2003). Mapping the themes of Māori talk about health. The New Zealand Medical Journal, 116(1170).

Czerwiec, M., Williams, I., Squier, S., Green, M., Myers, K., \& Smith, S. (2015). Graphic medicine manifesto. University Park. PA: Pennsylvania State University Press.

Dowell A, Garrett, S., Collings S, McBain, L., McKinlay, E., \& Stanley, J. (2009). Evaluation of the Primary Mental Health Initiatives: Summary Report. Ministry of Health: Wellington. 
Durie, M. (1999). Mental Health and Māori Development. Australian \& New Zealand Journal of Psychiatry, 33(1), 5-12. doi: 10.1046/j.1440-1614.1999.00526.x

Durie, M. H. (2004). Indigeniety and the Promotion of Positive Mental Health, New Zealand Mental Health Promotion and Prevention Newsletter, Summer 20045

Durie, M. (1985.). A Māori perspective of health. Social Science \& Medicine, 20(5), 483-486. doi: 10.1016/0277-9536(85)90363-6

Durie, M. (2009). Māori knowledge and medical science. In M, Incayawar., R, Wintrob, R., L, Bouchard, L., \& G, Bartocci, Psychiatrists and traditional healers: Unwitting partners in global mental health (pp 237-249). West Sussex, UK: John Wiley \& Sons

Dyck, I., \& Kearns, R. (1995). Transforming the relations of research: towards culturally safe geographies of health and healing. Health \& Place, 1(3), 137147. doi: 10.1016/1353-8292(95)00020-M

Eketone, A. (2008). Theoretical underpinnings of Kaupapa Māori directed practice. Mai Review, 1, 1-11.

Elder, H. (2008). Ko wai ahau?(Who am I?) How cultural identity issues are experienced by Mäori psychiatrists and registrars working with children and adolescents. Australasian Psychiatry, 16(3), 200-203. doi:

10.1080/10398560701875199

Elder, H., Milne, M., Witehira, H., Mendes, P., Heslin, A., Cribb-su'a, \& Kalra, V. (2009). Whakaora nga moemoea o nga tūpuna - Living the dreams of the ancestors. Future planning in a Kaupapa Māori CAMHS team. Australasian Psychiatry, 17(1), 104-107. doi: 10.1080/10398560902948597

Eruera, M. (2010). Ma Te Whānau Te Huarahi Motuhake: Whānau Participatory Action Research groups. MAI Review, 3(1), 1-9.

Eruera, M. \& Dobbs, T. (2009). Taitamariki Māori kōrero about intimate partner relationships. Unpublished manuscript.

Everall, R. D., Altrows, K. J., \& Paulson, B. L. (2006). Creating a future: A study of resilience in suicidal female adolescents. Journal of Counseling \& Development, 84(4), 461-470. doi: 10.1002/j.1556-6678.2006.tb00430.x 
Farmstrong. (2017). Farm Strong - Live Well Farm Well. Retrieved from http://farmstrong.co.nz/

Farthing, A., \& Priego, E. (2016). 'Graphic Medicine' as a Mental Health Information Resource: Insights from Comics Producers. Journal of Comics Scholarship, 6(1). doi: $10.16995 / \mathrm{cg} .74$

Field. (1979). Screenplay: The Foundations of Screenwriting. New York: Dell.

Fjeldsoe, B. S., Marshall, A. L., \& Miller, Y. D. (2009). Behavior change interventions delivered by mobile telephone short-message service. American journal of preventive medicine, 36(2), 165-173. doi:

10.1016/j.amepre.2008.09.040

Freire, P. (1972). Pedagogy of the oppressed. London: Penguin

Gaines, P., Bower, A., Buckingham, B., Eagar, K., Burgess, P., \& Green, J. (2003). New Zealand mental health classification and outcomes study. Auckland, NZ: Health Research Council of New Zealand

Gavala, J., \& Taitimu, M. (2007). Training and supporting a Māori workforce. In I. M. Evans, J. J. Rucklidge, \& M. O’Driscoll (Eds.) Professional practice of psychology in Aotearoa New Zealand (pp. 229-244). Wellington: The New Zealand Psychological Society.

Gibson, S. \& Kindon, S. (2013). The Mixing Room project at Te Papa: Co-creating the museum with refugee-background youth in Aotearoa New Zealand. Tuhinga, 24, 65-83.

Gill, P., Stewart, K., Treasure, E., \& Chadwick, B. (2008). Methods of data collection in qualitative research: interviews and focus groups. BDJ, 204(6), 291-295. doi: 10.1038/bdj.2008.192

Glaser, B., \& Strauss, A. (1967). The Discovery of Grounded Theory: strategies for qualitative research. New Brunswick and London: AldineTransaction.

Glover, M. (2002). A literature review and commentary on the use of a Kaupapa Māori approach within a doctoral study of Māori smoking cessation. Auckland: University of Auckland

Green, M., \& Myers, K. (2010). Graphic medicine- Use of comics in medical education and patient care. British Medical Journal, 340(7746), 574-577. doi: 10.1136/bmj.c863 
Guerra, N. G., \& Bradshaw, C. P. (2008). Linking the prevention of problem behaviors and positive youth development: Core competencies for positive youth development and risk prevention. New directions for child and adolescent development, 2008(122), 1-17.doi: 10.1002/cd.225

Hayward, J. (2012). Biculturalism - From bicultural to monocultural, and back. Retrieved from http://www.TeAra.govt.nz/en/biculturalism/page-1

Holgate, H.S., Evans, R., \& Yuen, F.K.O. (2006). Teenage pregnancy and parenthood: Global perspectives, issues and interventions. New York: Routledge.

Hollands, T., Sutton, D., Clair, V., \& Hall, R. (2015). Māori mental health consumers' sensory experience of Kapa Haka and its utility to occupational therapy practice. New Zealand Journal of Occupational Therapy, 62(1), 3-11.

Hope, T. L., Wilder, E. I., \& Watt, T. T. (2003). The relationships among adolescent pregnancy, pregnancy resolution, and juvenile delinquency. The Sociological Quarterly, 44(4), 555-576.doi: 10.1111/j.1533-8525.2003.tb00525.x

Horwood, J., \& Fergusson, D. (1998). PSYCHIATRIC DISORDER AND TREATMENT SEEKING IN A BIRTH COHORT OF YOUNG ADULTS. Ministry of Health: Manatu Hauora, Wellington, New Zealand.

Houston, D., Ck Ee, K., Carroll, L., \& Arsh, H. (1998). Using humour to promote psychological wellbeing in residential homes for older people. 2(4), 328-332. doi: $10.1080 / 13607869856588$

Irwin, K. (1994). Māori research methods and practices: an exploration. Sites, 28, 2543.

Jones, A., McCulloch, G., Marshall, J., Smith G. H., Smith, L. T. (1990). Myths and realities, schooling in New Zealand. Dunmore Press: Palmerston North, New Zealand.

Jones, B., Ingham, T., Davies, C., \& Cram, F. (2010). Whānau Tuatahi: Māori community partnership research using a Kaupapa Māori methodology. MAI Review, 3(1), 1-14. 
Kendall, J., \& Peterson, G. (1996). A School-Based Mental Health Clinic for Adolescent Mothers. Journal of Child and Adolescent Psychiatric Nursing, 9(2), 7-17. doi: 10.1111/j.1744-6171.1996.tb00253.x

Kerr, S., Penney, L., Moewaka Barnes, H., \& McCreanor, T. (2010). Kaupapa Māori Action Research to improve heart disease services in Aotearoa, New Zealand. Ethnicity \& Health, 15(1), 15-31. doi: 10.1080/13557850903374476

Kerstetter, K. (2012). Insider, Outsider, or Somewhere in Between: the impact of researchers' identities on the community-based research process. Journal of Rural Social Sciences, 27(2), 99-117.

Keys, D. (2007). Opportunity for change: Young motherhood and homelessness. A report from the Becoming a Mother project. Melbourne, Australia: Key Centre for Women's Health in Society - University of Melbourne:

Kidd, S. A., \& Kral, M. J. (2005). Practicing participatory action research. Journal of Counseling Psychology, 52(2), 187. doi: 10.1037/0022-0167.52.2.187

Kings College London. (2017). MOVIE AND DOCUMENTARY IN MENTAL HEALTH: FROM RESEARCH TO PUBLIC ENGAGEMENT. Retrieved from https://www.kcl.ac.uk/ioppn/news/events/2016/July/Movie-and-documentaryin-mental-health.aspx

Kitzrow, M. (2003). The Mental Health Needs of Today's College Students: Challenges and Recommendations. Journal of Student Affairs Research and Practice, 41(1), 167-181. doi: 10.2202/1949-6605.1310

Koole, S. L. (2009). The psychology of emotion regulation: An integrative review. Cognition and emotion, 23(1), 4-41. doi: 10.1080/02699930802619031

Krishna, S., Boren, S. A., \& Balas, E. A. (2009). Healthcare via cell phones: a systematic review. Telemedicine and e-Health, 15(3), 231-240. doi: 10.1089/tmj.2008.0099

Lapadat, J., \& Lindsay, A. (1999). Transcription in Research and Practice: From Standardization of Technique to Interpretive Positionings. Qualitative Inquiry, 5(1), 64-86. doi: 10.1177/107780049900500104 
Larøi, F., \& Van der Linden, M. (2009). The effects of a documentary film on reducing stigmatisation about schizophrenia. Psychosis, 1(1), 61-72. doi: $10.1080 / 17522430802578395$

Le Va. (2014). Albert Fale's story. Retrieved from https://www.youtube.com/watch?v=Rz5KPnQ3vng

Lewin, K. (1946). Action research and minority problems. Journal of social issues, 2(4), 34-46.doi: 10.1111/j.1540-4560.1946.tb02295.x

Liao, T. (2003). Mental health, teenage motherhood, and age at first birth among British women in the 1990s (No. 2003-33). Colchester: University of Essex.

Marks, G., \& Houston, D. M. (2002). Attitudes towards work and motherhood held by working and non-working mothers. Work, employment and society, 16(3), 523-536. doi: 10.1177/095001702762217470

Maguire, P. (1993). Challenges, contradictions, and celebrations: Attempting participatory research as a doctoral student. Voices of change: Participatory research in the United States and Canada, 157-176.

Martin, S., Martin, G., Lequertier, B., Swannell, S., Follent, A., \& Choe, F. (2013). Voice movement therapy: evaluation of a group-based expressive arts therapy for nonsuicidal self-injury in young adults. Music Med, 5(1), 31-38. doi: $10.1177 / 1943862112467649$

McTaggart, R. (1997). Participatory action research: International contexts and consequences. State University of New York Press: Albany, New York.

McCusker, K., \& Gunaydin, S. (2015). Research using qualitative, quantitative or mixed methods and choice based on the research. Perfusion, 30(7), 537-542. doi: $10.1177 / 0267659114559116$

Mane, J. (2009). Kaupapa Māori: A community approach. Mai Review, 3(1), 9. Mental Health Foundation of New Zealand (MHFNZ). (2012). Opening Doors. Retrieved from https://www.youtube.com/watch?v=Cgmw_hNLGck\&list=PLB7w1elq23doC 9bOSTx5EaYUiwZBkUDKN

Mental Health Foundation of New Zealand (MHFNZ). (2017). Addressing issues in our mental health system - a position paper. Retrieved from 
https://www.mentalhealth.org.nz/home/our-work/page/17/10/addressingissues-in-our-mental-health-system-a-position-paper

Mental Health Foundation of New Zealand (MHFNZ). (2017). Mental Health Foundation of New Zeland. Retrieved from https://www.mentalhealth.org.nz/ Mental Health Foundation of New Zealand. (2017). Mental Health Foundation of New Zealand: mauri tu, mauri ora. Resources. Retrieved from https://www.mentalhealth.org.nz/get-help/resources

Merry, S., Mcdowell, H., Wild, C., Bir, J., \& Cunliffe, R. (2004). A Randomized Placebo-Controlled Trial of a School-Based Depression Prevention Program. Journal of the American Academy of Child and Adolescent Psychiatry, 43(5), 538-547. doi: 10.1097/00004583-200405000-00007

Merry, S., Stasiak, K., Shepherd, M., Frampton, C., Fleming, T., \& Lucassen, M. (2012). The effectiveness of SPARX, a computerised self help intervention for adolescents seeking help for depression: randomised controlled non-inferiority trial. $B M J, 344(2598)$. doi: 10.1136/bmj.e2598

Milne, K., Bowler, S., Li, J., \& Salmon, P. (2008). Evaluation of the first year of the Txt2Quit service. Wellington, New Zealand: The Quit Group.

Te Pou (2010). He Rongoa kei te Korero. Talking therapies for Māori: Wise practice guide for mental health and addiction services. Auckland, New Zelaland: Te Pou o Te whakaaro Nui

Mind and Body Consultants Ltd. (2012). reTHiNK: Changing our attitudes towards mental health. Retrieved from http://rethink.org.nz/

Ministry of Health. (2001). Building on Strengths: A Guide for Action A New Approach to Promoting Mental Health in New Zealand/Aotearoa Building on Strengths: A guide for action iii A New Approach to Promoting Mental Health in New Zealand/Aotearoa. Wellington, New Zealand: Ministry of Health.

Ministry of Health. (2004). Draft operational framework for PHO performance management. Wellington, New Zealand: Ministry of Health. 
Ministry of Health. (2006a). A guide to developing public health programmes: a generic programme logic model. Occasional bulletin no. 35. Wellington, New Zealand: Ministry of Health

Ministry of Health. (2006b). Tatau kahukura: Māori health chart book. Wellington, New Zealand: Ministry of Health.

Ministry of Health \& University of Otago. (2006). Decades of disparity III: Ethnic and socioeconomic inequalities in mortality, New Zealand 1981-1999. Wellington, New Zealand: Ministry of Health and University of Otago. Ministry of Health. (2014). Suicide Facts: 2014 data. Retrieved from http://www.health.govt.nz/publication/suicide-facts-2014-data

Ministry of Social Development \& Te Manatū Whakahiato Ora. (2004). Children and Young People: Indicators of Wellbeing in New Zealand. Wellington, New Zealand: Ministry of Social Development and Te Manatū Whakahiato Ora

Ministry of Health. (2009). Evaluation of the Primary Mental Health Initiatives: Summary report 2008. Wellington: University of Otago and Ministry of Health.

Ministry of Youth Development. (2009). "Keepin' it real”. A resource for involving young people. Wellington, New Zealand: Ministry of Youth Development Ministry of Health. (2016). Closer to home: Ka aro mai ki te kāinga. Retrieved from https://www.health.govt.nz/new-zealand-health-system/new-zealand-healthstrategy-roadmap-actions-2016/section-action-areas/closer-home

Moewaka-Barnes, H. (2000). Kaupapa Māori: explaining the ordinary. Pacific Health Dialog, 7(1), 13-16.

Morton, L. P. (2002). Targeting generation Y. Public Relations Quarterly, 47(2), 46.

Moffitt, T. E., Arseneault, L., Belsky, D., Dickson, N., Hancox, R. J., Harrington, H., ... \& Sears, M. R. (2011). A gradient of childhood self-control predicts health, wealth, and public safety. Proceedings of the National Academy of Sciences, 108(7), 2693-2698. doi: 10.1073/pnas.1010076108

New Zealand Psychologists Board. (2002). Code of Ethics For Psychologists Working in Aotearoa/New Zealand. Wellington, New Zealand: The Psychologists Board 
Nepe, T. M. (1991). Te toi huarewa tipuna: Kaupapa Māori, an educational intervention system (Unpublished Doctoral dissertation). The University of Auckland, Auckland, New Zealand.

Bushnell, J. A., McLeod, D., Dowell, A. D., Salmond, C., Ramage, S., Collings, S., Ellis, P. M., Kljakovic, M. \& McBain, L. (2003). The nature and prevalence of psychological problems in New Zealand primary healthcare: a report on Mental Health and General Practice Investigation ( MaGPIe). New Zealand Medical Journal, 116 (1171), 1-15.

Pacific Incorporated. (2017). Le Va. Retrieved from https://www.leva.co.nz/

Pernice, R. (1996). Methodological issues in unemployment research: Quantitative and/or qualitative approaches? Journal of Occupational and Organizational Psychology, 69, 339-349. doi: 10.1111/j.2044-8325.1996.tb00620.x

Pidduck, P. (2016). What do tamariki have to say about Hauora? A qualitative study using photography (Unpublished Masters Thesis). University of Otago, Otago, New Zealand.

Pihama, L. (2001). Tîhei mauri ora: honouring our voices: mana wahine as a kaupapa Māori: theoretical framework (Unpublished Doctoral dissertation). The University of Auckland, Auckland, New Zealand.

Pihama, L. K., Smith, K., Taki, M., \& Lee, J. (2004). A literature review on kaupapa Māori and Māori education pedagogy. Auckland: International Research Institute for Māori and Indigenous Education.

Pihama, L. (2011). A conversation about Kaupapa Māori theory and research. Wellington, New Zealand: Kei Tua o te Pae Hui.

Pihama, L. (2012). Kaupapa Māori theory: transforming theory in Aotearoa. He Pukenga Korero, 9(2), 5-14.

Pihama, L., Cram, F., \& Walker, S. (2002). Creating methodological space: A literature review of Kaupapa Māori research. Canadian Journal of Native Education, 26(1), 30-43.

Pillow, W. (2004). Pillow, W. S. (2004). Unfit subjects: Educational policy and the teen mother. New York: RoutledgeFalmer. 
Pathak, V., Jena, B., \& Kalra, S. (2013). Qualitative research. Perspectives in clinical research, 4(3), 192. doi: 10.4103/2229-3485.115389

Pipi, K. (2010). The PATH planning tool and its potential for whānau research. Mai Review, 3, 84-91.

Pipi, K., \& Baker., M. (2014). Action research 3 (phase 5) report. Report presented to Te Puni Kōkiri. New Zealand: Takitini Whānau Ora Action Research Collective.

Pitama, S., Wells, J. E., Faatoese, A., Tikao-Mason, K., Robertson, P., Huria, T., ... \& Sheerin, I. (2011). A Kaupapa Māori approach to a community cohort study of heart disease in New Zealand. Australian and New Zealand journal of public health, 35(3), 249-255. doi: 10.1111/j.1753-6405.2011.00702.x

Pōmare, E., Keefe-Ormsby, V., Ormbsy, C., Pearce, N., Reid, P., \& Watene-Haydon, B. R. N. (1995). Hauora: A Study of the Years 1970-1991. Wellington, New Zealand: Eru Pomare Māori Health Research Centre.

Potter, J., \& Wetherell, M. (1987). Discourse and social psychology: Beyond attitudes and behaviour. California: Sage.

Primary Mental Health. (2017). Primary Mental Health and Addiction. Retrieved from http://www.primarymentalhealth.org.nz/

Procci, K., Bowers, C., Wong, C., \& Andrews, A. (2013). Minigames for mental health: improving warfighters' coping skills and awareness of mental health resources. Games for Health, 2(4), 240-246. doi: 10.1089/g4h.2013.0014

Pulotu-Endeman, F. K. (2001). Fonofale: Model of Health. Retrieved from: http://www.hpforum.org.nz/resources/Fonofalemodelexplanation.pdf

Quinlivan, J. A., \& Evans, S. F. (2002). The impact of continuing illegal drug use on teenage pregnancy outcomes - a prospective cohort study. BJOG: An International Journal of Obstetrics \& Gynaecology, 109(10), 1148-1153. doi: 10.1111/j.1471-0528.2002.01536.x

Quinlivan, J., Petersen, R., \& Gurrin, L. (1999). Adolescent Pregnancy: Psychopathology Missed. Australian and New Zealand Journal of Psychiatry, 33(6), 864-868. doi: 10.1046/j.1440-1614.1999.00592.x 
Reason, P. (1994). Three approaches to participative inquiry. In N. K. Denzin \& Y. S. Lincoln (Eds.), Handbook of qualitative research (pp. 324-339). Thousand Oaks, CA: Sage Publications.

Reason, P., \& Bradbury, H. (Eds.). (2001). Handbook of action research: Participative inquiry and practice. California: Sage.

Robson, B., Purdie, G. \& Cormack, D. (2006). Unequal impact: Māori and nonMāori cancer statistics, 1996-2001. Wellington, New Zealand: Ministry of Health.

Salusky, I. (2013). The meaning of motherhood: Adolescent childbearing and its significance for poor Dominican females of Haitian descent. Journal of Adolescent Research, 28(5), 591-614. doi: 10.1177/0743558413487589

Shanok, A. F., \& Miller, L. (2005). Fighting and depression among poor pregnant adolescents. Journal of reproductive and infant psychology, 23(3), 207-218. doi: 10.1080/02646830500165770

Short, J., \& Reeves, T. (2009). The Graphic Novel: a "Cool" Format for Communicating to Generation Y. Business Communication Quarterly, 72(4), 414-430. doi: 10.1177/1080569909336464

Simmonds, S., Robson, B., Cram, F., \& Purdie, G. (2008). Kaupapa Maori epidemiology. Australasian Epidemiologist, 15(1), 3.

Simpson, J., Wicken, A., Duncanson, M., Adams, J., \& Oben, G. (2016). Te Ohonga Ake The Determinants of Health for Māori Children and Young People in New Zealand Series Two. Dunedin, New Zealand: NZ Child and Youth Epidemiology Service.

Smith, G. (1997). The development of Kaupapa Māori: theory and praxis (Unpublished Doctoral Thesis). University of Auckland, Auckland, New Zealand.

Smith, L. T. (1999). Decolonizing methodologies, research and indigenous peoples. New York: Zed Books.

Smith, L. T. (2005). On Tricky Ground: Researching the Native in the Age of Uncertainty. In The Sage Handbook of Qualitative Research (pp. 85-107). California: Sage Publications. 
Smith, G. H. (2012). The politics of reforming Māori education: The transforming potential of Kura Kaupapa Māori. In Towards successful schooling (pp 7387). Oxon: Routledge

Smith, L. (2015). Kaupapa Māori Research-Some Kaupapa Māori Principles. Kaupapa Rangahau: A Reader, 46-53.

Smith, L., \& Reid, P. (2000). Māori research development. Kaupapa Māori principles and practices, A literature review. Wellington, New Zealand: Te Puni Kokiri.

SmithBattle, L. (2003). Understanding teenage mothering: conventional and unconventional wisdom. Prevention Researcher, 10(3), 1-4

SmithBattle, L. (2007). "I wanna have a good future": Teen mothers' rise in educational aspirations, competing demands, and limited school support. Youth \& Society, 38(3), 348-371. doi: 10.1177/0044118X06287962

Sommer, M. A., \& Wurtz, R. H. (2002). A pathway in primate brain for internal monitoring of movements. Science, 296(5572), 1480-1482. doi:

10.1126/science. 1069590

Spinz. (2017). Spinz: Supporting People in Need. Retrieved from http://www.spinz.org.nz/

Statistics New Zeland. (2017). Births and Deaths: Year ended December 2016 and March 2017 Key facts. Statistics New Zealand.

Taylor, S. J., \& Bogdan, R. (1984). Introduction to qualitative research methods: The search for meaning. New York: Wiley.

Te Kete Ipurangi (TKI). (2009). The concept of a tuakana-teina relationship. Retrieved from http://health.tki.org.nz/Key-collections/Exploring-te-aokori/Planning-learning-experiences/Teaching-methods

Te Pou o Te Whakaaro Nui. (2009). Working with Māori Essential level learning module 2 Working with Māori - Essential level Learning module - print version. Auckland, New Zealand: The National Centre of Mental Health Research, Information and Workforce Development. 
Te Rau Matatini. (2009). Service review: Manawa ora o nga taiohi (a Mental Health Foundation rangatahi mental health promotion programme). Wellington, New Zealand: Te Rau Matatini.

Walker, S., Eketone, A., \& Gibbs, A. (2006). An exploration of kaupapa Māori research, its principles, processes and applications. International Journal of Social Research Methodology, 9(4), 1364-5579. doi: $10.1080 / 13645570600916049$

Webb, T. L., Joseph, J., Yardley, L., \& Michie, S. (2010). Using the internet to promote health behavior change: a systematic review and meta-analysis of the impact of theoretical basis, use of behavior change techniques, and mode of delivery on efficacy. Journal of medical Internet research, 12(1). doi: 10.2196/jmir. 1376

Whānau Ora Taskforce. (2009). Whānau ora: A whānau-centred approach to Māori wellbeing. Wellington, New Zealand: Ministry of Social Development.

Whittaker, R., Maddison, R., McRobbie, H., Bullen, C., Denny, S., Dorey, E., . . . Rodgers, A. (2008). A multimedia mobile phone-based youth smoking cessation intervention: Findings from content development and piloting studies. Journal of Medical Internet Research, 10(5), 1-13. doi: 10.2196/jmir.1007

Whittaker, R., Merry, S., Dorey, E., \& Maddison, R. (2012). A development and evaluation process for mHealth interventions: examples from New Zealand. Journal of health communication, 17(1), 11-21. doi: $10.1080 / 10810730.2011 .649103$

Williams, I. (2012). Graphic medicine: comics as medical narrative. Medical Humanities, 38(1), 21-27. doi: 10.1136/medhum-2011-010093

WINZ. (2017a). Young Parent Payment. Retrieved from https://www.workandincome.govt.nz/products/a-z-benefits/young-parentpayment.html

WINZ. (2017b). Young Parent Payment (current). Retrieved from https://www.workandincome.govt.nz/map/deskfile/youth-servicetables/young-parent-payment-current.html 
World Health Organization. (2011). mHealth: New horizons for health through mobile technologies. Switzerland: World Health organisation.

World News. (2012). You Belong Alpha Rev. Retrieved from https://wn.com/you_belong_alpha_rev

Youth Wellbeing Study. (2014). A Choice. Wellington, New Zealand: Youth Wellbeing Study.

Youth Wellbeing Study. (2016). A Change. Wellington, New Zealand: Youth Wellingbeing Study. 


\section{Appendix A - Email to schools}

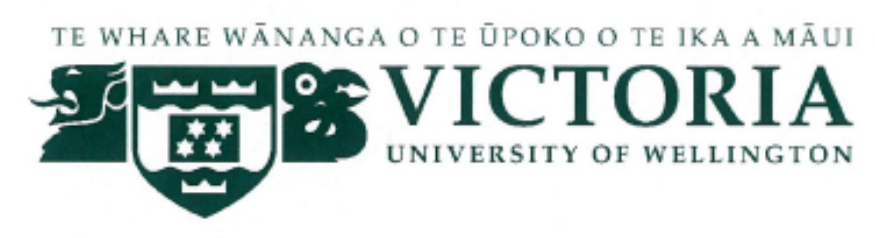

\section{Rangatahi Perspectives on Mental Health Issues in Aotearoa \\ EMAIL TO SCHOOLS}

Kia Ora

My name is Catherine Pihema. I am a student Clinical Psychologist at Victoria University and am also working to complete my Master's Thesis this year.

I am working under Associate Professor Dr Marc Wilson and am part of the Youth Wellbeing Research team. I am also receiving cultural supervision through $\mathrm{Dr}$ Tia Neha. This team should be familiar to you in light of your school's involvement in the Youth Wellbeing longitudinal study, Tahlia Kingi's PhD work with rangatahi and Dr Neha's work within your Psychology Department. Tawa College has made huge contributions to the success of our research projects and we really appreciate the support from your school.

\section{What am I interested in?}

Loosely speaking the aim of my Masters project is to develop understanding around rangatahi perspectives on mental health issues and cultural coping strategies. I plan to do this through Participatory Action Research guided by kaupapa Mãori principles. This would involve working with rangatahi over a series of focus hui to create a tool which encompasses their understanding of an identified problem and how aspects of their Mãori culture can help protect against this problem. This would involve around 5-6 hui. The tool can be anything proposed by the rangatahi but an example created in the past includes a graphic novel (see attached example a graphic novel produced by an earlier storyboard group).

\section{Getting involved}

I was emailing to see whether you would be interested in meeting to further discuss this project and the potential of working with your students. I am able to come out to Tawa and meet with you and anyone else you feel appropriate, at any time on either a Monday or Friday.

If you could let me know if you would like to meet and if so when is a good time for you, I would really appreciate that.

I look forward to hearing from you.

Ngā Mihi,

Catherine Pihema 


\section{Appendix B - Consent and Information Pamphlet}
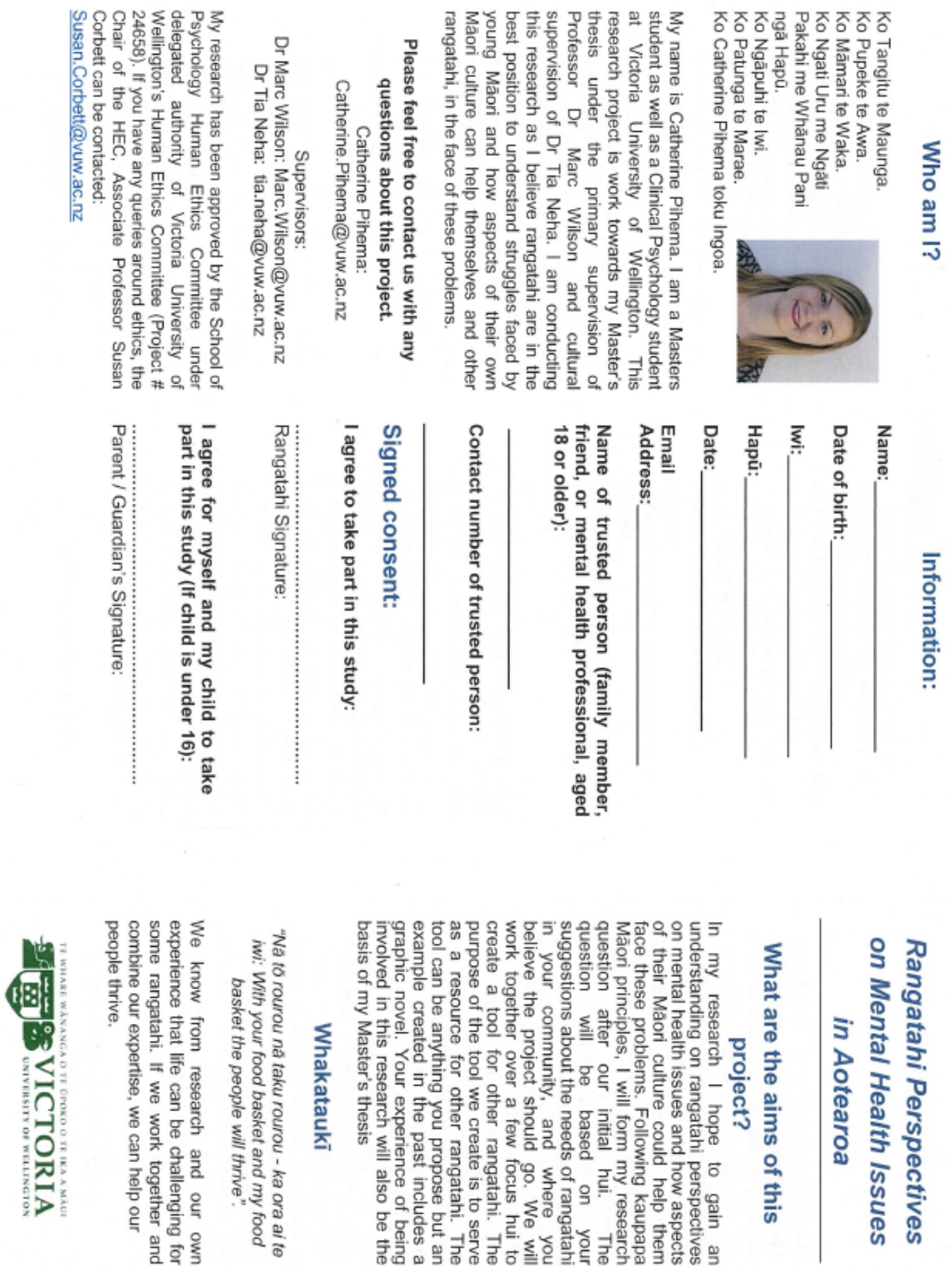

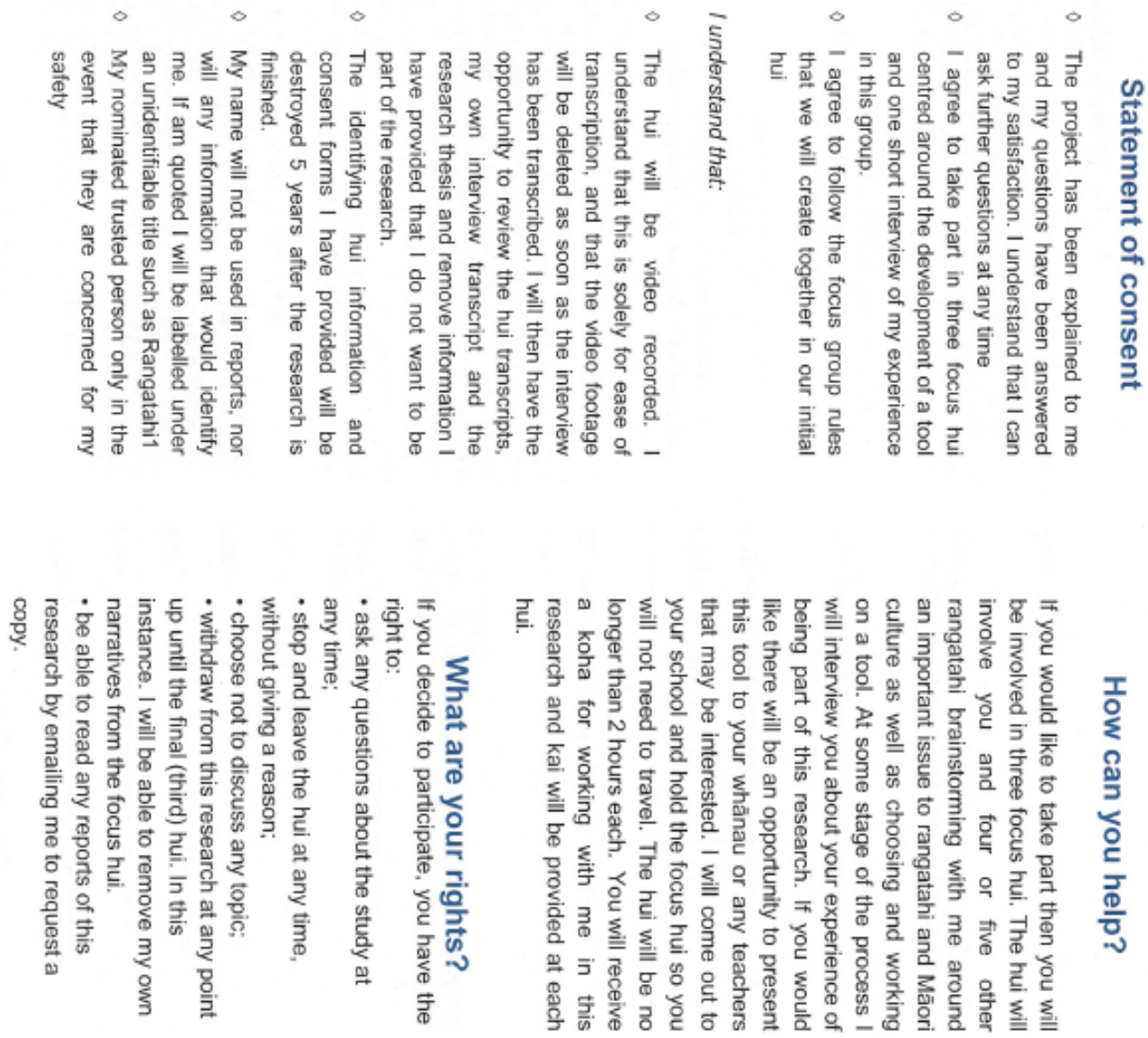

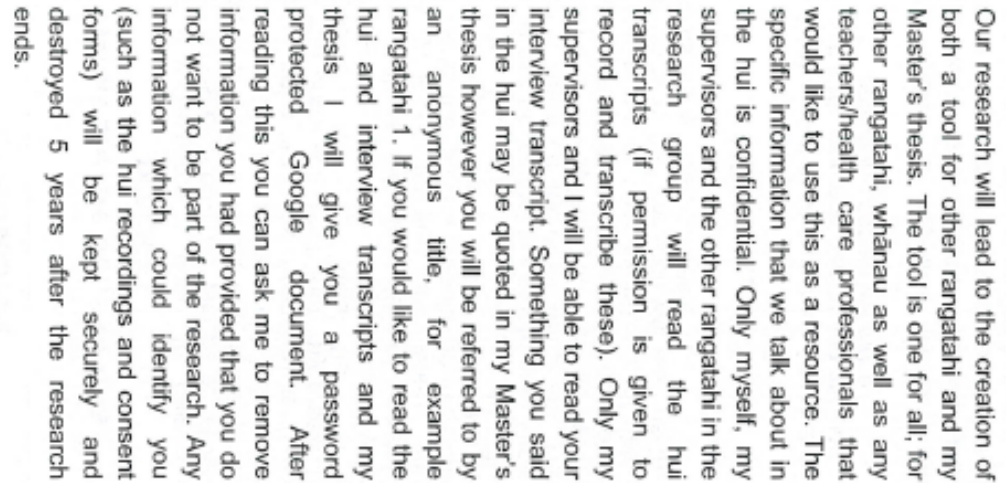

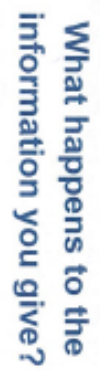




\title{
Appendix C - Debriefing forms for Hui 1 and 2
}

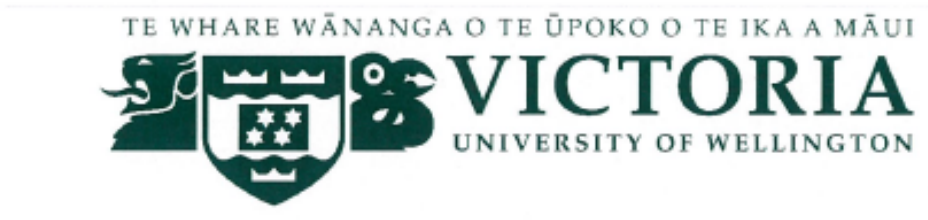

\section{Rangatahi Perspectives on Mental Health Issues in Aotearoa DEBRIEFING FORM-Hui 1}

\begin{abstract}
Thank you for being part of this research process. In this first hui we have gotten to know each other, whakawhānaungatanga, and have talked about challenging experiences faced by rangatahi and Mãori culture. We have also chosen a tool, we would like to make to demonstrate how aspects of Mãori culture could help rangatahi manage difficulties they may face. We will begin this process in the next hui. The process of developing this tool and your experience of being involved in this research will form the basis of my Master's thesis.
\end{abstract}

We may have discussed some sensitive or personal experiences across our hui's. If you feel like you need any support and want to talk further about what we covered you are welcome to contact me by emailing me at Catherine.Pihema@vuw.ac.nz and I am more than happy to help. You can also contact my supervisors: Dr Marc Wilson at Marc.Wilson@vuw.ac.nz or Dr Tia Neha at tia.neha@vuw.ac.nz with any questions you may have. Alternatively your whānau/family and friends/ō hoa are great sources of support and it can be helpful to talk to them about any concerns you may have after this research.

Lastly, your guidance counsellor, or an external organisation are available to provide support if you need following this research:

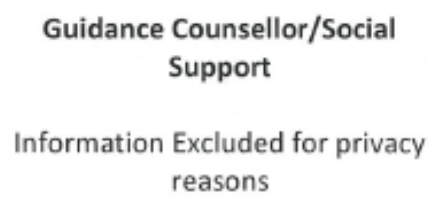

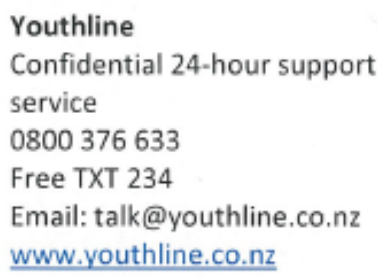

If you have any concerns about the ethical conduct of the research you may contact the Victoria University HEC Convener: Associate Professor Susan Corbett. Email susan.corbett@vuw.ac.nz or telephone +64-4-463 54 


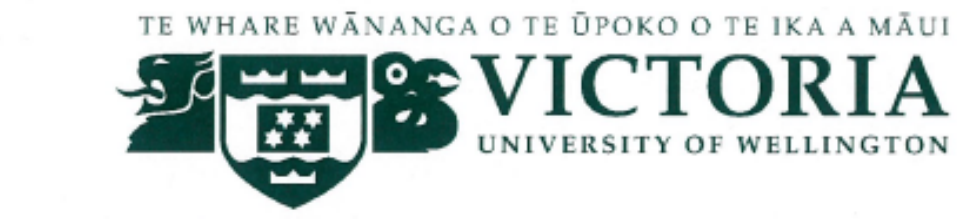

\section{Rangatahi Perspectives on Mental Health Issues in Aotearoa DEBRIEFING FORM - Hui 2}

Thank you for being part of this research process. In this second hui we have brainstormed about our experiences around judgment, stigma and coping, the issues faced by rangatahi you identified as most important in hui 1 . We have worked together and started to gather all ideas for the short film resource. In the next hui we will finish gathering all information and ideas which will enable the resource to start to be created. This process of developing this tool and your experience of being involved in this research will form the basis of my Master's thesis.

We may have discussed some sensitive or personal experiences across our hui's. If you feel like you need any support and want to talk further about what we covered you are welcome to contact me by emailing me at Catherine.Pihema@vuw.ac.nz and I am more than happy to help. You can also contact my supervisors: Dr Marc Wilson at Marc.Wilson@vuw.ac.nz or Dr Tia Neha at tia.neha@vuw.ac.nz with any questions you may have. Alternatively your whānau/family and friends/hoa are great sources of support and it can be helpful to talk to them about any concerns you may have after this research.

Lastly, your guidance counsellor, or an external organisation are available to provide support if you wish to talk further about the topics and issues raised in this study.

\section{Guidance Counsellor \\ Information excluded for privacy reasons}

Youthline Confidential 24-hour support service 0800376633 Free TXT 234 Email: talk@youthline.co.nz www.youthline.co.nz

If you have any concerns about the ethical conduct of the research you may contact the Victoria University HEC Convener: Associate Professor Susan Corbett. Email susan.corbett@vuw.ac.nz or telephone +64-4-4635480. 


\section{Appendix D - Hui Plans}

\section{Set up example 1}

\section{Hui 1 Plan}

1) Whakawhanungatanga:

Imagine the floor is a map of New Zealand or wider. Place yourself on the map on where you whakapapa or the place you call home.

- Tell us a bit about:

- Who you are(mihi),

- Where you're from

- How far along are you or what's your baby's name

2) Housekeeping/small agenda for the day - ask permission to be recorded.

\section{3) Develop group kawa (rules)}

4) Comfort scale

Line up in terms of:

- How far along you are/due date or how old baby is

- How involved are you with your Maori culture/do you have anything to do with it? (Go through and ask what they do)

- How comfortable are you talking about:
- Maori culture
- The topic of mental health
- Listening to other's experience
- Talking about my own experiences

4) Activity

$4 a-$ In small groups:

- Get a big piece of paper and a stack of round stickies. You'll notice the page has a waka on it. This is to represent your journey through life since become young adults / rangatahi. Draw a timeline, decorate it, do whatever you like - just make it your own. What it'd be great if you can do is if you think of some major life events you have experienced that you think are important to you-they can be good or bad ones ( 5 events?). Jot the on the stickies and place them on your wakas journey. Once you've place on what you think is important write on the smaller stickies what are some things you might have been feeling at that time or what might have been going on for you. Place the above or around the events.

- (Do my own example for them to see).

$4 b$ - With whole group:

Group timeline

- Ask people what kind of experiences they identified. Ask if they would like to peel their ideas off and put them on the group time line to see if there are any common events that popped up.

- If they are not confident ask them to shout out a few ideas and put them on the board.

- Group these together in themes. With the one that seems like the most people identified, ask if people would like to work off this experience for the project. 
- Ask people who identified this experience what they were feeling or others what they think they may feel like if it they did.

- Prompt around areas like Te Whare Tapa Wha model of health.

- Put up the model and see if can get more answers

- Sort in to different areas of wellbeing

$4 c$ - With the selected theme:

Think about what we would like to showcase about this experience/issue (from what's on the board-circle/highlight)

Think about the myths we want to debunk and stereotypes we want to address o this area.

5) Project creation

Talk about how this project is theirs and you just want to facilitate it. It could be a resource for other rangatahi or it could be something personal. Say we are wanting to capture an issue or an experience they think is important. We want to tell it through your perspective and have your own voice. We also want to show the benefits of Mãori

6) Give example of graphic novel and explain how that worked in the past and what its use is. Give other ideas.

- Graphic Novel

- Short film

- Website

- Information poster

- Carving

- Ask them what they would like to make

7) Take a blind vote. Ask them if they are happy with the answers.

8) Make a plan of attach for the next week.

9) Construct a group Facebook group. 


\section{Set up example 2}

\section{Hui 2 Plan}

1- Go over main ideas from film as identified in previous hui last time. Overall idea followed by quotes they said to prompt discussion:

- Addressing stigma and stereotypes around being a young Maori Mother. Show how capable/mature you are and how you are good mothers

- "The day to day basis of a teen mum. About all the judgements and shit we get. Short film we get on the bus."

- "You know how everyone labels us as teens so we will show what their words have put us through and then the end result of us actually being happy and showing that we got over this stuff and it doesn't affect us now."

- "Wants it to show how mature we have become and just have our kids playing even if it's at a park..."

- "It will go viral if we did it cos there are so many teen porents these days especially in this generation."

- "Hoving us jumping on the bus in the morning...our doily routine.... weekend have life still a teenager then back to Monday and back to mum duties. It's a never ending story when you're a teen mum."

- "Show us woking up early, nappies on your foce"

- "What do you want to call it?- "I don't like the word teen it casts judgement". Will figure this out loter"

- "We aren't what you say we are..."

- Talk about some of the challenges you have been through (e.g. Drugs/suicide) and how you can get through it and end up happy with baby. Main goal is to instil hope for others.

- "Do story on suicide, drugs and alcohol"

- "Because we are all teen mums how about we do one on depression..."

- "Each of one of us soys a judgement. And next person suicide... something like that and then have a norrotor go and tell the story and then hove all of these films on the ways of being hurt and then we all have our babies and we look at our babies and then hundy smile. And they'll be like "wow they are actually happy with their kid...It'll be gangster no one's done that."

- "Watching the film and it'll touch us and then other mums can watch it and have hope."

- "After all the challenges scene at the end where we all come together and say 'we got there'."

- "Yeah hard I want to chonge people's lives"...My sister and cousin are pregnant and I don't want them to go through what I went through..."

- "It will be hope"

\section{2 - Check in on *homework*}

- Review their ideas on their experience of judgement and stereotypes and how this could work in film:

- What exactly are the myths and stereotypes around being a young Maori mother that you want to shutdown? How could you visually depict ways to shut down these stereotypes? In 5 or 6 minutes you can't achieve everything What are the key messages you want to get across the world?

- Review their ideas on challenges and hope they want to include in the film: 
- This is awesome to talk about getting through the challenges you have and there happy with baby now being a good mum. Think of some exact things that helped get you through these times though like how you guys said whanau support, asking for help or setting goals for your up and coming whanau. What other exact things helped you get through. Remember this is a video to help others. What advice would you give to them so maybe they could lean on these supports and maybe detour around some of the challenges you faced?

3 - Plan times for future hui times:

- What days after school/weekend days would suit for rehearsal/film so we can lock them in too?

\section{4- If time get group to think of specific examples of how judgements have come across:}

- From People

- From society:

- Use of public services

5-Get group to think about coping mechanisms/support that got them through: Coping mechanisms:

Note to self:

If group is focussing too much on challenges open up new perspectives for strength based filmy:

$\rightarrow$ When the young people talk about how they want to talk about suicide or drug taking and how they got through it, it's an end point. Explain to the young people that that's an end point of a lot of stress and a way to cope. It's a bit sad to focus on that.

$\rightarrow$ What comes FIRST before considering these options? A person shouldn't have to go through all of those challenging times to get to the positives (holding baby, loving life as mums etc.). What are the detours around these events (the strength based helping part)?

$\rightarrow$ "How are you a different person now compared to how you started your journey? 


\title{
Hui plan for script development example
}

\author{
Hui 5 Plan
}

Agenda/considerations to be covered off:

- Run the idea of "A day in the life of". Exact same ideas and events except it's a bit easier to follow (on advice of film lecturer).

- One has just found out they are pregnant, one has a young baby. One experiences and has to deal with judgement. One has to deal with the isolated/Alone story.

- Plan event gaps

- Add ongoing support in to story

- Plan feelings you want to show

- Plan characters

- Plan dialogue

- Music/Colours

- Draw exact scenes

- Actors

1- How this agenda will work: Story Boarding activity: To DO (see next page):

- Figure out triangle 1 , Triangle 2

- Figure out feelings-people and decision scene

- Figure out smiley 1 and 2

- Figure out bigger grin 1 and 2

- Figure out happy mum - exact events

\section{2- Figure out and solidify characters}




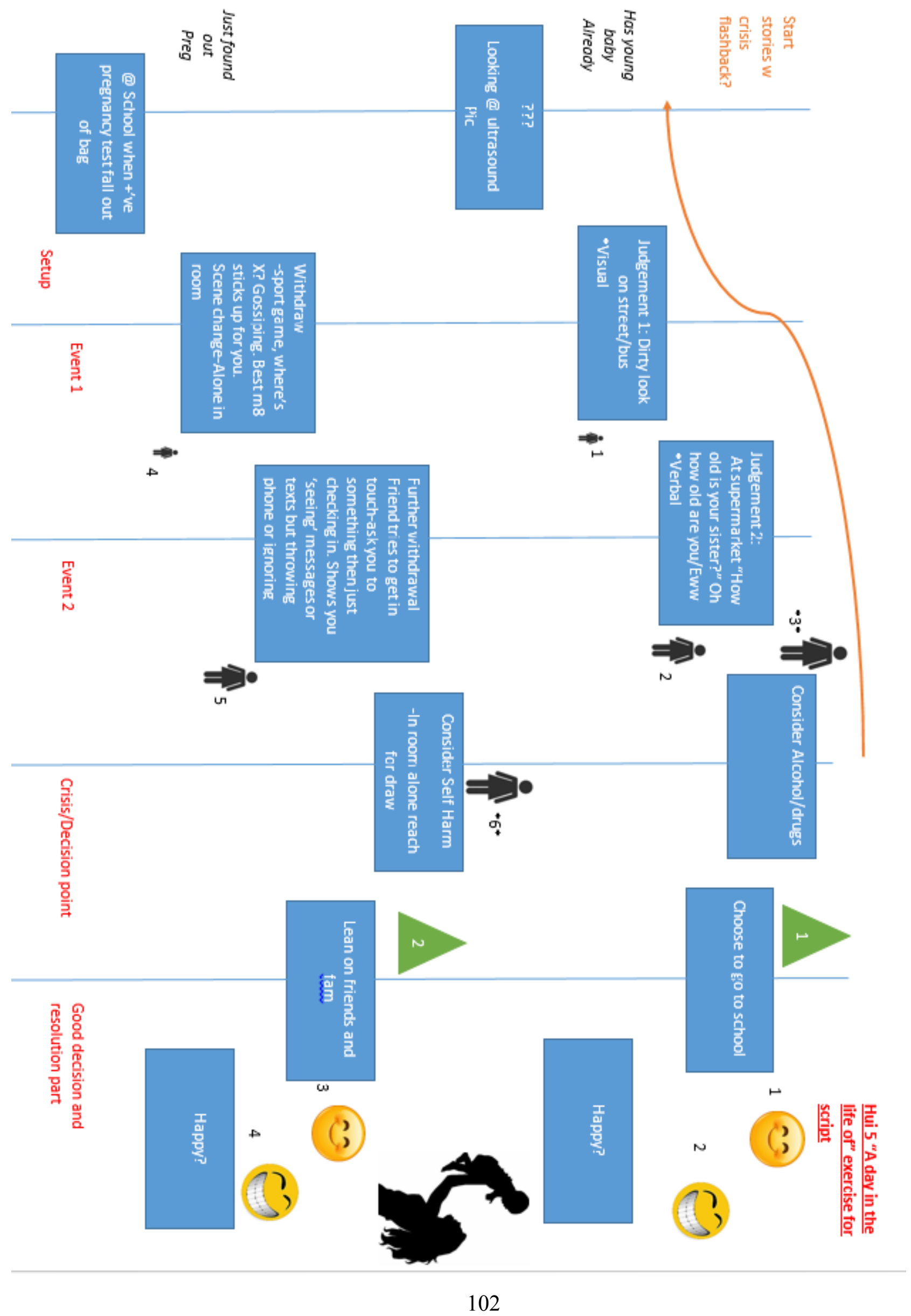




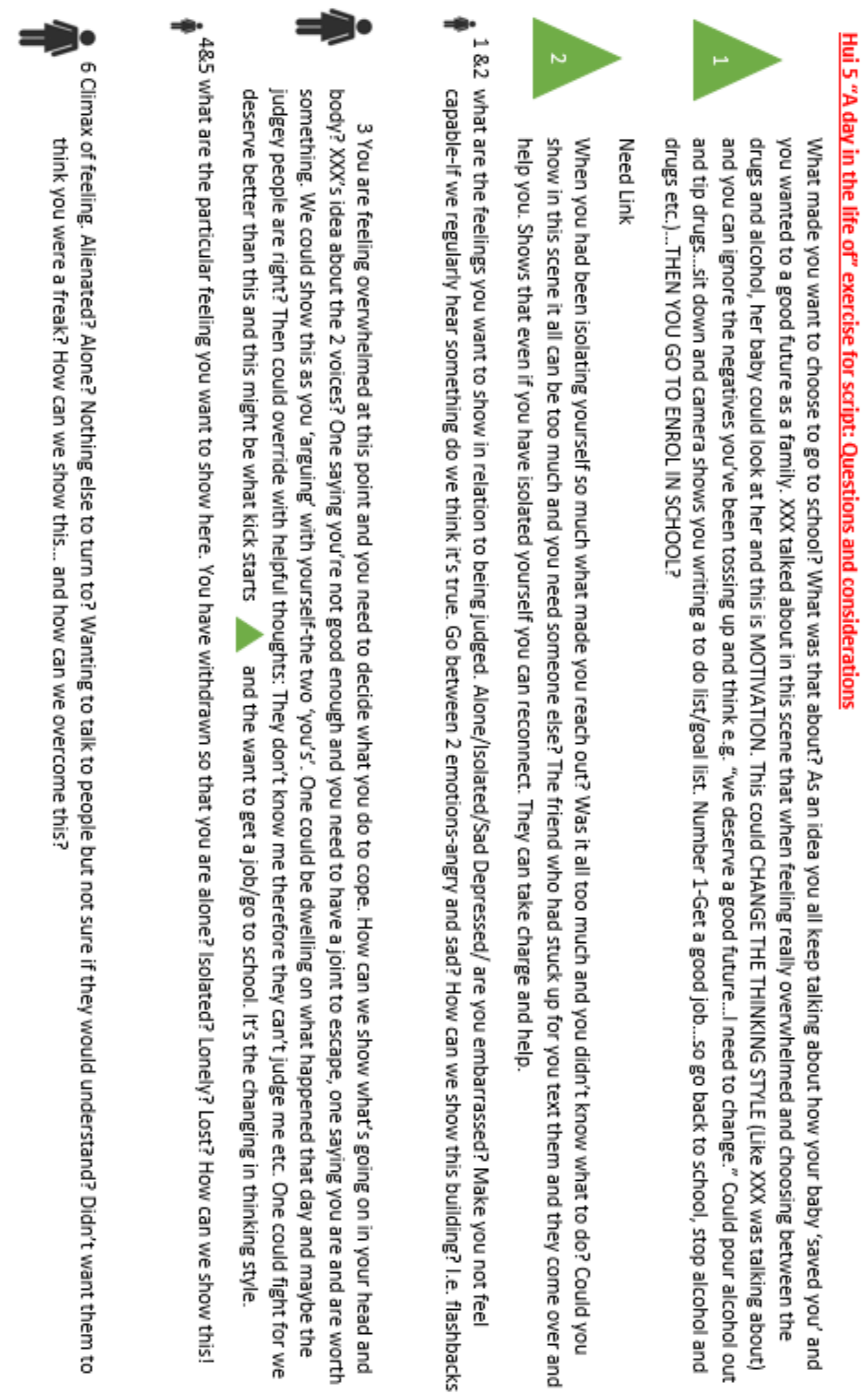



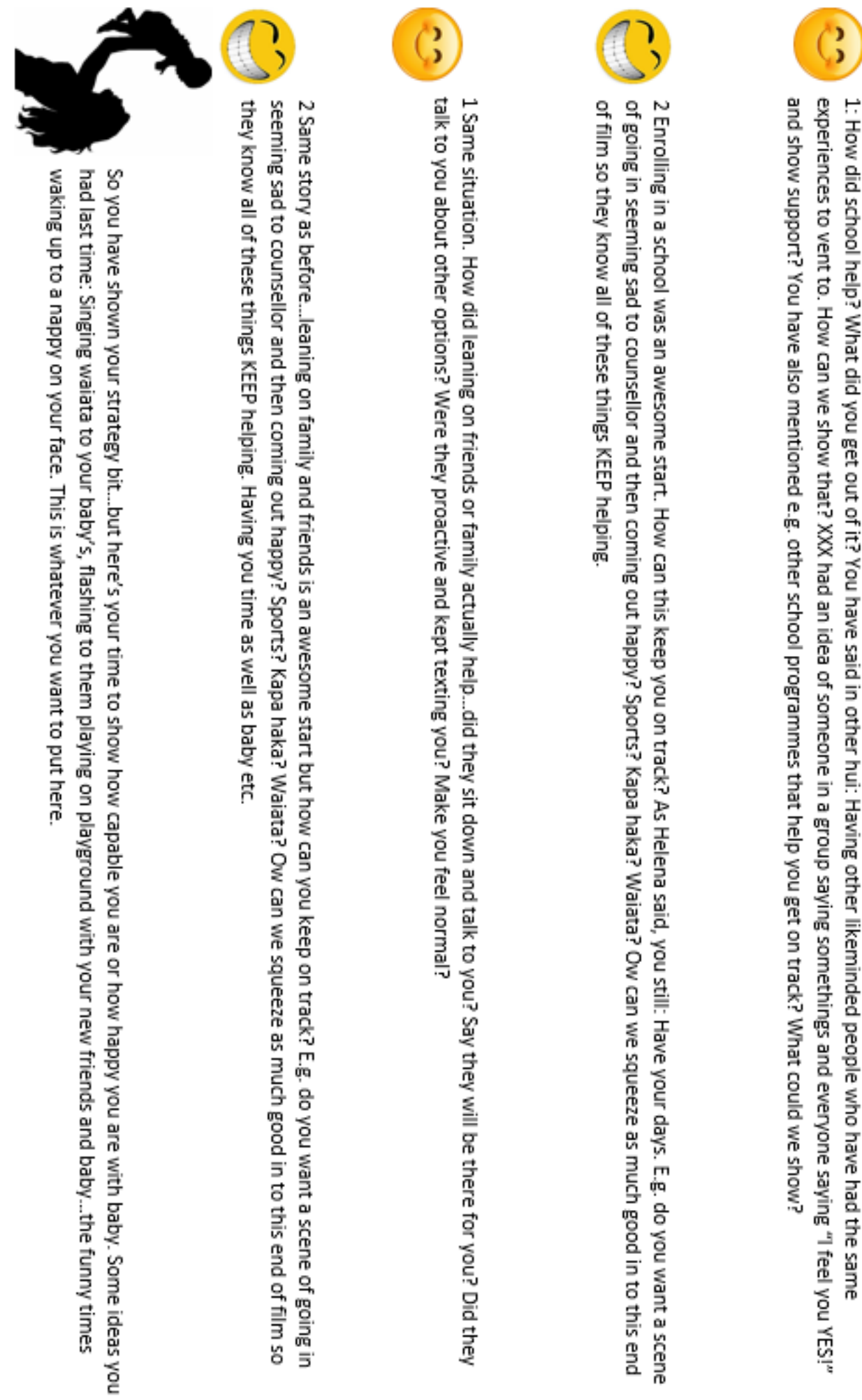

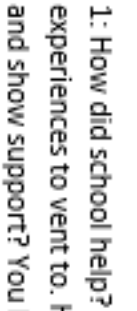

을음

初

壱言:

몽

总高

言哭

를

罦

은

离高

ऽ응

营高

힟 혗

응ㅎํ있

蛋

害. 离高

盈

留言?

兽高

高

흥 尊

ㄴํㅇ응

공영

즘 믁

总蛋

兽恋

高

이읻

ㅁํㅇ

高

‡

望

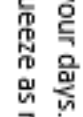

严

명 응

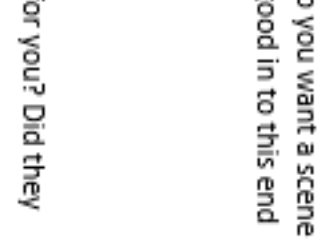

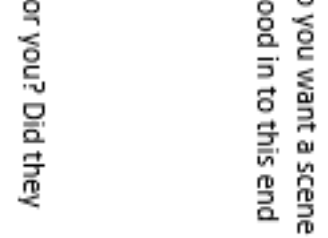

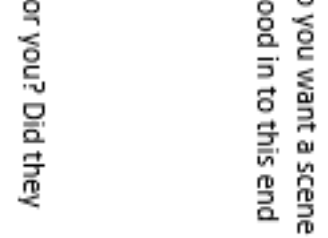

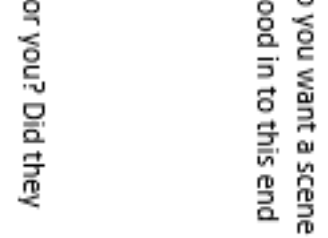

힊 종

흥 옹 흠

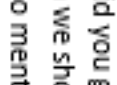

氙高挐

옴

in

唋

혹 홍

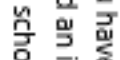

음 흠

잉을 흘

일

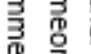

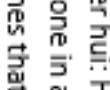

흠 명 崩

高哭

骂念商

응

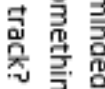

嵒咅

멱 믐음

อ

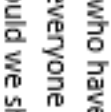

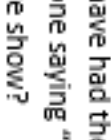

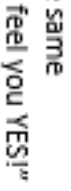




\section{Hui Preproduction Plan Example}

\section{Hui 7 Plan}

\section{Agenda}

- 1- Update girls on the process and talk about what we have done

- Sharing stories->want to make film->planned film themes$>$ planned actual events on 3 act structure->had draft script!

- 2- Divvy girls up in to art, structure and script development and other teams. Girls work in small groups to brainstorm specific things and plan of attack to achieve film faster

- Art

- Props needed from script

- Costume for each character

- Make up for each character

- What's needed in each set?

- Script

- Look through script and see if anything else you want to add in/change. Too late to change entire storyline

- Start to go through some of the feedback on poster, can "answer the questions"

- Acting

- Pick who wants a main role

- Assign main role to people

- Decide number of other less prominent roles

- Go around other girls and 'recruit' for the 'background' roles

- All groups to plan scheduled activities and when they need to be finished

- Make a plan on when they will meet again, decide who and what you need (Catherine, Andy, Money for props etc.)

- Come back and each small group report back on plan of attack

- Plan next full group hui

- Check in on rehearsal and shoot day dates 


\title{
Film Roles
}

\section{What is this?}

This is a sheet where you put yourself forward for roles in the film making. It's getting a bit hard all meeting together so we split up in to smaller groups that all work at the same time and the film comes together! Yay so close

\section{What to do?}

You must nominate yourself for three different roles by Wednesday the $9^{\text {th }}$ of August. Please write down whether each role is your $1^{\text {st }}$, second or $3^{\text {rd }}$ preference. By getting involved in the suggested activities listed against each area you may gain a better idea of which job you will be best suited to.

\author{
About the groups \\ 1. Script Development \\ 2. Art Department \\ 3. Acting \\ 4. Sound/Music \\ 5. Continuity \\ 6. Lighting \\ 7. Unit
}

Different groups are busier and quieter at different times. So be sure to check your availability and see if you're more available sooner or later. The order of the job business is normally as follows:

***Note: Suggested 'Actions' have been added to each category which the various volunteers can be pursuing in order to drive the process forward and build momentum. Let's get busy! 


\begin{tabular}{|c|c|c|}
\hline $\begin{array}{c}\text { Areas of } \\
\text { involvement }\end{array}$ & Roles & Actions \\
\hline $\begin{array}{l}\text { Art Department } \\
\text { Various areas of work } \\
\text { which will determine } \\
\text { the look and feel of the } \\
\text { film }\end{array}$ & $\begin{array}{l}\text {-Wardrobe/costume } \\
\text {-Make Up } \\
\text {-Set dressing/props } \\
\text {-Set-design }\end{array}$ & $\begin{array}{l}\text { Agree who will do each } \\
\text { role. } \\
\text { Analyse the script to } \\
\text { determine what is } \\
\text { needed by marking up } \\
\text { your copy of script (one } \\
\text { for make-up, one for } \\
\text { costume etc) } \\
\text { How many actors, what } \\
\text { costumes they will need, } \\
\text { how many changes, etc? } \\
\text { Go through each scene } \\
\text { and list the number of } \\
\text { props involved by } \\
\text { marking-up script. } \\
\text { Prepare some proposals } \\
\text { for how the film should } \\
\text { 'look' on a scene by } \\
\text { scene basis (i.e. bright \& } \\
\text { cheerful, dark \& } \\
\text { gloomy) }\end{array}$ \\
\hline $\begin{array}{l}\text { Script Development } \\
\text { Requires 2-3 dedicated } \\
\text { participants to develop } \\
\text { the story and create a } \\
\text { shape/journey which } \\
\text { the characters take the } \\
\text { audience on }\end{array}$ & $\begin{array}{l}\text {-Story line } \\
\text {-Characters } \\
\text {-Settings } \\
\text {-Names } \\
\text { After developing } \\
\text { changes to the script. } \\
\text { These will be presented } \\
\text { to the whole group for } \\
\text { approval } \\
\text {-SP/AF/MC }\end{array}$ & $\begin{array}{l}\text { Propose some } \\
\text { suggested names for } \\
\text { characters. } \\
\text { Analyse story } \\
\text { 'Time-Lines', do they } \\
\text { make sense to the } \\
\text { audience? } \\
\text { Is the intended message } \\
\text { of the film clear at all } \\
\text { times? } \\
\text { Are there any places } \\
\text { where the intended } \\
\text { message can be 'shown' } \\
\text { to the audience in a } \\
\text { simpler way, rather } \\
\text { than telling them in } \\
\text { words. }\end{array}$ \\
\hline
\end{tabular}




\begin{tabular}{|c|c|c|}
\hline $\begin{array}{l}\text { Sound/music } \\
\text { Assisting the sound } \\
\text { engineer in recording } \\
\text { the scenes of the film }\end{array}$ & $\begin{array}{l}\text { Selection of suitable } \\
\text { music and/or songs for } \\
\text { backing track and title } \\
\text { music. } \\
\text { Including } \\
\text { singers/performers } \\
\text { Assisting with boom } \\
\text { (The big long fluffy mic) }\end{array}$ & $\begin{array}{l}\text { Make proposals for } \\
\text { soundtrack music and } \\
\text { title music. The initial } \\
\text { stage will be to agree a } \\
\text { 'type' of music to give } \\
\text { the film the desired } \\
\text { 'feel'. } \\
\text { Existing commercially } \\
\text { produced music is not } \\
\text { feasible as the rights } \\
\text { have to be purchased } \\
\text { for many thousands of } \\
\text { dollars. The best option } \\
\text { is to use 'original' sound } \\
\text { tracks and/or } \\
\text { traditional songs/music } \\
\text { which are not covered } \\
\text { by copyrights. }\end{array}$ \\
\hline $\begin{array}{l}\text { Continuity } \\
\text { Very important role }\end{array}$ & $\begin{array}{l}\text { Keeping the records of } \\
\text { each shot and ensuring } \\
\text { all takes/camera angles } \\
\text { used match up eg coffee } \\
\text { cup in left hand, same } \\
\text { costumes }\end{array}$ & $\begin{array}{l}\text { Breakdown the script } \\
\text { into scenes and start to } \\
\text { establish 'running time' } \\
\text { By having read-through } \\
\text { with stopwatch. }\end{array}$ \\
\hline Acting & $\begin{array}{l}\text { Main Roles } \\
\text { Support roles } \\
\text { Extra roles }\end{array}$ & $\begin{array}{l}\text { Research acting } \\
\text { techniques online } \\
\text { (YouTube). Practice } \\
\text { acting techniques, learn } \\
\text { some scenes to act out } \\
\text { from other productions } \\
\text { (not scenes from our } \\
\text { film) and practice with a } \\
\text { friend. Have someone } \\
\text { film you on your phone } \\
\text { and look at the results. } \\
\text { Auditions will be held for } \\
\text { the Main Roles to } \\
\text { determine the best } \\
\text { casting - so it will be } \\
\text { competitive. }\end{array}$ \\
\hline Lighting & $\begin{array}{l}\text { Assisting lighting gaffer } \\
\text { in positioning and } \\
\text { operating film lights }\end{array}$ & $\begin{array}{l}\text { Not much to do at this } \\
\text { stage but this area can } \\
\text { also be researched } \\
\text { online, there are lots of } \\
\text { very informative } \\
\text { tutorials on YouTube. }\end{array}$ \\
\hline
\end{tabular}




\title{
Appendix G - Fully produced script
}

In a sparsely furnished bedroom an adolescent girl (AWHINA) lies curled up in a fetal position, crying. The room is dimly lit, the girl lifts her head and looks at a selection of drugs and alcohol on the bedside table.

In another bedroom, another adolescent girl (KAEA)lies upside down on a bed with her feet on the wall above where the pillow should be. She has a vacant and empty look on her face as if staring in to space and isn't saying anything. She swings her legs around onto the floor and stands up all in one (gymnast like) motion. Her heart begins to race, she is now standing in front of a set of drawers, she opens the top drawer and surveys the self harm equipment contained in it.

Close up of Awhina, dressed in school uniform, she adjusts her tie in the mirror. She bends down (as shot widens to reveal a pram) puts her hand to baby's face.

\section{AWHINA}

Come-on my son, let's get your cough looked at.

EXTERNAL-DAY

Kaea is talking with some friends. A girl (MICHELLE) approaches the group, she gives Kaea a hug.

\section{MICHELLE}

Hey! Congrats! Your brother told

me the news. (releasing her hug and patting her on the tummy) My mum's gone out looking for a pressie already. Classic mum!

Kaea shuffles uncomfortably on the spot, avoiding eye contact with her friends.

KAEA

\author{
Thanks \\ (in a barely audible mumble)
}


Awhina enters the surgery dressed in school uniform and pushing a pram. There are six seats, four of which are occupied. (Camera goes to Awhina's POV) the occupants of the seats are all now dressed in Judge's outfits. Awhina starts to breathe faster and wipes her hand sweat on her blazer, she makes her way past the others and takes a seat. A WOMAN in the seat beside her bends down to the floor and picks up a baby's shoe. She turns to Awhina.

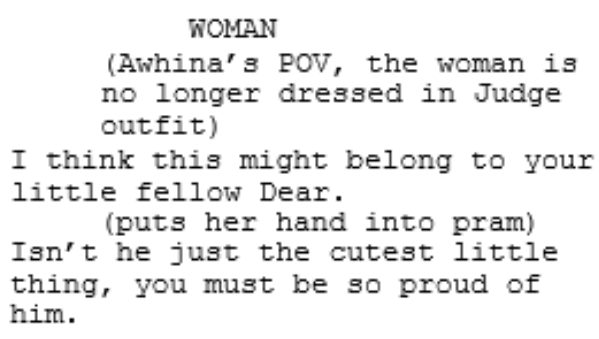

EXTERNAL-NETBALL COURTS-DAY

Girls wearing netball bibs are standing around the court.

GIRL 1

Hey, where's Kaea?

GIRL 2

I heard from Lisa that she's pregnant so she probably isn't coming.

GIRL 1

Oooh, really.

Kaea's friend (CHELSEA) interrupts the two girls, showing her obvious disapproval.

\section{CHELSEA}

Why does it matter if she's

pregnant or not? It's none of your business!

Chelsea takes out her mobile phone and begins to write a message.

TXT BUBBLE Hey, Coach and girls

want to know if you're coming? Game's in 20??? 7 
INTERNAL-BEDROOM-DAY

Kaea sits on her bed, she is dressed in her pajamas, the curtains are closed. She has her knees drawn up to her chin and her arms wrapped around her legs. Her phone is lying on the bed, out of her reach. A message notification sounds. Kaea looks at the phone then draws her knees closer and drops her head onto her knees.

Awhina enters the room, her sister HERA is sitting at the table. Awhina is pushing her pram which has full

supermarket bags looped over the handles. The baby is crying. Awhina takes the bags from the pram and places them on the table. She tries to comfort the baby.

HERA

That's what you get for having a

baby! Can't bloody look after it!

Awhina looks at her sister who she now sees dressed in a Judge's outfit. She shakes her head and her sister is dressed in normal clothes again.

AWHINA

(shouting)

You do it better then!

Awhina takes the baby from the pram, walks over to Hera and puts the baby in her lap. She then storms out of the room, slaming the door as she exits.

INTERNAL-BEDROOM-DAY

Awhina paces back and forth in her room, she approaches the bedside table and opens the drawer, which contains drug paraphernalia and alcohol. There is a knock on the door and Awhina quickly closes the drawer again. Hera enters the room.

HERA

Hey Sis, you okay?

Hera walks towards her sister and makes to put her arm around her. Awhina turns her shoulder towards Hera in rejection.

HERA

Sorry Sis, I didn't mean it. I've

had a crap day and was just taking 


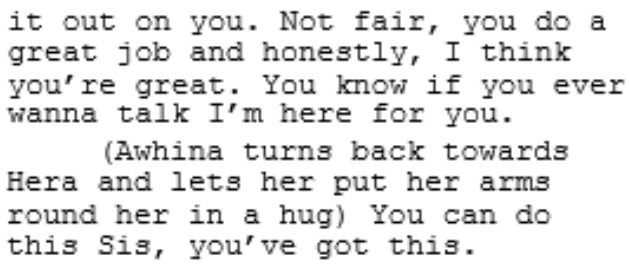

Kaea is sitting on her bed, still in her pajamas. Her phone sounds a notification again. She picks the phone up and looks at it.

TXT BUBBLE (INCOMING)

Bro, why are you ignoring me?

You've given me the seen... Do you

want me to come over?

Kaea starts to type in a response on her phone.

TXT BUBBLE (OUTGOING)

Yeah actually, can you? I need you.....

KAEA

(thought voiceover) She won't get it and will think I'm stupid. She'll be angry at me.

Kaea looks down at her tummy. The txt bubble with the unfinished message (which has remained on screen) starts to backspace until the message is gone. Bubble fades to nothing. Kaea throws the phone down on the bed.

KAEA

I'm alone in this.

Awhina sits on her bed, hands over her face, crying. (MCU from foot of bed). The camera tracks out to reveal another Awhina kneeling on either side of her bed on the floor, in the manner of a child saying bedtime prayers. The Awhina on camera left is wearing devil horns, the Awhina on camera right has a small halo.

AWHINA - BAD INNER SELE

Sis' is right. We're so young, we 


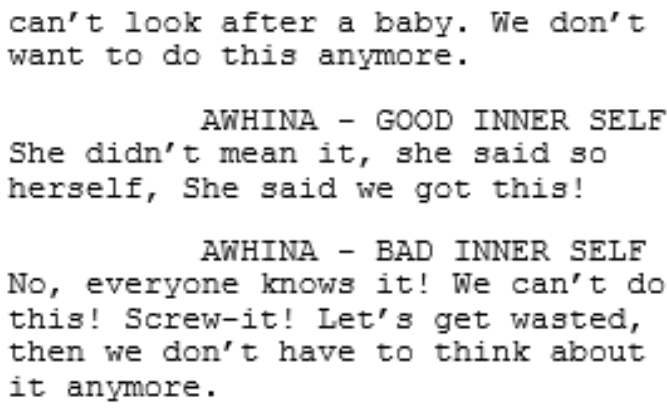

Awhina turns to look at the vodka and drugs on the bedside table, she ponders for several beats. She turns back and wraps her arms around herself tightly.

\section{AWHINA}

No! Actually - they all don't know what I can do and can achieve. $I^{\prime}$ ve got this far....

A pleasant gurgling sound comes from the baby's cot, Awhina looks over in the direction of the cot and smiles.

\section{AWHINA}

I want to be a good influence for my baby. I want to be a role model to my child. I want to make something of myself and get a job! I should finish school!

Awhina Good Inner Self cradles her head in her own hands and gives a satisfied smile. Awhina Bad Inner Self drops her face into her hands in despair. Both inner selves fade out, Awhina gets up from her bed and starts to dispose of drugs and alcohol.

\section{FADE 12 INTERNAL-BEDROOM-NIGHT}

Awhina is sitting cross legged on her bed with her laptop open in front of her.

COMPUTER SCREEN Screen

shows HHT website and scrolls slowly down through pastpupils' stories.

\section{AWHINA}

Far, these girls have done some awesome stuff. That's gonna be you and me son, that's gonna be us! 


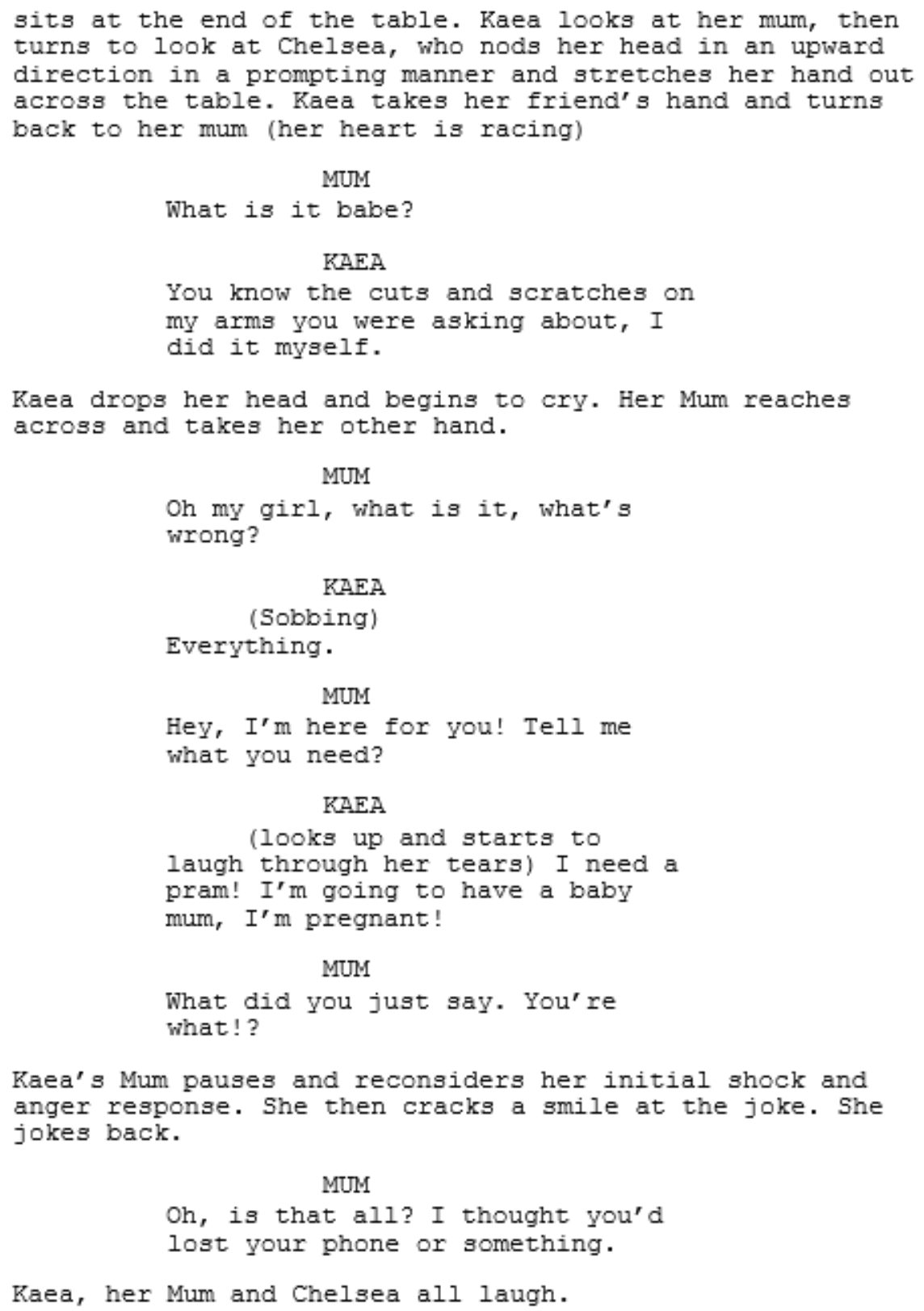

MUNA

Oh my girl, what is it, what's wrong?

KAEA

(Sobbing)

Everything .

MUNM

Hey, I'm here for you! Tell me what you need?

\section{KAEA}

(looks up and starts to

laugh through her tears) I need a

pram! I'm going to have a baby

mum, I'm pregnant!

MUNM

What did you just say. You're what!?

Kaea's Mum pauses and reconsiders her initial shock and anger response. She then cracks a smile at the joke. She jokes back.

MUMA

Oh, is that all? I thought you'd

lost your phone or something.

Kaea, her Mum and Chelsea all laugh.

MUNM 


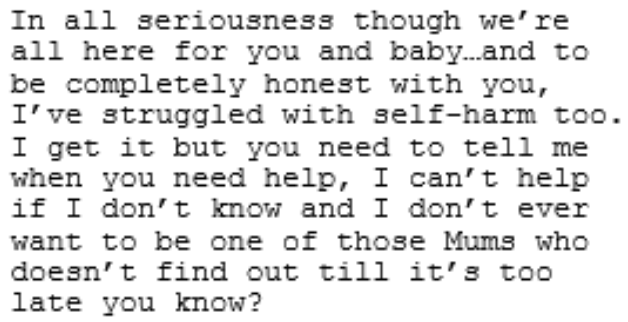

Kaea's sister walks over to Kaea and bends down to hug her where she sits, her brother looks on (knowingly) in the background.

Love you Sis.

KAEA'S SISITER

Kaea is warming up along with some other girls from the team. Chelsea approaches.

Hey Bro!

\section{CHELSEA}

(She places her hand on

Kaea's tummy and rubs) Ready for

the game? Don't run around too

much. Be careful out there.

\section{KAEA}

(laughs)

Hey G, Don't worry. I will.

Rest of the team are smiling agreeably in the background.

EXTERNAL-SCHOOL-DAY

Awhina getting off the He Huarahi Tamariki School bus.

NAIA

Hi, you're new eh? Follow me, school's up this way.

Awhina smiles and follows Naia up the path.

MRS WILSON is sitting at her desk, Awhina enters the office, Mrs Wilson stands up to greet her. 
MRS WILSON

Hi Awhina, welcome to He Huarahi

Tamariki, I know you're going to

enjoy it here. We say to all our

new girls that; your future starts

here! And on your first day we ask

you to fill in this My Future

Starts Here form. This enables us

to see what you need and where you

want to get to, so we can help

make sure you get there.

Mrs Wilson hands the form over to Awhina.

\section{AWHINA}

Cool, I'm tryna suss some mahi at the moment.

(Awhina starts to look

through the form)

Wow! Childcare, Driving Lessons,

Doctors, Counselling, Interview

Practice... You got some mean

choices here.

\section{MRS WILSON}

Yes we do, and its not a matter of choice, you can tick them all if you like. How far you go is up to you, and we'll back you all the way.

\section{AWHINA}

Man, can't believe I'm sitting

here, I didn't even know this school was a thing a week ago.

\section{INTERNAL-SCHOOL DINING ROOM-DAY}

Awhina gets provided lunch from the kitchen and sits down with group of girls. The girls are talking among

themselves, Awhina tunes into the conversation.

HINE

What'd you get up to last night man?

AROHA

Oh I stayed up rocking baby all

night, I'm so tired 


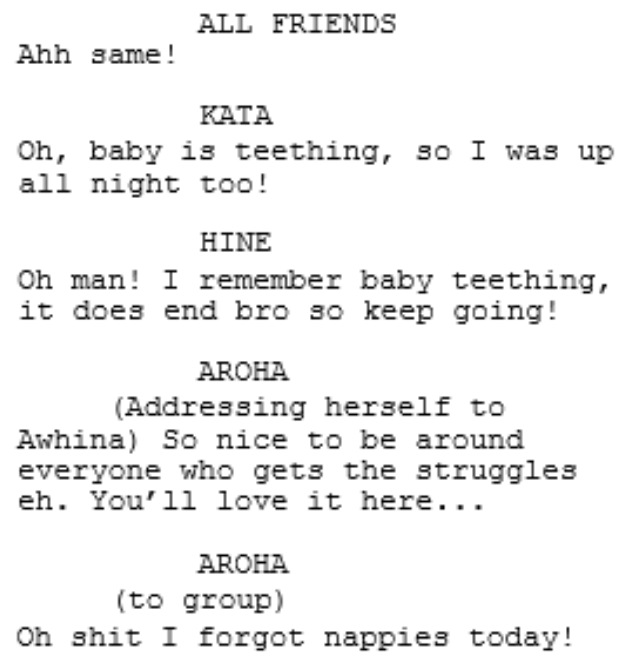

All girls start laughing. Awhina joins in the laughter.

Kaea boards a bus, she is wearing a raincoat, she pays her fare then removes her wet coat under which she is dressed in her school uniform, her bump is showing, she is clearly pregnant. Kaea looks up to see all the other passengers on the bus looking at her, they are all dressed in Judge' $s$ outfits, her heart starts to pound. As she makes her way up the bus (Kaea's POV - heart racing) all the seats are occupied, one older man shakes his head and tuts as she approaches. A few seats further back there is a spare aisle seat available, but as she approaches the woman sitting in the window seat takes her handbag off her knee and places it on the vacant seat. (Camera switches to looking down the bus at Kaea's approach) There is a vacant window seat on camera left with someone sitting in the aisle seat, the person stands up (still in their judge outfit, back to camera) Returning to Kaea's POV we see the person is Awhina and her Judge outfit has disappeared.

\section{AWHINA}

There's a seat here next to me.

Kaea sits down followed by Awhina.

AWHINA

Havin' a baby huh? 
Kaea smiles shyly in acknowledgement but doesn't answer.

AWHINA (Taking out her mobile phone and offering the screen up to Kaea)

This is my little boy, just turned one.

KAEA

You're a mum!

\section{AWHINA}

Yeah Bro. Not only a mum, the best damn mum in Aotearoa!

KAEA

Wow, you seem so chilled about it. AWHINA

I am. But it wasn't always this way.

KAEA

I feel so... I dunno, nervous, anxious, its like everybody' $s$ looking at me all the time, and they're all judging me.

\section{AWHINA}

Nah, they ain't, it feels that way at first and sure some are, meh, I reckon if they are, its their problem not yours.

KAEA

Yeah, suppose so.

\section{AWHINA}

You gotta get over it, this isn't about a bunch of people you don't even know or care about. This is about you Bro, you and little pepe in there. You gotta do what' $s$ best for you, you and your little one.

KAEA

Yeah! I'm tryin', but the problem is I don't know what's best. I'm not sure what to do.

\section{AWHINA}


Yeah I get that, been there. You

need to come join the Sisterhood!

KAEA Ae

Ae! Are you a nun!

They both laugh and we see that Kaea has truly relaxed in Awhina's company.

\section{AWHINA}

Nah bro, I applied but they

already had all the saints they

need. (both laugh)

What you need is to be surrounded

by a cool crew of people that get

the struggles ae. I'm talking

about He Huarahi Tamariki G! The

coolest bunch of mums you ever

met!

KAEA

Never heard of it.

AWHINA

Neither had I, but once you do, your life has changed for ever.

(Awhina stands up)

Hey I gotta go. I'm Awhina by the

way.

Kaea KAEA

Awhina gets her phone and types in He Huarahi Tamariki in to Facebook search and then clicks on the group. She shows Kaea.

\section{AWHINA}

G check this. Hit us up on

facebook and join the group, then

come join us. It's the best thing

since sex.

Awhina leaves Kaea laughing as she exits the bus. Kaea watches her go, the grumpy man and woman are the only two still dressed in Judge's outfits, everyone else is just going about their own business. 
Awhina and Kaea are standing with their HHT friends. They are laughing at their babies playing together. One of their friends is breastfeeding her baby.

\section{KAEA}

Hey Bro could you look after baby

[baby in pram] while I go to the

toilet?

AWHINA

(laughs)

Yeah man!

KAEA

Thanks! I normally have to take

the pram in and baby just watches

me while I go, like it's a show

(laughs)

AWHINA

(laughs)

Algoods, us young mums need to

look out for each other ae?

KAEA

You bet we do...

Kaea walks off leaving Awhina with pram talking to other HHT friends

Happy real-life shots of school, mums \& babies in

classroom, dining, early learning, playground

etc. (Background music Mai Moa) 


\section{Appendix H - Shoot schedule (production example)}

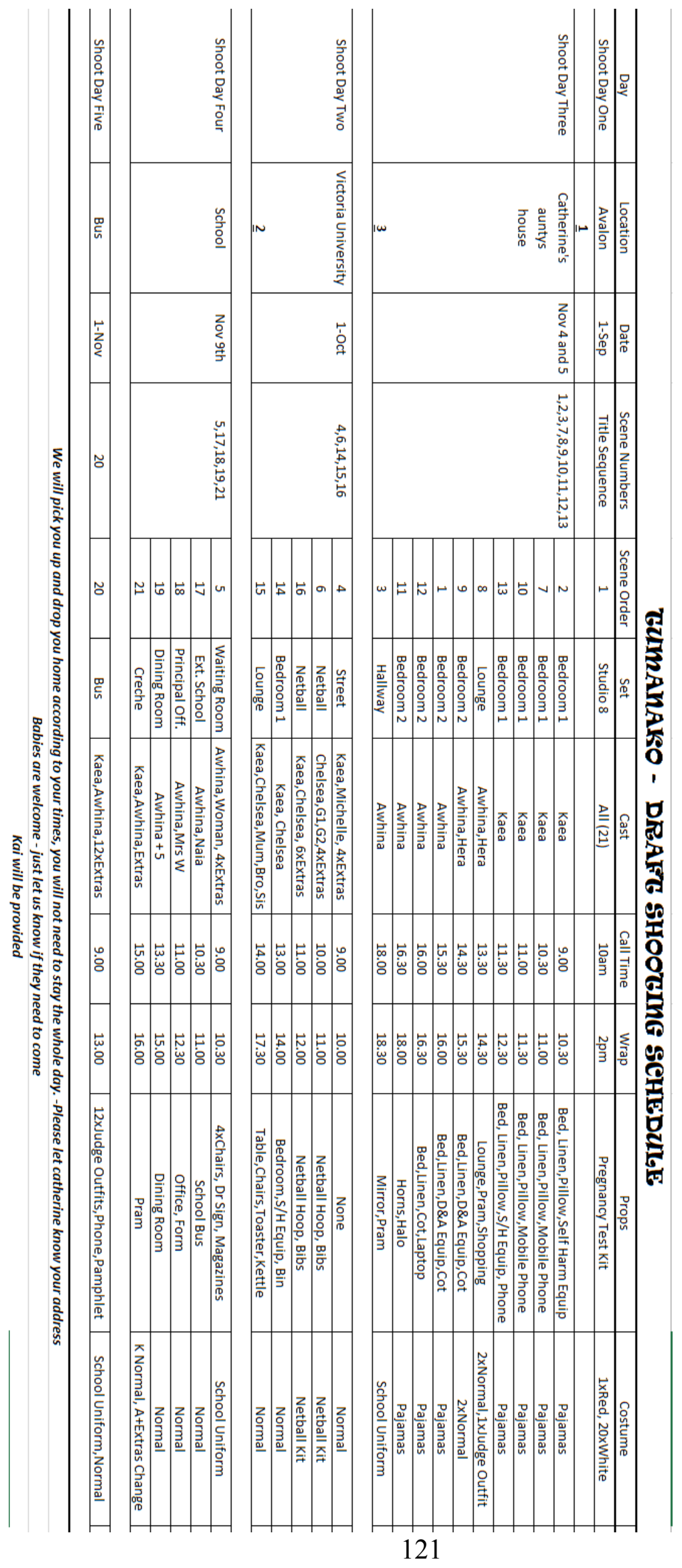




\section{Appendix I - Shoot Call Sheet (production example)}
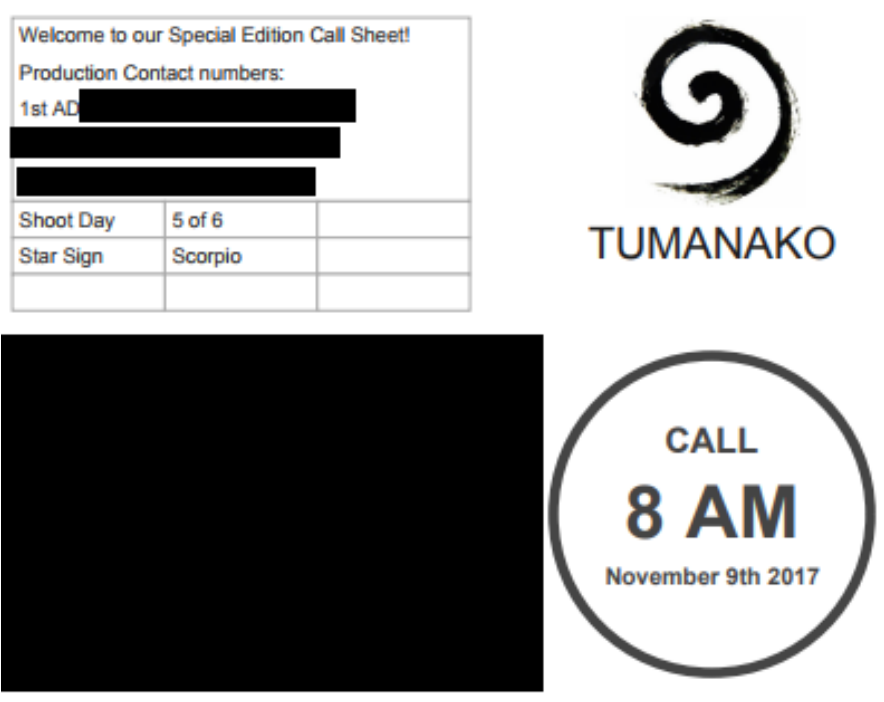

\begin{tabular}{|l|l|}
\hline Breakfast & 845 AM \\
\hline Lunch & 1230 PM \\
\hline Sunrise & $6: 09$ AM \\
\hline Sunset & $8: 09$ PM \\
\hline Weather & Cloudy w chance of cloud. \\
\hline & \\
Nearest Hospital & \\
\cline { 2 - 2 } & \\
\cline { 2 - 2 } & \\
&
\end{tabular}

Additional Notes:

Parking instructions: Some on-site and street parking available.

This is a busy day with lots of extras to wranale, and visitors/students will be on-site a

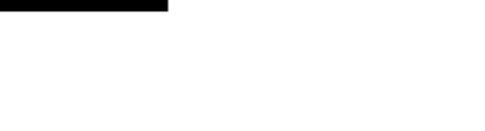

\begin{tabular}{|c|c|c|c|c|c|}
\hline SCENES & SET AND DESCRIPTION & CHARACTER \# & $\mathrm{D} / \mathrm{N}$ & PAGES & LOCATION/NOTES \\
\hline \multirow{2}{*}{$8: 30 A M: 5$} & INT. WAITING ROOM & $1+5$ Extras & Day & & \multirow{2}{*}{$\begin{array}{l}6 \text { shots: WS } \times 2 \mid \text { CU } \times 3 \mid \text { MS } \times 1 \mid \\
\text { Wardrobe from Hallway Scene } 3 \text {. Pram. }\end{array}$} \\
\hline & \multicolumn{4}{|c|}{ AWHINA takes her son to the doctor's and sees the JUDGES. She meets a nice LADY. } & \\
\hline \multirow{2}{*}{ 10:30AM : 17} & EXT. SCHOOL & 3 & Day & & \multirow{2}{*}{$\begin{array}{l}3 \text { shots: Steady WS } \times 1 \text { | WS x1 | MS x2 | } \\
\text { Mini Van Driver needed. }\end{array}$} \\
\hline & \multicolumn{4}{|c|}{ AWHINA gets out of the van taking her to HHT. She meets NAIA. } & \\
\hline \multirow{2}{*}{ 11:30AM : 18} & INT. PRINCIPAL'S OFFICE & 2 & Day & & \multirow{2}{*}{$\begin{array}{l}\text { SHOTS 3: MCU x2 | CUTAWAYS } \\
\text { School entry-form }\end{array}$} \\
\hline & \multicolumn{4}{|c|}{ AWHINA meets the PRINCIPAL and gets amped. } & \\
\hline \multirow{2}{*}{$1-30 \mathrm{PM}: 19$} & INT. DINING ROOM & $1+5$ Extras & Day & & \multirow{2}{*}{$\begin{array}{l}\text { SHOTS 5: WS x1 | MSx } 3 \text { | CUx1 } \\
\text { Picnic-table style table preferred. }\end{array}$} \\
\hline & \multicolumn{4}{|c|}{ AWHINA meets the other girls and feels hope. } & \\
\hline \multirow{2}{*}{ 3:00 PM : 21} & INT. CRECHE & $2+3 / 4$ Extras & Day & & \multirow{2}{*}{$\begin{array}{l}\text { SHOTS TBC Little children may be } \\
\text { involved. Pram needed. }\end{array}$} \\
\hline & \multicolumn{4}{|l|}{ KAEA and AWHINA talk together. } & \\
\hline \multirow{2}{*}{ 4:00PM } & PICKUPS & 2 & Day & $M+A$ & \multirow{3}{*}{$\begin{array}{l}\text { SHOTS x } 1 \\
\text { Drugs \& Alcohol from Bedroom Scene } 1 .\end{array}$} \\
\hline & \multicolumn{4}{|c|}{ Scene 11 Drugs and Alcohol thrown into bin. Scene 13 KAEA'S Wildlines } & \\
\hline & & Total Pages: & & & \\
\hline
\end{tabular}

\begin{tabular}{|l|l|l|l|l|}
\hline$\#$ & \multicolumn{1}{|c|}{ CAST } & \multicolumn{1}{|c|}{ CHARACTER } & \multicolumn{1}{c|}{ CALL TIME } & \multicolumn{1}{c|}{ SPECIAL INSTRUCTIONS } \\
\hline 1 & & AWHINA & $8: 30 \mathrm{AM}$ & 3 Wardrobe changes, Sam's Pram needed. \\
\hline 2 & & KAEA & $3: 00 \mathrm{PM}$ & Pram needed. \\
\hline 3 & & PRINCIPAL & $10-30 \mathrm{AM}$ & the actual Principal. \\
\hline 4 & & $8: 30 \mathrm{AM}$ & Judges Outfits needed. \\
\hline 5 & 5 People & SCENE 5 LADY & $8: 30 \mathrm{AM}$ & \\
\hline 6 & 5 HHT Girls & SCENE 5 EXTRAS & $1: 30 \mathrm{PM}$ & \\
\hline 7 & 3 People & SCENE 19 EXTRAS & $3: 00 \mathrm{PM}$ & Normal School Clothes \\
\hline 8 & Mini Van Driver & SCENE 21 EXTRAS & $10: 30 \mathrm{AM}$ & \\
\hline
\end{tabular}




\section{Appendix $\mathbf{J}$ - Consent for film credit inclusion}

TE WHARE WĀNANGA O TE ÜPOKO O TE IKA A MĀUI

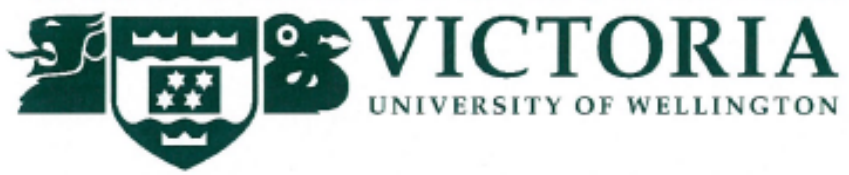

Rangatahi Perspectives on Mental Health Issues in Aotearoa CONSENT for credit to be given on short film Tūmanako

This consent form will be held for 5 years after the research is finished

Researcher: Catherine Pihema, School of Psychology, Victoria University of Wellington

Supervisors: Professor Dr Marc Wilson, Dr Tia Neha; School of Psychology, Victoria University of Wellington

I have had the opportunity to discuss what it means to be named on the credits with the researcher. I am satisfied with the answers I have been given.

I understand that if I choose to be named on the short film in the credits:

- My full name will be published as an actor on the film Tũmanako

- The Short Film will be referred to in the thesis produced from this research. Something you said in the hui may be quoted in the thesis. Although you will be referred to by an anonymous title in the thesis, if you choose to be named as an author on this film, someone reading the thesis could know you are part of the subgroup that was involved in the research. They would not know what/if any information relates to you.

In light of the above information, I would like my name to be listed on the credits of the film: Yes № No

In light of the above information, I would like my child to be listed on the credits of the film: Yes 圆 No요

Name of participant:

Signature of participant:

Date: 


\section{Appendix K - Dissemination examples (media)}

1. http://www.maoritelevision.com/news/regional/teen-mums-speak-help-otheryoung-parents-cope

2. http://www.arataiohi.org.nz/latest-happenings/news-stories/new-short-filmmental-health-resource-for-young-mums-tuumanako

3. https://www.stuff.co.nz/dominion-post/capital-life/capital-day/99307078/teenmums-share-experiences-through-film

4. https://www.victoria.ac.nz/news/2017/09/behind-the-scenes 


\section{Appendix L - Thematic Map}
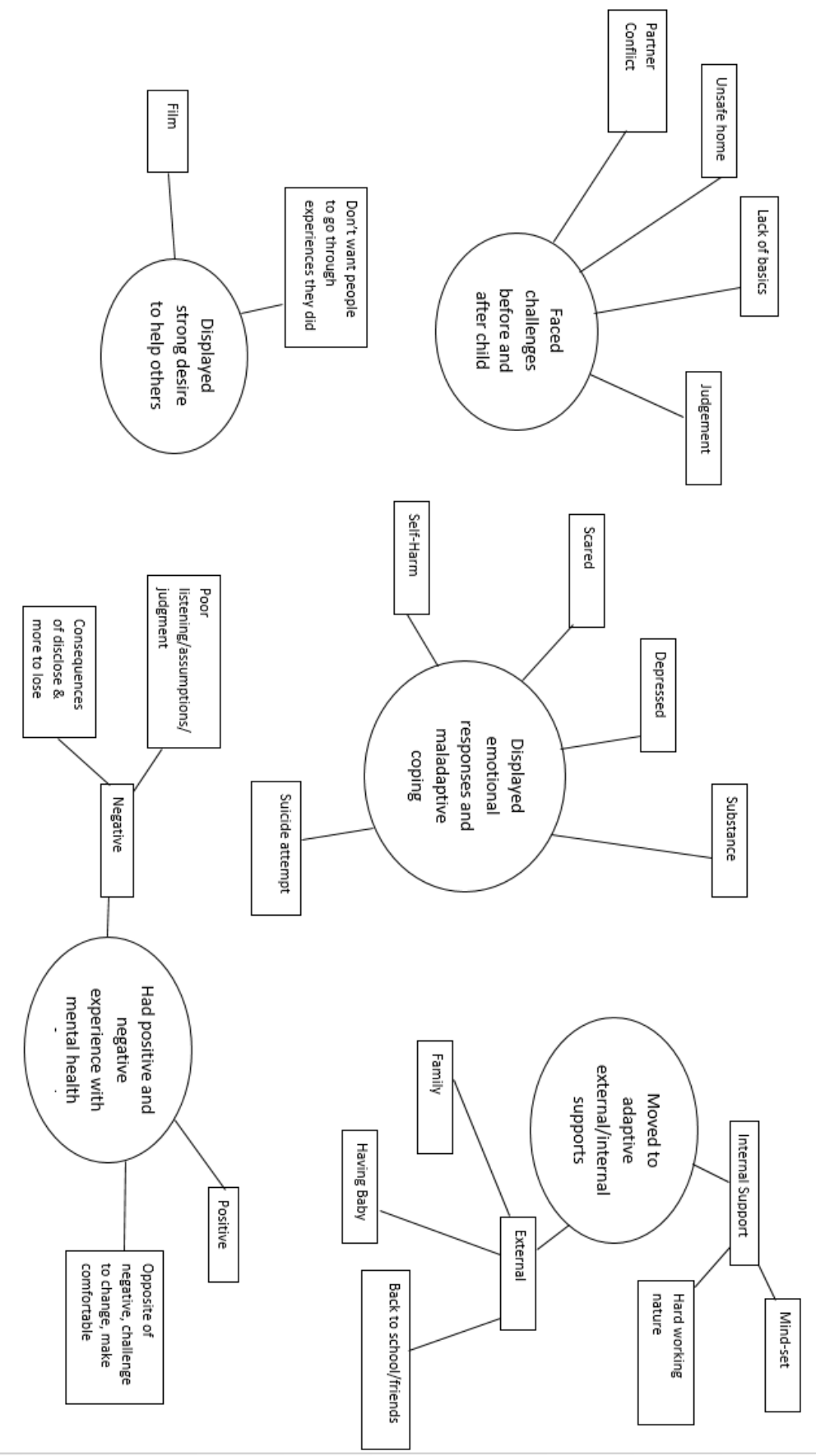